\title{
Multi-Gene Phylogeny and Morphology Reveal Haplohelminthosporium gen. nov. and Helminthosporiella gen. nov. Associated with Palms in Thailand and A Checklist for Helminthosporium Reported Worldwide
}

\author{
Sirinapa Konta ${ }^{1,2,3}$, Kevin D. Hyde ${ }^{1,2}$, Samantha C. Karunarathna ${ }^{1}\left(\mathbb{D}\right.$, Ausana Mapook ${ }^{2}$, \\ Chanokned Senwanna ${ }^{4}$ D, Lucas A. P. Dauner ${ }^{1}$, Chandrika M. Nanayakkara ${ }^{5}$, Jianchu Xu ${ }^{1}$, \\ Saowaluck Tibpromma ${ }^{1, *}$ and Saisamorn Lumyong ${ }^{6,7, *}$
}

check for

updates

Citation: Konta, S.; Hyde, K.D.; Karunarathna, S.C.; Mapook, A.; Senwanna, C.; Dauner, L.A.P.;

Nanayakkara, C.M.; Xu, J.;

Tibpromma, S.; Lumyong, S.

Multi-Gene Phylogeny and

Morphology Reveal

Haplohelminthosporium gen. nov. and Helminthosporiella gen. nov.

Associated with Palms in Thailand and A Checklist for Helminthosporium Reported Worldwide. Life 2021, 11, 454. https://doi.org/10.3390/ life11050454

Academic Editor: Arnold J

M. Driessen

Received: 16 March 2021

Accepted: 11 May 2021

Published: 19 May 2021

Publisher's Note: MDPI stays neutral with regard to jurisdictional claims in published maps and institutional affiliations.

Copyright: (C) 2021 by the authors. Licensee MDPI, Basel, Switzerland. This article is an open access article distributed under the terms and conditions of the Creative Commons Attribution (CC BY) license (https:// creativecommons.org/licenses/by/ $4.0 /)$.
1 CAS Key Laboratory for Plant Diversity and Biogeography of East Asia, Kunming Institute of Botany, Chinese Academy of Sciences, Kunming 650201, China; sirinapakonta@gmail.com (S.K.); kdhyde3@gmail.com (K.D.H.); samantha@mail.kib.ac.cn (S.C.K.); luke.dauner1@gmail.com (L.A.P.D.); jxu@mail.kib.ac.cn (J.X.)

2 Center of Excellence in Fungal Research, Mae Fah Luang University, Chiang Rai 57100, Thailand; phung.ausana@gmail.com

3 School of Science, Mae Fah Luang University, Chiang Rai 57100, Thailand

4 Department of Entomology and Plant Pathology, Faculty of Agriculture, Chiang Mai University, Chiang Mai 50200, Thailand; chanokned.swn@gmail.com

5 Department of Plant Sciences, University of Colombo, Colombo 00300, Sri Lanka; chandi@pts.cmb.ac.lk

6 Research Center of Microbial Diversity and Sustainable Utilization, Faculty of Science, Chiang Mai University, Chiang Mai 50200, Thailand

7 Academy of Science, The Royal Society of Thailand, Bangkok 10300, Thailand

* Correspondence: saowaluckfai@gmail.com (S.T.); saisamorn.1@cmu.ac.th (S.L.)

Abstract: Palms (Arecaceae) are substrates for a highly diverse range of fungi. Many species are known as saprobes and many are important plant pathogens. Over the course of our studies of microfungi from palms in Thailand, two new taxa were discovered. Morphological characteristics and phylogenetic analyses of combined ITS, LSU, SSU, and tef1- $\alpha$ sequence data revealed their taxonomic positions within Massarinaceae. There are currently ten genera identified and accepted in Massarinaceae, with the addition of the two new genera of Haplohelminthosporium and Helminthosporiella, that are introduced in this paper. Each new genus is provided with a full description and notes, and each new taxon is provided with an illustration for the holotype. A list of identified and accepted species of Helminthosporium with morphology, host information, locality, sequence data, and related references of Helminthosporium reported worldwide is provided based on records in Species Fungorum 2021. This work provides a micro-fungi database of Haplohelminthosporium, Helminthosporiella, and Helminthosporium which can be modified and validated as new data come to light.

Keywords: 4 new taxa; Massarinaceae; morphology; multi-genes; palm fungi; Thailand

\section{Introduction}

In Thailand, a large number of novel fungi from a variety of hosts have been recently described, adding to the region's highly known fungal diversity [1,2]. This diversity is supported by various factors, including host-plant species relationships, geography, seasons, air humidity, and temperature. Many interesting fungi from Thai monocotyledons such as bamboo (Poaceae) and Pandanaceae have been described in previous studies, and some new taxa and records of microfungi on palms have been published, especially from the southern region of Thailand [3-11]. However, more research on fungal diversity on palms in Thailand is needed. 
Pleosporales is the largest order in Dothideomycetes [12] with 566 genera in 91 families accepted, while 48 genera have been placed in Pleosporales genera incertae sedis with an estimated stem age of 205 MYA [12,13]. Massarinaceae is a family within Pleosporales introduced by Munk [14] to accommodate the genus Massarina, with M. eburnea being designated as the type species and described based on the sexual morph [15]. Hongsanan et al. [12] and Wijayawardene et al. [13] accepted nine genera in Massarinaceae (Byssothecium, Helminthosporiella, Helminthosporium, Massarina, Pseudodidymosphaeria, Pseudosplanchnonema, Semifissispora, Stagonospora, and Suttonomyces).

Helminthosporium has the asexual morph of $H$. velutinum as the type species. It is characterized by terminal and intercalary conidiogenous cells as well as solitary conidia with distosepta [16]. The members of this genus are commonly found as saprobes and endophytes, but they are often isolated from dead corticated twigs or wood, living leaves, and soils [17-23]. Most Helminthosporium species have been described based on their asexual morph, and only a few species have been described based on both morphs viz., $H$. massarinum, $H$. microsorum, $H$. oligosporum, $H$. quercicola, $H$. quercinum, and $H$. tiliae $[19,21,24]$. Several species in the Helminthosporium complex are polyphyletic and have been placed in other genera viz. Bipolaris, Curvularia, and Exserohilum within Pleosporales, other families viz. Corynesporaceae, Massarinaceae, and Mycosphaerellaceae within Dothideomycetes, or other unrelated Ascomycetes groups that were initially based on morphological characteristics and later on molecular data, although some species still remain unresolved [20,25-37]. Wijayawardene et al. [13] approximated the number of taxa in Helminthosporium at 416 species. However, this genus was not updated with the DNA sequencesin the most recent monograph.

Few previous studies have investigated the Helminthosporium-like taxa from plants, particularly palms, in Thailand. In this study, we were able to isolate Helminthosporiumlike taxa from palms collected in Thailand. Morphology and multi-gene phylogenetic analyses showed two Helminthosporium-like taxa are novel in Massarinaceae. In addition, we provide a checklist of Helminthosporium and the name for Helminthosporiella stilbacea is also validated.

\section{Materials and Methods}

\subsection{Collection, Isolation, and Identification}

The plant materials containing the fungal structures were collected from Krabi and Prachuap Khiri Khan Provinces, Thailand, from living and dead parts of palm trees (Calamus sp. and Cocos nucifera). Samples were taken to the laboratory for morphological study following the methods provided by Konta et al. [9]. Single spore isolates were obtained following the method of Senanayake et al. [38]. Measurements were taken using an Image Framework program. Illustrations were made in Adobe Photoshop CS6. Specimens and cultures were deposited in the herbarium of Mae Fah Luang University (MFLU) and Mae Fah Luang Culture Collection (MFLUCC). Faces of Fungi and Index Fungorum numbers were registered as outlined in Jayasiri et al. [39] and Index Fungorum [40], respectively.

\subsection{DNA Extraction and Amplification (PCR)}

DNA extraction was performed using the Biospin Fungus genomic DNA extraction kit-BSC14S1 (Bioflux, P.R. China) according to Dissanayake et al. [41]. Partial nucleotide genes were subjected to PCR amplification and sequencing of the large subunit (28S, LSU) [42], the internal transcribed spacer (ITS) [43], the small subunit (18S, SSU) [43], and the translation elongation factor 1-alpha $(t e f 1-\alpha)$ was performed [44,45]. For primers and conditions, see Table 1. PCR amplification and sequencing were carried out following Konta et al. [9]. The resulting fragments were sequenced in both forward and reverse directions, the generated DNA sequences were analysed, and the consensus sequences were computed using SeqMan software. New sequences generated in this study were deposited in GenBank (Table 2). 
Table 1. Details of genes/loci with PCR primers and PCR conditions.

\begin{tabular}{lll}
\hline \multicolumn{1}{c}{ Genes/loci } & \multicolumn{1}{c}{$\begin{array}{c}\text { PCR Primer } \\
\text { (Forward/Reverse) }\end{array}$} & \multicolumn{1}{c}{ PCR Conditions } \\
\hline LSU & LR0R/LR5 & \\
ITS & ITS5/ITS4 & a $; 95^{\circ} \mathrm{C}: 30 \mathrm{~s}, 55^{\circ} \mathrm{C}: 50 \mathrm{~s}, 72{ }^{\circ} \mathrm{C}: 30 \mathrm{~s}(35 \mathrm{cycles}) ;{ }^{\mathrm{b}}$ \\
SSU & NS1/NS4 & \\
tef1- $\alpha$ & $983 \mathrm{~F} / 2218 \mathrm{R}$ & \\
\hline
\end{tabular}

a Initiation step of $95^{\circ} \mathrm{C}: 3 \mathrm{~min} ;{ }^{\mathrm{b}}$ Final elongation step of $72{ }^{\circ} \mathrm{C}: 10 \mathrm{~min}$ and final hold at $4{ }^{\circ} \mathrm{C}$.

\subsection{Phylogenetic Analyses}

The sequences generated in this study were subjected to a BLAST search in GenBank to identify closely related sequences. Sequence data retrieved from GenBank and recent publications were used as references [24]. Sequence data for the ITS, LSU, SSU, and tef1- $\alpha$ regions were analysed both individually and in combination. A total of 93 taxa were used for the combined phylogenetic analyses (ITS, LSU, SSU, and tef1- $\alpha$ ) in order to find a natural classification placement. In addition, 103 taxa of ITS and 113 taxa of LSU were used for phylogenetic analyses. For both the individual and combined phylogenetic analyses, Cyclothyriella rubronotata (Cyclothyriellaceae) was selected as the outgroup taxon. Absent sequence data (i.e., ITS, LSU, SSU, tef1- $\alpha$ sequence data) in the alignments were treated with gaps as missing data. Sequence alignments were carried out with MAFFT v.6.864b [46] and were manually improved where necessary. The single gene datasets were combined using Mega7 [47]. Data were converted from fasta to nexus and PHYLIP format with Alignment Transformation Environment online, https://sing.ei.uvigo.es / ALTER/ (accessed on 15 July 2020) [48]. The tree topologies obtained from single gene sequence data were compared prior to the combined gene analysis in order to check for incongruence in the overall topology of the phylogenetic tree. Maximum likelihood (ML) analysis was accomplished using RAxML-HPC2 (v.8.2.12) on XSEDE in the CIPRES Science Gateway platform (http:/ /www.phylo.org) (accessed on 12 May 2020) [49] with GTRGAMMA model and set as 1000 bootstrap replicates. Bayesian analysis was performed at CIPRES using Bayesian analysis on XSEDE (v.3.2.7) as part of the "MrBayes on XSEDE" tool [49-51]. GTR+I+G model was selected by using MrModelTest 2.2 [52] under the Akaike information criterion (AIC) as the best-fit models of the combined dataset for maximum likelihood and Bayesian analysis [52]. Bayesian posterior probabilities (BYPP) were determined by Markov Chain Monte Carlo sampling (MCMC) in MrBayes on XSEDE v.3.2.7. Six simultaneous Markov chains were run for 5,000,000 generations and trees were sampled every 1000th generation. An MCMC heated chain was set with a "temperature" value of 0.20. All sampled topologies beneath the asymptote $(25 \%)$ were discarded as part of a burn-in procedure; the remaining trees (7502) were used for calculating posterior probabilities in the majority rule consensus tree. Bootstrap support values for ML and BYPP are given near to each node (Figures 1 and 2). The phylogenetic trees were configured in FigTree v1.4.0 [53] and edited using Microsoft Office PowerPoint 2016 and Adobe Photoshop CS6 (Adobe Systems, San Jose, CA, USA). 


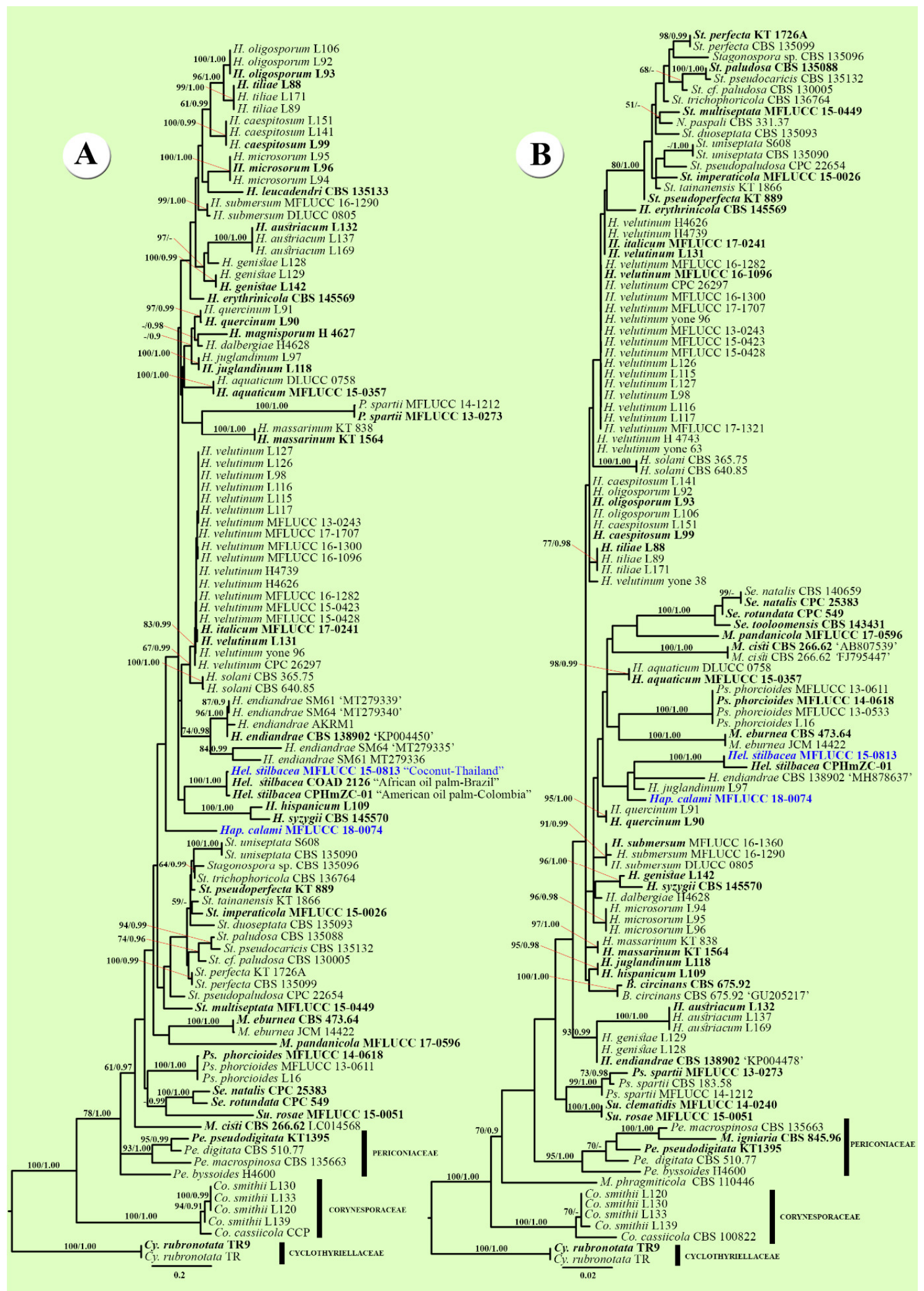

Figure 1. Comparison of the topology of Maximum likelihood majority rule consensus tree for the analyses of some selected Corynesporaceae, Massarinaceae, and Perioconiaceae isolates. (A) Phylogenetic tree of the dataset for ITS sequence data. (B) Phylogenetic tree of the dataset for LSU sequence data. Bootstrap support values for maximum likelihood (ML) equal to or higher than 50\%, and Bayesian Posterior Probabilities (BYPP) equal to or greater than 0.90 are given above each branch. Novel taxa are in blue. Ex-type strains are in bold. The tree is rooted to Cyclothyriella rubronotata strains TR, TR9 (Cyclothyriellaceae). 


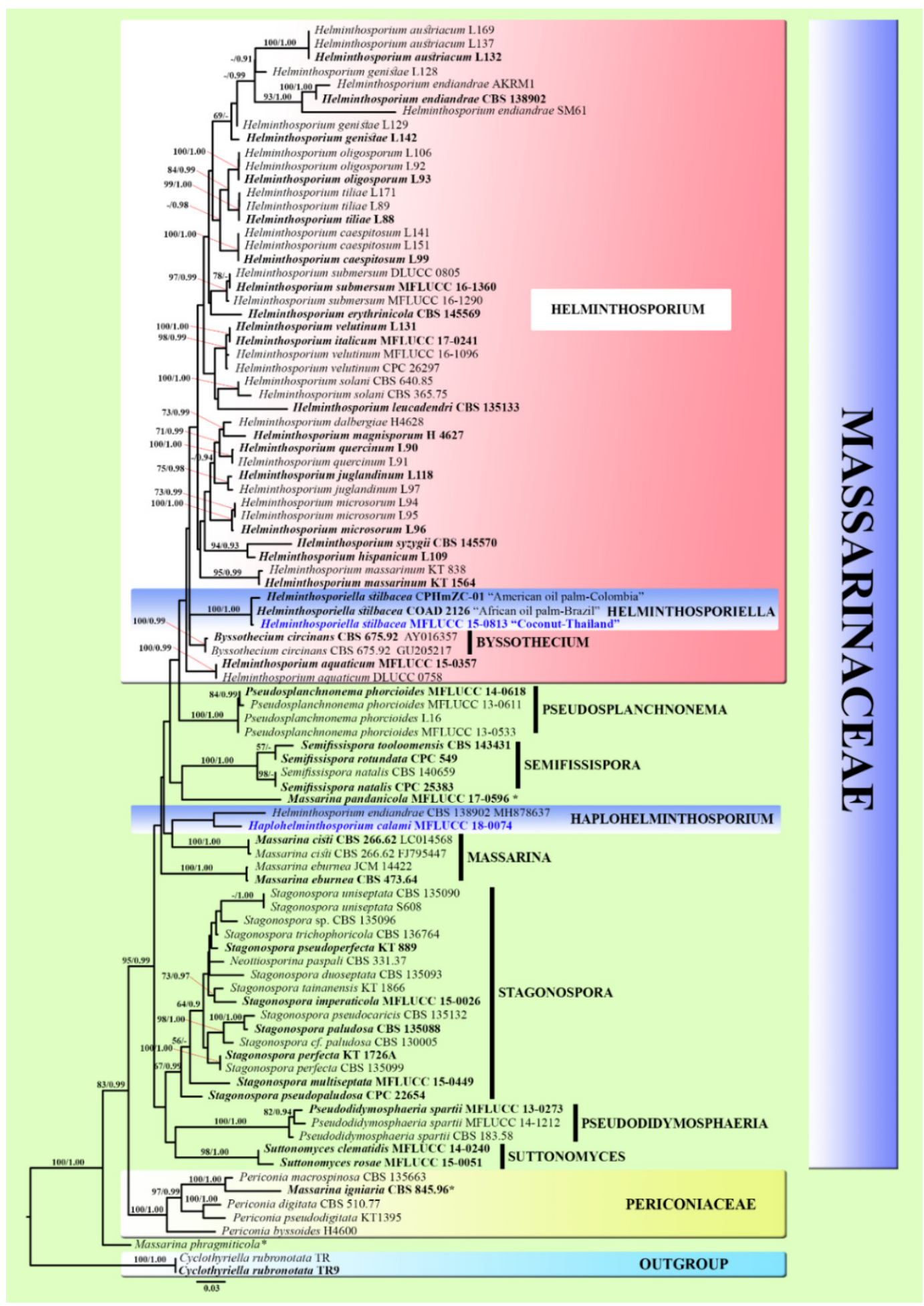

Figure 2. Maximum likelihood majority rule consensus tree for the analyses of Massarinaceae and sister family Perioconiaceae isolates based on a dataset of combined ITS, LSU, SSU, and tef1- $\alpha$ sequence data. Bootstrap support values for maximum likelihood (ML) equal to or higher than 50\%, and Bayesian posterior probabilities (BYPP) equal to or greater than 0.90 are given above each branch. Novel taxa are in blue. Ex-type strains are in bold. The tree is rooted to Cyclothyriella rubronotata strains TR, TR9 (Cyclothyriellaceae). 
Table 2. Taxa names, strain numbers and GenBank accession numbers of the sequences used in phylogenetic analyses.

\begin{tabular}{|c|c|c|c|c|c|c|c|}
\hline \multirow{2}{*}{ Family } & \multirow{2}{*}{ Species } & \multirow{2}{*}{ Strain No. } & \multicolumn{4}{|c|}{ GenBank Accession No. } & \multirow{2}{*}{ References } \\
\hline & & & ITS & LSU & SSU & tef1- $\alpha$ & \\
\hline Corynesporaceae & Corynespora cassiicola & CBS 100,822 & - & GU301808 & GU296144 & GU349052 & {$[54]$} \\
\hline Corynesporaceae & Corynespora smithii & CBS 139,925 & KY984299 & KY984299 & - & - & [21] \\
\hline Corynesporaceae & Corynespora smithii & L120 & KY984297 & KY984297 & - & KY984435 & [21] \\
\hline Corynesporaceae & Corynespora smithii & L130 & KY984298 & KY984298 & KY984419 & KY984436 & [21] \\
\hline Corynesporaceae & Corynespora smithii & L139 & KY984300 & KY984300 & - & - & [21] \\
\hline Cyclothyriellaceae & Cyclothyriella rubronotata & $\mathrm{TR}$ & KX650541 & KX650541 & - & KX650516 & [56] \\
\hline Cyclothyriellaceae & Cyclothyriella rubronotata & TR9* & KX650544 & KX650544 & KX650507 & KX650519 & [56] \\
\hline Massariaceae & Byssothecium circinans & CBS 675.92 & - & GU205217 & GU205235 & GU349061 & [54] \\
\hline Massarinaceae & Byssothecium circinans & CBS 675.92 & - & AY016357 & AY016339 & - & {$[57,58]$} \\
\hline Massarinaceae & Haplohelminthosporium calami & MFLUCC 18-0074* & MT928158 & MT928156 & MT928160 & - & This study \\
\hline Massarinaceae & Helminthosporium aquaticum & MFLUCC 15-0357 & KU697302 & KU697306 & KU697310 & - & [20] \\
\hline Massarinaceae & Helminthosporium austriacum & L132* & KY984301 & KY984301 & KY984420 & KY984437 & [21] \\
\hline Massarinaceae & Helminthosporium austriacum & L169 & KY984303 & KY984303 & - & KY984439 & [21] \\
\hline Massarinaceae & Helminthosporium austriacum & L137 & KY984302 & KY984302 & - & KY984438 & {$[21]$} \\
\hline Massarinaceae & Helminthosporium caespitosum & L99* & JQ044429 & JQ044448 & KY984421 & KY984440 & {$[21]$} \\
\hline Massarinaceae & Helminthosporium caespitosum & L141 & KY984305 & KY984305 & - & - & {$[21]$} \\
\hline Massarinaceae & Helminthosporium caespitosum & L151 & KY984306 & KY984306 & - & - & {$[21]$} \\
\hline Massarinaceae & Helminthosporium dalbergiae & H 4628 & LC014555 & AB807521 & AB797231 & AB808497 & [19] \\
\hline Massarinaceae & Helminthosporium endiandrae & CBS $138902 *$ & KP004450 & KP004478 & - & - & [59] \\
\hline Massarinaceae & Helminthosporium endiandrae & CBS 138,902 & - & MH878637 & - & - & {$[60]$} \\
\hline
\end{tabular}


Table 2. Cont.

\begin{tabular}{|c|c|c|c|c|c|c|c|}
\hline \multirow{2}{*}{ Family } & \multirow{2}{*}{ Species } & \multirow{2}{*}{ Strain No. } & \multicolumn{4}{|c|}{ GenBank Accession No. } & \multirow{2}{*}{ References } \\
\hline & & & ITS & LSU & SSU & tef1- $\alpha$ & \\
\hline Massarinaceae & Helminthosporium endiandrae & SM64 & MT279335 & - & - & - & Unpublished \\
\hline Massarinaceae & Helminthosporium endiandrae & SM64 & MT279340 & - & - & - & Unpublished \\
\hline Massarinaceae & Helminthosporium endiandrae & SM61 & MT279336 & - & - & - & Unpublished \\
\hline Massarinaceae & Helminthosporium endiandrae & AKRM1 & MN880136 & - & - & - & Unpublished \\
\hline Massarinaceae & Helminthosporium erythrinicola & CBS 145,569 & MK876391 & MK876432 & - & - & {$[22]$} \\
\hline Massarinaceae & Helminthosporium genistae & L128 & KY984308 & KY984308 & KY984422 & - & [21] \\
\hline Massarinaceae & Helminthosporium genistae & L129 & KY984309 & KY984309 & KY984423 & - & [21] \\
\hline Massarinaceae & Helminthosporium genistae & L142* & KY984310 & KY984310 & - & - & [21] \\
\hline Massarinaceae & Helminthosporium hispanicum & L109* & KY984318 & KY984318 & KY984424 & KY984441 & [21] \\
\hline Massarinaceae & Helminthosporium italicum & MFLUCC 17-0241 & KY797638 & KY815015 & - & KY815021 & {$[61]$} \\
\hline Massarinaceae & Helminthosporium juglandinum & L97 & KY984322 & KY984322 & KY984425 & KY984445 & [21] \\
\hline Massarinaceae & Helminthosporium leucadendri & CBS 135133 * & KF251150 & KF251654 & - & KF253110 & [62] \\
\hline Massarinaceae & Helminthosporium magnisporum & $\mathrm{H} 4627^{*}$ & AB811452 & AB807522 & AB797232 & AB808498 & [19] \\
\hline Massarinaceae & Helminthosporium massarinum & KT $1564^{*}$ & AB809629 & AB807524 & AB797234 & AB808500 & [19] \\
\hline Massarinaceae & Helminthosporium massarinum & KT 838 & AB809628 & AB807523 & AB797233 & AB808499 & {$[19]$} \\
\hline Massarinaceae & Helminthosporium microsorum & L94 & KY984327 & KY984327 & KY984426 & KY984446 & [21] \\
\hline Massarinaceae & Helminthosporium microsorum & L95 & KY984328 & KY984328 & - & KY984447 & [21] \\
\hline Massarinaceae & Helminthosporium microsorum & L96* & KY984329 & KY984329 & KY984427 & KY984448 & [21] \\
\hline Massarinaceae & Helminthosporium oligosporum & L92 & KY984332 & KY984332 & KY984428 & KY984450 & {$[21]$} \\
\hline Massarinaceae & Helminthosporium oligosporum & L93 * & KY984333 & KY984333 & - & KY984451 & [21] \\
\hline
\end{tabular}


Table 2. Cont.

\begin{tabular}{|c|c|c|c|c|c|c|c|}
\hline \multirow{2}{*}{ Family } & \multirow{2}{*}{ Species } & \multirow{2}{*}{ Strain No. } & \multicolumn{4}{|c|}{ GenBank Accession No. } & \multirow{2}{*}{ Reference } \\
\hline & & & ITS & LSU & SSU & tef1- $\alpha$ & \\
\hline Massarinaceae & Helminthosporium oligosporum & L106 & KY984330 & KY984330 & - & KY984449 & [21] \\
\hline Massarinaceae & Helminthosporium quercinum & L91 & KY984340 & KY984340 & - & KY984454 & [21] \\
\hline Massarinaceae & Helminthosporium solani & CBS 365.75 & KY984341 & KY984341 & KY984430 & KY984455 & [21] \\
\hline Massarinaceae & Helminthosporium solani & CBS 640.85 & KY984342 & KY984342 & - & - & [21] \\
\hline Massarinaceae & Helminthosporiella stilbacea & CPHmZC-01 & KX228298 & KX228355 & - & - & [63] \\
\hline Massarinaceae & Helminthosporiella stilbacea & COAD 2126 & MG668862 & - & - & - & [64] \\
\hline Massarinaceae & Helminthosporiella stilbacea & MFLUCC 15-0813* & MT928159 & MT928157 & MT928161 & MT928151 & This study \\
\hline Massarinaceae & Helminthosporium submersum & MFLUCC 16-1360 * & - & MG098787 & MG098796 & MG098586 & [24] \\
\hline Massarinaceae & Helminthosporium submersum & MFLUCC 16-1290 & MG098780 & MG098788 & MG098797 & MG098587 & [24] \\
\hline Massarinaceae & Helminthosporium submersum & DLUCC 0805 & MG098781 & MG098789 & MG098798 & - & [24] \\
\hline Massarinaceae & Helminthosporium syzygii & CBS $145,570 *$ & MK876392 & MK876433 & - & - & [22] \\
\hline Massarinaceae & Helminthosporium tiliae & L89 & KY984346 & KY984346 & - & - & [21] \\
\hline Massarinaceae & Helminthosporium tiliae & L171 & KY984343 & KY984343 & - & KY984456 & [21] \\
\hline Massarinaceae & Helminthosporium velutinum & yone 38 & - & AB807527 & AB797237 & AB808502 & [19] \\
\hline Massarinaceae & Helminthosporium velutinum & yone 63 & - & AB807528 & AB797238 & AB808503 & [19] \\
\hline Massarinaceae & Helminthosporium velutinum & MFLUCC 15-0423 & KU697300 & KU697304 & KU697308 & - & {$[20]$} \\
\hline Massarinaceae & Helminthosporium velutinum & MFLUCC 15-0428 & KU697299 & KU697303 & KU697307 & - & {$[20]$} \\
\hline Massarinaceae & Helminthosporium velutinum & H 4626 & LC014556 & AB807530 & AB797240 & AB808505 & {$[19]$} \\
\hline Massarinaceae & Helminthosporium velutinum & L117 & KY984349 & KY984349 & - & KY984460 & {$[21]$} \\
\hline Massarinaceae & Helminthosporium velutinum & L126 & KY984350 & KY984350 & - & KY984461 & [21] \\
\hline Massarinaceae & Helminthosporium velutinum & L131* & KY984352 & KY984352 & KY984432 & KY984463 & [21] \\
\hline
\end{tabular}


Table 2. Cont.

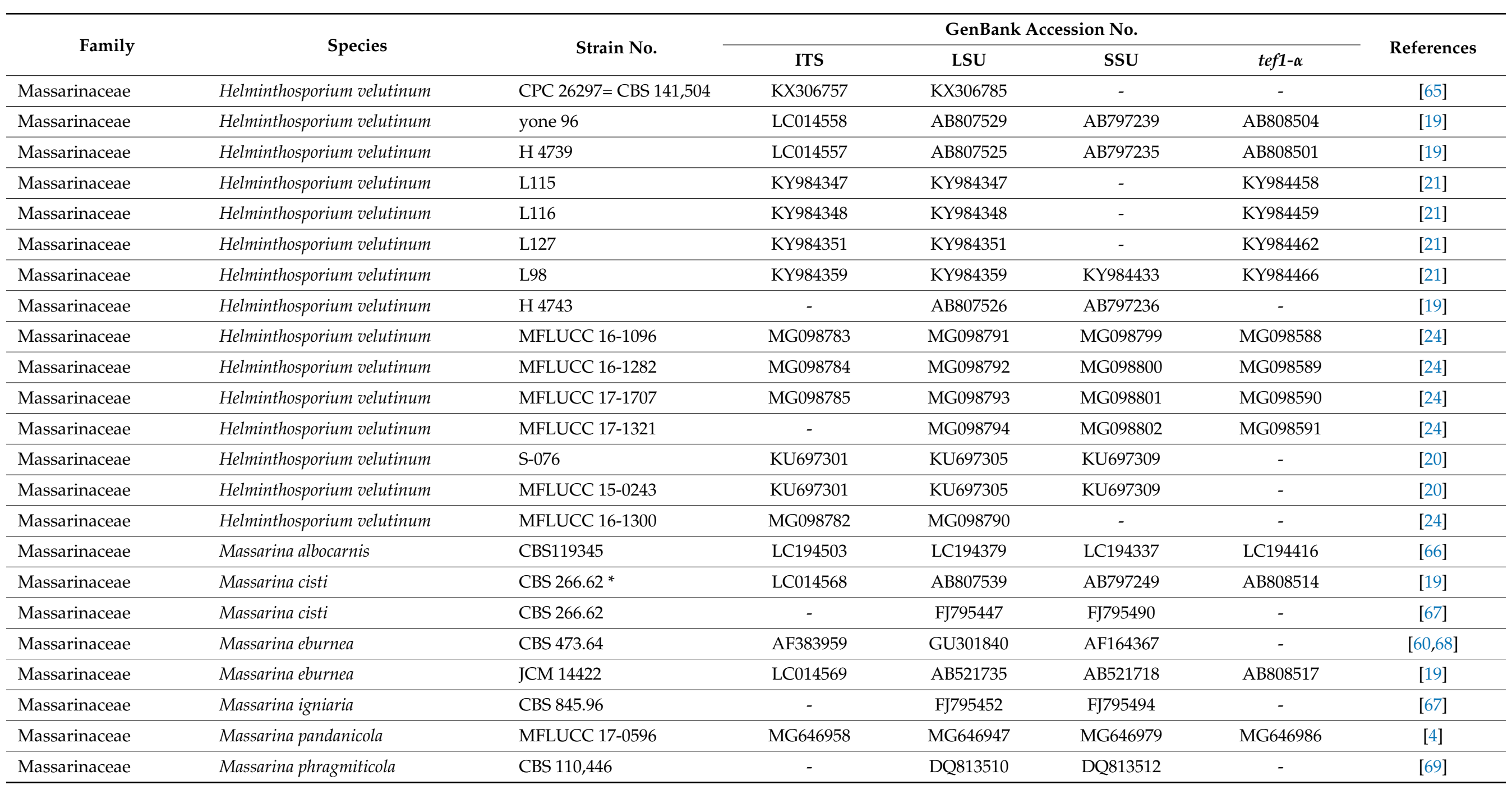


Table 2. Cont.

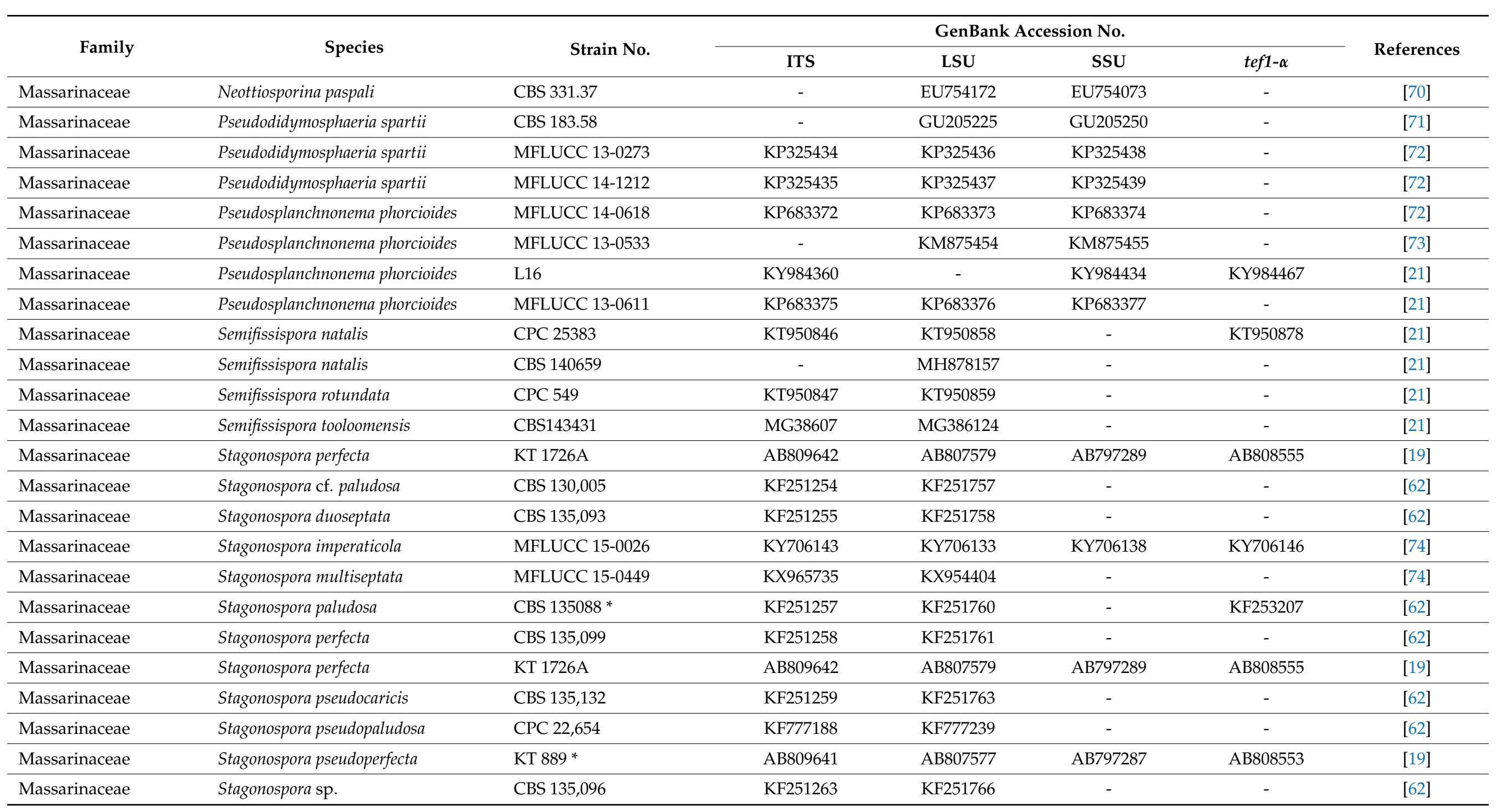


Table 2. Cont.

\begin{tabular}{|c|c|c|c|c|c|c|c|}
\hline \multirow{2}{*}{ Family } & \multirow{2}{*}{ Species } & \multirow{2}{*}{ Strain No. } & \multicolumn{4}{|c|}{ GenBank Accession No. } & \multirow{2}{*}{ References } \\
\hline & & & ITS & LSU & SSU & tef1- $\alpha$ & \\
\hline Massarinaceae & Stagonospora tainanensis & KT 1866 & AB809643 & AB807580 & AB797290 & AB808556 & [19] \\
\hline Massarinaceae & Stagonospora trichophoricola & CBS 136,764 & KJ869110 & KJ869168 & - & - & [75] \\
\hline Massarinaceae & Stagonospora uniseptata & CPC 22,150 & KF251266 & KF251769 & - & - & {$[62]$} \\
\hline Massarinaceae & Stagonospora uniseptata & CBS 135,090 & KF251264 & KF251767 & - & - & {$[62]$} \\
\hline Massarinaceae & Suttonomyces clematidis & MFLUCC 14-0240 & - & KP842917 & KP842920 & - & [76] \\
\hline Massarinaceae & Suttonomyces rosae & MFLUCC 15-0051 & MG828973 & MG829085 & MG829185 & - & [77] \\
\hline Periconiaceae & Periconia byssoides & H 4600 & LC014581 & AB807570 & AB797280 & AB808546 & [19] \\
\hline Periconiaceae & Periconia digitata & CBS 510.77 & LC014584 & AB807561 & AB797271 & AB808537 & [19] \\
\hline Periconiaceae & Periconia macrospinosa & CBS 135,663 & KP183999 & KP184038 & KP184080 & - & [78] \\
\hline Periconiaceae & Periconia pseudodigitata & KT 1395 * & LC014591 & AB807564 & AB797274 & AB808540 & [19] \\
\hline
\end{tabular}




\section{Results and Discussion}

\subsection{Phylogenetic Analyses}

The individual datasets for ITS and LSU regions comprised selected isolates from closely related families (Figure 1). The RAxML analyses of the ITS dataset yielded the best-scoring trees with a final ML optimization likelihood value of -9830.778478 (Figure 1A). The matrix had 531 distinct alignment patterns with $51.80 \%$ undetermined characters or gaps. Estimated base frequencies were as follows: $\mathrm{A}=0.227770, \mathrm{C}=0.273565$, $\mathrm{G}=0.243931, \mathrm{~T}=0.254733$; substitution rates $\mathrm{AC}=2.172295, \mathrm{AG}=3.427213, \mathrm{AT}=2.029849$, $\mathrm{CG}=0.957843, \mathrm{CT}=5.859679, \mathrm{GT}=1.000000$; and gamma distribution shape parameter $\alpha=0.350193$. In Figure 1A, the novel taxon Haplohelminthosporium calami grouped within Massarinaceae and was well separated from other genera but without good bootstrap support. Helminthosporiella stilbacea (MFLUCC 15-0813) is closely related to Hel.stilbacea (strains CPHmZC-01 and COAD 2126) with 100\% ML/1.00 BYPP.

The RAxML analyses of the LSU dataset yielded the best-scoring trees with a final ML optimization likelihood value of -4283.882978 (Figure 1B). The matrix had 307 distinct alignment patterns with $12.16 \%$ undetermined characters or gaps. Estimated base frequencies were as follows: $\mathrm{A}=0.246483, \mathrm{C}=0.214075, \mathrm{G}=0.309890, \mathrm{~T}=0.229553$; substitution rates $\mathrm{AC}=1.828869, \mathrm{AG}=4.019496, \mathrm{AT}=3.119987, \mathrm{CG}=0.662100, \mathrm{CT}=12.098644$, $\mathrm{GT}=1.000000$; and gamma distribution shape parameter $\alpha=0.159335$. In Figure 1B, the novel taxon Haplohelminthosporium calami was also well separated within Massarinaceae and clustered with Helminthosporium and Helminthosporiella. Helminthosporiella stilbacea (MFLUCC 15-0813) is closely related to Hel. stilbacea (strain CPHmZC-01) with 100\% ML/1.00 BYPP.

The RAxML analysis of the combined (ITS, LSU, SSU, and tef1- $\alpha$ ) dataset yielded a best scoring tree with a final ML optimization likelihood value of -22122.846454 (Figure 2). The matrix had 1363 distinct alignment patterns, with $41.38 \%$ undetermined characters or gaps. Estimated base frequencies were as follows: $A=0.241467, C=0.241603$, $\mathrm{G}=0.271551, \mathrm{~T}=0.245380$; substitution rates $\mathrm{AC}=1.860804, \mathrm{AG}=3.064520, \mathrm{AT}=1.916442$, $\mathrm{CG}=1.009390, \mathrm{CT}=7.530432, \mathrm{GT}=1.000000$; and gamma distribution shape parameter $\alpha$ $=0.183588$. In the phylogenetic analyses (Figure 2), twelve genera are included in the tree. The novel taxon of Haplohelminthosporium calami grouped within Massarinaceae without strong bootstrap support. Haplohelminthosporium calami is closely related to H. endiandrae (CBS 138902, MH878637), but this is statistically unsupported. Helminthosporiella stilbacea (MFLUCC 15-0813) constitutes a sister phylogenetic affiliation to Hel. stilbacea (strains CPHmZC-01 and COAD 2126) with 100\% ML/1.00 BYPP statistical support.

The phylogenetic analyses (Figures 1 and 2) showed several topologies of the tree had generally rather low support (ML $\leq 50 \%$ and BYPP $\leq 0.90$ ). This reflects the relatively high amount of homoplasy in the data. Most Helminthosporium-like taxa did not have SSU and tef1- $\alpha$ sequence data for the phylogenetic analyses. In the future, divergent time estimations will be needed for Helminthosporium-like taxa to resolve taxonomic confusion and placement.

\subsection{Taxonomy}

3.2.1. Haplohelminthosporium Konta \& K.D. Hyde, gen. nov

Index Fungorum number: IF557873; Facesoffungi number: FoF09169

Etymology-Haplo in Greek means single, which refers to the single conidium in each conidiophore. It is a close relative of Helminthosporium.

Saprobic on living leaves and petioles of Calamus sp. On living leaves, small spots, circular to irregular, yellow in the beginning, later becoming red brown surrounded by yellow. Colonies on natural substrate forming black patches on the upper leaf, petiole surfaces. Sexual morph: Undetermined. Asexual morph: Hyphomycetous. Colonies on natural substrate forming black patches on the upper leaf, petiole surfaces. Mycelium mostly immersed, partly on the surface forming small stroma-like aggregations of red brown pseudoparenchymatous cells. Conidiophores arising singly or fasciculate from stroma 
cells, erect, simple, unbranched, straight, curved and swollen at apex, septate, thick-walled, cylindrical, smooth, bulbous at base, hyaline in the middle, brown to yellow-brown at 1-2-cells above the base, pale brown to yellow-brown at apical cell. Conidiogenous cells monotretic, terminal, determinate, cylindrical, wide and yellow-brown with a well-defined, small, noncicatrized pore at the apex. Conidia one for each conidiophore, obpyriform to lageniform, straight or curved, smooth, olive-brown, distoseptate, with a dark scar at the base.

Type species-Haplohelminthosporium calami Konta \& K.D. Hyde

Notes: Haplohelminthosporium is established as a monotypic genus with Hap. calami as the type species. ITS phylogenetic analyses separated this genus from other genera, while in the LSU and multigene analyses it clustered with Helminthosporium and Helminthosporiella, but both without good statistical support (Figures 1 and 2). Haplohelminthosporium is presented herein as an asexual morph (hyphomycete) similar to Helminthosporium and Helminthosporiella in that it is hyphomycete with an erect conidiophore, monotretic conidiogenous cell and distoseptate conidia $[19,22,63]$. The type species of Helminthosporium has pale to dark brown, septate conidiophores, with terminal and intercalary polytretic conidiogenous cells, noncicatrized pores at the apex and upper 3-4 cells, solitary or short catenate conidia that are subhyaline to brown, distoseptate, and is dark brown to black scar at the base [19]. Helminthosporiella has brown to red-brown conidiophores with terminal, polytretic conidiogenous cells, with catenate and easily disarticulating chains of conidia that are medium brown, striated at surface and distoseptate [63]. However, Haplohelminthosporium is distinguished by its unbranched conidiophores arising solitarily or fasciculate from the stroma-like bulbous basal cells that are hyaline in the middle, brown to red-brown at 1-2-cells above the base, pale brown to red-brown and curved at the apical cell with well-defined non-cicatrized small pores and with a single olive-brown conidium arising from each conidiophore (Figure 3). In the BLAST search of GenBank, the closest match of the LSU, ITS, and SSU sequence data were identical to Helminthosporium spp. Based on distinguishing morphological characteristics together with single/multigene phylogenetic analyses we introduce the newly described strain as a new genus Haplohelminthosporium in Massarinaceae.

Haplohelminthosporium calami Konta \& K.D. Hyde, sp. nov.

Index Fungorum number: IF557874, Facesoffungi number: FoF09170, Figure 3

Etymology: Referring to the genus of palm trees Calamus L.

Holotype: MFLU 20-0520.

Saprobic on living leaves and petioles of Calamus sp. On living leaves, small spots, circular to irregular, yellow in the beginning, later becoming red-brown surrounded by yellow. Colonies on natural substrate forming black patches on the upper leaf, petiole surfaces. Sexual morph: Undetermined. Asexual morph: Mycelium mostly immersed, on the surface forming small stroma-like aggregations of red brown pseudoparenchymatous stromal cells $(7-) 10-14(-20) \mu \mathrm{m}(\bar{x}=12 \mu \mathrm{m})$. Conidiophores $(110-) 140-175(-215) \times(4-) 5-7(-8)$ $\mu \mathrm{m}(\bar{x}=160 \times 6 \mu \mathrm{m}, \mathrm{n}=50)$, wide at the base and apex, macronematous, mononematous, arising singly or fasciculate from the stroma cells, erect, simple, unbranched, straight, curved and swollen at the apex, thick-walled, cylindrical, smooth, bulbous at base, hyaline in the middle, brown to red-brown at 1-2-cells above the base, pale brown to red brown at the last cell of the apex, (3-)4-5(-6) septa. Conidiogenous cells monotretic, terminal, determinate, cylindrical, with well-defined small noncicatrized pores at the apex, wide and yellow-brown at the apex. Conidia (55-)70-100(-120) $\times(13-) 17-20(-23) \mu \mathrm{m}(\bar{x}=80 \times 20 \mu \mathrm{m}, \mathrm{n}=60)$, one on each conidiophore, obpyriform to lageniform, straight or curved, smooth, olive-brown, (3-)4-6(-7)-distoseptate, with a dark scar at the base. 

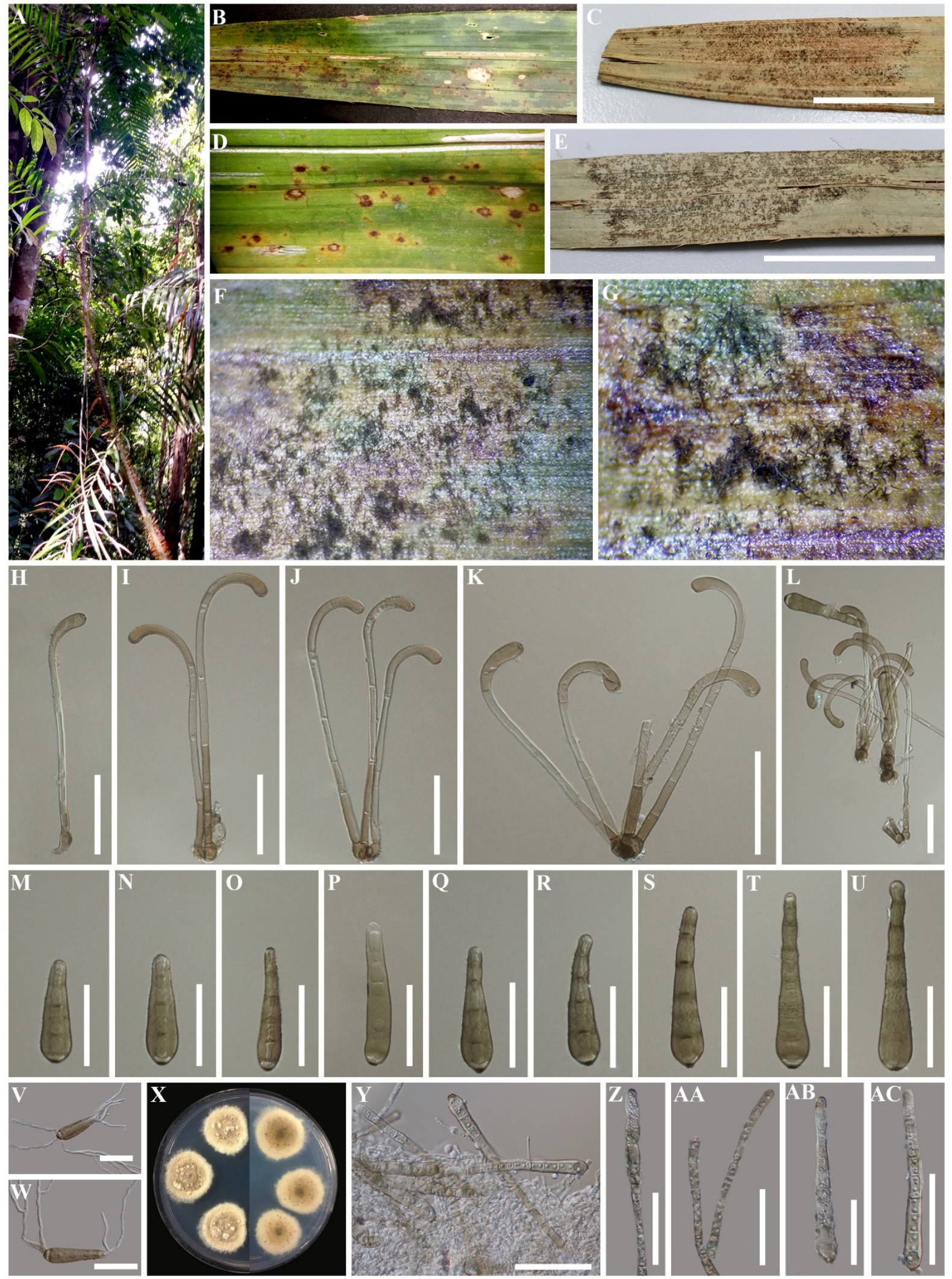

Figure 3. Haplohelminthosporium calami (MFLU 20-0520, holotype) (A) The forest in Krabi Province. (B-E) Fresh and herbarium palm samples. (F,G) Colonies on living leaf. (H-L) Conidiophores. (M-U) Conidia. (V,W) Germinated conidia. (X) Culture on PDA. (Y) Conidiophore and conidia on culture. (Z) Conidiogenesis. (AA) Conidiophores. (AB,AC) Conidia. Scale bars: C, E =2 cm, H-W, Y-AC $=50 \mu \mathrm{m}$. 
Culture characteristics: Culture on PDA, colony yellow-gray-brown at the center, turning dull creamy white toward to margin, smooth, dense, zonate at the margin (Figure 3X).

Material examined: THAILAND, Krabi Province, on living leaves and petioles of Calamus sp. (Arecaceae), 14 December 2015, Sirinapa Konta, KHNPR-2 (MFLU 20-0520, holotype); ex-type living culture, MFLUCC 18-0074.

Notes: BLAST search of the ITS sequence of the newly described strain (Haplohelminthosporium calami) shows 88.89\% similarity with Helminthosporium juglandinum (L118), the LSU sequence shows $98.75 \%$ similarity with H. aquaticum (MFLUCC 15-0357), and the SSU sequence shows $99.52 \%$ similarity with $H$. quercinum (L90). Based on ITS phylogenetic analysis, Haplohelminthosporium calami formed a single branch at the basal clades of Helminthosporiella and Helminthosporium (Figure 1A), while based on LSU analysis, Hap. calami clustered together with H. juglandinum (L97), H. endiandrae (CBS 138902, MH878637), and Hel. stilbacea with no strong statistical support for both analyses. The phylogenetic results of the combined dataset indicated that Hap. calami clustered with $H$. endiandrae (CBS 138902, MH878637) without strong bootstrap support (Figure 2). Comparison of base pair differences between LSU loci for isolates of Hap. calami strains MFLUCC 18-0074 and H. endiandrae strains CBS 138,902 (KP004478; Ex-type from the holotype, and MH878637; sister strain) including gaps showed $1.74 \%(15 / 861 \mathrm{bp})$ differences, and the position of each base pair difference is shown in Table 3. Other H. endiandrae strains (AKMR1, CBS 138902; ex-type from the holotype, and SM61) grouped together in Helminthosporium, as the other strains have an ITS region, but the H. endiandrae (CBS 138902, MH878637) strain that grouped with our new collection lacks the ITS region. Therefore, we compared the morphology of these two species and found that Hap. calami differs from H. endiandrae with respect to its smaller conidiophores $((110-) 140-175(-215) \times(4-) 5-7(-8)$ vs. $200-300 \times 5-7 \mu \mathrm{m})$, number of conidiophore septa ((3-)4-5(-6) vs. 8-16 septa), larger conidia ((55-)70-100(-120) $\times(13-) 17-20(-23)$ vs. (35-)37-45(-57) $\times(7-) 8(-9) \mu \mathrm{m})$, solitary conidium per conidiophore, and higher number of distoseptate ((3-)4-6(-7)-distoseptate vs. 3(-4)-distoseptate). The results show the placement of Haplohelminthosporium calami within Massarinaceae, and that this species is distinct from other known species. Therefore, we introduce Hap. Calami as a new species based on both morphological and phylogenetic data.

Table 3. Polymorphic nucleotides from sequence data of the LSU loci for isolates of Haplohelminthosporium calami MFLUCC 18-0074 and Helminthosporium endiandrae CBS 138,902 (KP004478, MH878637).

\begin{tabular}{|c|c|c|c|c|c|c|c|c|c|c|c|c|c|c|c|c|}
\hline \multirow{2}{*}{ Species } & \multirow{2}{*}{ Strain } & \multicolumn{15}{|c|}{ LSU } \\
\hline & & 6 & 34 & 74 & 270 & 400 & 412 & 419 & 427 & 480 & 484 & 490 & 491 & 524 & 644 & 843 \\
\hline $\begin{array}{l}\text { Haplohelminthosporium calami } \\
\text { (this study) }\end{array}$ & $\begin{array}{l}\text { MFLUCC } \\
18-0074\end{array}$ & - & $\mathrm{A}$ & $\mathrm{A}$ & $\mathrm{T}$ & $\mathrm{T}$ & $\mathrm{T}$ & $\mathrm{C}$ & $\mathrm{C}$ & A & $C$ & A & $\mathrm{T}$ & $\mathrm{T}$ & $\mathrm{T}$ & $\mathrm{G}$ \\
\hline $\begin{array}{l}\text { Helminthosporium endiandrae } \\
\text { (Ex-type from the holotype) }\end{array}$ & $\begin{array}{l}\text { CBS 138,902 } \\
(\mathrm{KP} 004478)\end{array}$ & - & C & C & $\mathrm{C}$ & C & C & $\mathrm{T}$ & $\mathrm{T}$ & C & $\mathrm{T}$ & $\mathrm{T}$ & G & $\mathrm{C}$ & G & $\mathrm{G}$ \\
\hline $\begin{array}{l}\text { H. endiandrae (sister strain in } \\
\text { Figures } 1 \mathrm{~B} \text { and } 2 \text { ) }\end{array}$ & $\begin{array}{l}\text { CBS 138,902 } \\
(\mathrm{MH} 878637)\end{array}$ & C & $\mathrm{A}$ & $\mathrm{C}$ & C & C & C & $\mathrm{T}$ & $\mathrm{T}$ & C & $\mathrm{T}$ & $\mathrm{T}$ & G & C & G & - \\
\hline
\end{tabular}

\subsubsection{Helminthosporiella Konta \& K.D. Hyde, gen. nov.}

Index Fungorum number: IF558311, Facesoffungi number: FoF09171

Helminthosporiella Hern.-Restr., Sarria \& Crous, in Crous et al., Persoonia 36: 437 (2016), MycoBank MB816988, Nom. inval., Art. 40.3 (Shenzhen)

Saprobic on dead petiole of Cocos nucifera.Sexual morph: Undetermined. Asexualmorph:Colony on natural substrate black, hairy. Mycelium mostly immersed, at the surface forming small stroma-like aggregations of dark brown pseudoparenchymatous cells. Conidiophores macronematous, wide at the apex and base, arising singly from the stroma cells, erect, simple, unbranched, straight or flexuous, thick-walled, cylindrical, smooth-walled, dark brown, becoming pale brown at the apex, septate. Conidiogenous cells terminal and intercalary, polytretic, with well-defined thick, pale brown pores. Conidia obpyriform to 
lageniform, straight or curved, smooth-walled, subhyaline to light brown, distoseptate, with a thick scar at the base.

Type species-Helminthosporiella stilbacea Konta \& K.D. Hyde

Notes: Helminthosporiella was introduced by Crous et al. [63] to accommodate a new combination of Hel. stilbacea Hern.-Restr., Sarria \& Crous, in Massarinaceae, the basionym of the type species was not provided a Latin diagnosis [63]. In this paper we accept Helminthosporiella as a distinct genus, presently with a single species Helminthosporiella stilbacea. Since a Latin diagnosis is no longer required, we provide an English diagnosis and priority was given to the previous genus and species names. Furthermore, this study provides the holotype to validate the genus and species, and reports the first host record of Hel. stilbacea associated with coconut tree (Arecaceae) in Thailand. In particular, based on the present morphology and DNA sequence data, Helminthosporiella is identified as a monotypic genus, with Hel. stilbacea as the type species. The members of Helminthosporiella were found associated with leaf spots on oil palm (Arecaceae) [64].

Helminthosporiella stilbacea Konta \& K.D. Hyde, sp. nov.

Index Fungorum number: IF558312, Facesoffungi number: FoF09172, Figure 4.

=Cercospora palmicola f. stilbacea Moreau, Rev. Mycol. 12: 38. 1947 Nom. inval., Art. 39.1 (Shenzhen)

$\equiv$ Helminthosporiella stilbacea Hern.-Restr., Sarria \& Crous, in Crous et al., Persoonia 36: 437. 2016; Nom. inval., Art. 39.1 (Shenzhen)

Helminthosporium stilbaceum Moreau ex S. Hughes, Mycol. Pap.48: 38. 1952; Nom. inval., Art. 39.1 (Shenzhen).

Exosporium stilbaceum Moreau ex M.B. Ellis, Mycol. Pap.82: 38. 1961; Nom. inval., Art. 39.1 (Shenzhen).

=Exosporium stilbaceum var. macrosporum Subramon. \& V.G. Rao, Journal of the Annamalai University, part B, Sciences 29: 404. 1971; Nom. inval., Art. 35.1 (Shenzhen).

Saprobic on dead petiole of Cocos nucifera.Sexual morph: Undetermined. Asexualmorph: Colony on natural substrate black, hairy. Mycelium mostly immersed, at the surface forming small stroma-like aggregations of dark brown pseudoparenchymatous cells $(6-) 11-15(-25) \mu \mathrm{m}$ diam $(\bar{x}=14 \mu \mathrm{m})$. Conidiophores $(60-) 165-270(-310) \times(5-) 7-9(-12) \mu \mathrm{m}$ $(\bar{x}=200 \times 8 \mu \mathrm{m}, \mathrm{n}=30)$, macronematous, wide at the apex and base, arising singly from the stroma cells, erect, simple, unbranched, straight or flexuous, thick-walled, cylindrical, smooth-walled, dark brown, becoming pale brown at the apex, (4-)12-15-septate. Conidiogenous cells terminal and intercalary, polytretic, with well-defined thick, pale brown pores. Conidia (30-)45-60(-70) $\times 6-9 \mu \mathrm{m}(\bar{x}=50 \times 7 \mu \mathrm{m}, \mathrm{n}=30)$, obpyriform to lageniform, straight or curved, smooth-walled, subhyaline to light brown, 5-8-distoseptate, with a thick scar at the base.

Culture characteristics: Culture on MEA, colony yellow-green at the center, turning dull green, pale yellow next, becoming dull green again, pale yellow, and white toward the margin. Colony smooth, dense at the middle, zonate, fluffy at the margin (Figure 4P).

Material examined: THAILAND, Prachuap Khiri Khan Province, on dead petiole of Cocos nucifera L. (Arecaceae), 30 July 2015, Sirinapa Konta PJK04gHB (MFLU 20-0521, holotype); ex-type living culture, MFLUCC 15-0813. 


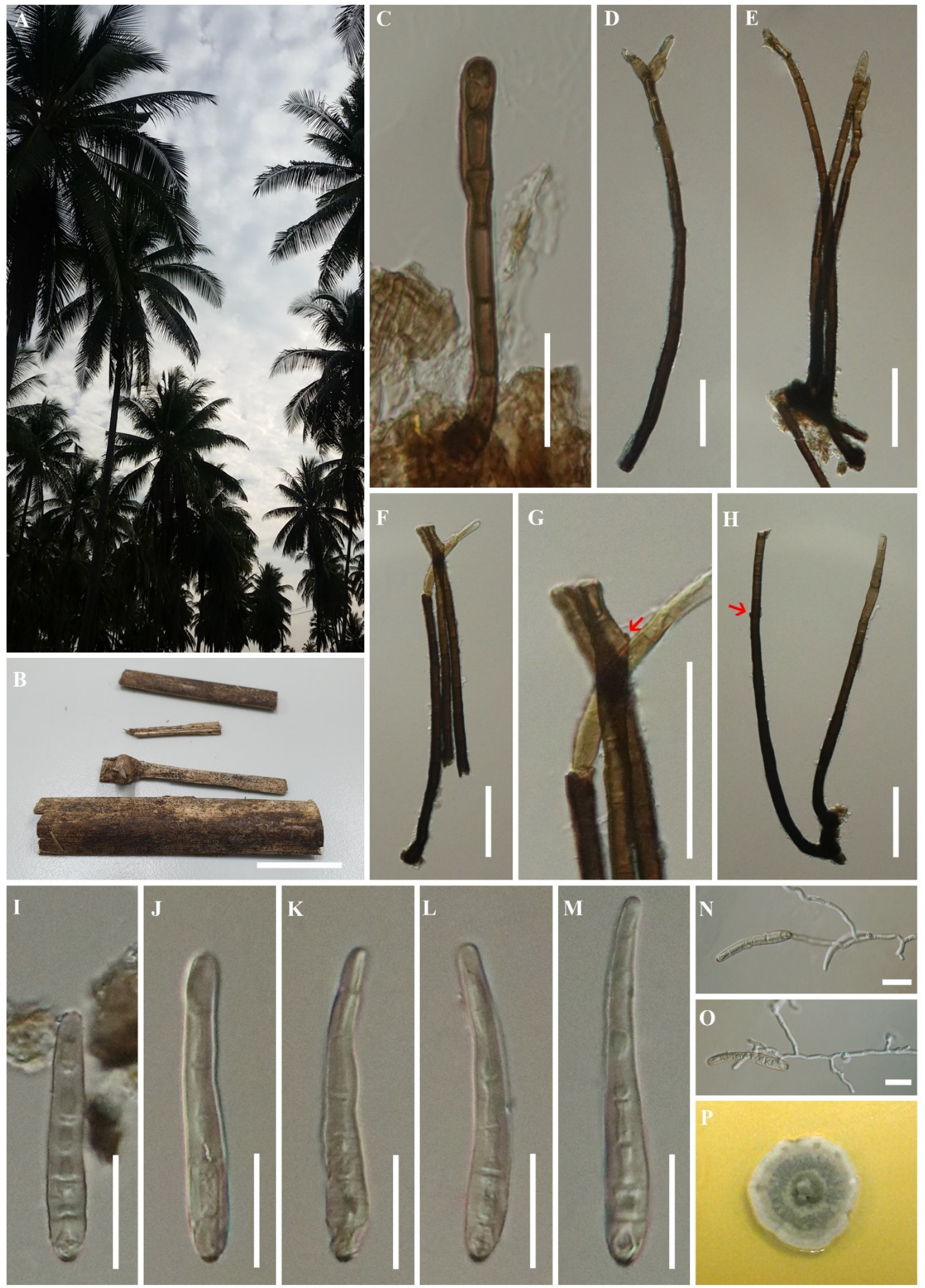

Figure 4. Helminthosporiella stilbacea (MFLU 20-0521, holotype) (A) A coconut plantation in Prachuap Khiri Khan Province. (B) Palm samples. (C-E) Conidiogenesis. (F-H) Conidiophores (at red arrow are pores). (I-M) Conidia. (N,O) Germinated conidia. (P) Culture on MEA. Scale bars: $\mathrm{B}=2 \mathrm{~cm}, \mathrm{C}, \mathrm{I}-\mathrm{O}=20 \mu \mathrm{m}, \mathrm{D}-\mathrm{H}=50 \mu \mathrm{m}$. 
Notes: Crous et al. [63] introduced a new genus Helminthosporiella with a new combination of Hel. stilbacea based on fresh collections from oil palm (Elaeis oleifera) in Colombia and the second collection of Hel. stilbacea was also collected from oil palm (Elaeis guineensis) in Brazil by Rosado et al. [64]. The full descriptions, illustrations, and sequence data are provided with interesting information as this species causes elliptical necrotic spots with a yellowish halo on living leaves of commercial oil palm plantations [63,64]. However, the type species was invalid because of the basionym lacked a Latin diagnosis [63]. From these, our fresh collection was collected from dead petiole of coconut (Cocos nucifera) and in phylogenetic analysis (Figures 1 and 2), three strains of Hel. stilbacea, including our strain, are grouped together with high bootstrap support. In this study, we therefore provide a holotype from our specimen, and introduce a new species Helminthosporiella stilbacea, complete with an English diagnosis, and validated by using the same name while linking to the valuable information provided from the previous publication of this species.

A BLAST search of the ITS sequence of our isolate showed $90.19 \%$ similarity with $H$. velutinum (L131), the LSU sequence showed $97.05 \%$ similarity with H. aquaticum (MFLUCC 15-0357), the SSU sequence showed $99.15 \%$ similarity with H. quercinum (L90), and the tef1- $\alpha$ sequence showed $92.61 \%$ similarity with $H$. tiliae (L88). These blast results do not match the results of the phylogenetic analyses.

The comparison between three strains of Hel.stilbacea (see Table 4) from three collections showed that our collection MFLU 20-0521 has several differences when compared with the other two strains CPHmZC-01 and COAD 2126. Our collection was obtained from a dead petiole, while the two other strains were isolated from living leaves [63,64]. Therefore, our new collection has been provided as a holotype for Hel. Stilbacea. It is also the first geographical record from Thailand, and is a new record of the species from a coconut host (Cocos nucifera). 
Table 4. Comparison of three strains of Helminthosporiella stilbacea.

\begin{tabular}{|c|c|c|c|c|c|c|c|c|}
\hline \multirow[b]{2}{*}{ No. } & \multirow[b]{2}{*}{$\begin{array}{l}\text { Herbarium/ } \\
\text { Culture No. }\end{array}$} & \multirow[b]{2}{*}{$\begin{array}{c}\text { Host } \\
\text { (Genus/Family) }\end{array}$} & \multirow[b]{2}{*}{ Locality } & \multicolumn{4}{|c|}{ Morphology } & \multirow[b]{2}{*}{ References } \\
\hline & & & & $\begin{array}{c}\text { Mycelia } \\
\text { ( } \mu \text { mWide) }\end{array}$ & $\begin{array}{l}\text { Conidiophores } \\
(\mu \mathrm{m})\end{array}$ & $\begin{array}{c}\text { Conidiogenous Cells } \\
(\mu \mathrm{m})\end{array}$ & $\begin{array}{l}\text { Conidia } \\
(\mu \mathrm{m})\end{array}$ & \\
\hline 1. & $\begin{array}{l}\text { Herbarium: - } \\
\text { Culture no.: } \\
\text { CPHmZC-01 }\end{array}$ & $\begin{array}{l}\text { On leaves of Elaeis } \\
\text { oleifera/Arecaceae }\end{array}$ & Colombia & $\begin{array}{l}\text { Hyaline to pale } \\
\text { brown, smooth, } \\
\text { branched, septate }\end{array}$ & $\begin{array}{l}\text { Erect, brown to red-brown, } \\
\text { synnematous, septate, } \\
\text { compacted, } 620-1400 \times \\
\text { 19-54, individual hyphae } \\
\text { 3-4 wide }\end{array}$ & $\begin{array}{l}\text { Mono- or polytretic, } \\
\text { integrated, determinate, } \\
\text { terminal, cylindrical, } \\
31-67 \times 4.5-7\end{array}$ & $\begin{array}{l}\text { Catenate, obclavate, } \\
\text { subcylindrical, } \\
\text { occasionally bifurcate, } \\
\text { medium brown, } \\
26-83 \times 7-10 \text {, } \\
(1-) 3-5(-6) \text {-distoseptate }\end{array}$ & [63] \\
\hline 2. & $\begin{array}{l}\text { Herbarium: - } \\
\text { Culture no.: } \\
\text { COAD } 2126\end{array}$ & $\begin{array}{l}\text { On old leaves of } \\
\text { Elaeis guineen- } \\
\text { sis / Arecaceae }\end{array}$ & Brazil & $\begin{array}{l}\text { Hyaline to pale } \\
\text { brown, 2-4 }\end{array}$ & $\begin{array}{l}\text { Erect, brown, septate, } \\
\text { synnematous, 66-201 }(-770) \\
\times 2.5-6(-18)\end{array}$ & $\begin{array}{l}\text { Mono or polytretic, } \\
\text { cylindrical, terminal, } \\
18-59 \times 4-7\end{array}$ & $\begin{array}{l}\text { Catenate, subcylindrical, } \\
\text { obclavate, brown, } 32-83 \\
\times 4-11,2-7 \text {-distoseptate }\end{array}$ & [64] \\
\hline 3. & $\begin{array}{l}\text { Herbarium: MFLU } \\
\text { 20-0521 } \\
\text { Culture no.: } \\
\text { MFLUCC 15-0813 }\end{array}$ & $\begin{array}{l}\text { On dead petiole of } \\
\text { Cocos } \\
\text { nucifera/Arecaceae }\end{array}$ & Thailand & $\begin{array}{l}\text { Mostly immersed, } \\
\text { dark brown }\end{array}$ & $\begin{array}{l}\text { Solitarily, erect, unbranched, } \\
\text { straight or flexuous, } \\
\text { cylindrical, bulbous at base, } \\
\text { dark brown, becoming pale } \\
\text { brown at the apex, } \\
(60-) 165-270(-310) \text {, } \\
(5-) 7-9(-12) \text { at the base, } 5-8 \\
\mu m \text { wide at the apex, } \\
(4-) 12-15 \text { septate }\end{array}$ & $\begin{array}{l}\text { Terminal and intercalary } \\
\text { with well-defined pores, } \\
\text { pale brown }\end{array}$ & $\begin{array}{l}\text { Obpyriform to } \\
\text { lageniform, straight or } \\
\text { curved, light brown, } \\
\text { (30-)45-60(-70) } \times 6-9 \text {, } \\
\text { 5-8-distoseptate }\end{array}$ & This study \\
\hline
\end{tabular}




\section{Conclusions}

In this study, we introduce the new genus Haplohelminthosporium, with Hap. calami as the type species. In multigene phylogenetic analyses, Hap.calami clustered together with Helminthosporium endiandrae (CBS 138902) without strong good bootstrap support (other H. endiandrae (AKRM1, CBS 138902 (ex-type), SM61) groups together in Helminthosporium). Moreover, we were unable to synonymize H. endiandrae (CBS 138902) under Haplohelminthosporium because $H$. endiandrae has only LSU sequence data available [60]. In the future, $H$. endiandrae needs more collections and sequence data to confirm taxonomic placement.

Another newly described isolate clusters together with Helminthosporiella stilbacea. Helminthosporiella was introduced by Crous et al. [63] but was invalidated as the type species was not provided with a Latin diagnosis. In this study, we validate Helminthosporiella with Hel. stilbacea as the type species. Moreover, the newly described strain from this study is the first saprobic report of Hel. stilbacea, as this was reported in previous studies as a pathogenic fungus on leaves $[63,64]$. Moreover, topological nodes in phylogenic analyses showed conflicting results (Figures 1 and 2). Probably, using only single gene ITS or LSU analyses will preclude the establishment of taxonomic placements, while combined gene analyses (including protein coding genes) provide sufficient molecular data to determine the placements.

Helminthosporium is generally described as a common saprobe found on leaf or twig litter, and it appears to have a diverse distribution. Occasionally, members of this genus are also described as pathogens, occurring on a wide range of hosts. Comparison of morphology is important for fungal identification [79]. In this study, we provide a checklist for Helminthosporium species reported worldwide including details of each species based on records from Species Fungorum [80] (Table 5). We noted that ten Helminthosporium species have been found on palm substrates (Arecaceae). Although Helminthosporium conidia superficially resemble many genera, such as Drechslera, Bipolaris, and Exserohilum, phylogenetic analyses have provided different results $[19,33,81-83]$. Furthermore, we recommend revision of the genus Helminthosporium with fresh collections and DNA sequence data (specifically the ITS region and protein coding genes). 


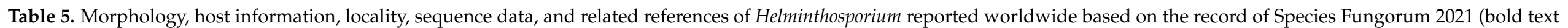
present Helminthosporium reported from Arecaceae).

\begin{tabular}{|c|c|c|c|c|c|c|}
\hline No. & Taxa & Host(Genus/Family) & Locality & Morphology & Sequence Data & References \\
\hline 1 & H. abietis & Abies sp./Pinaceae & U.S.A./Washington & $\begin{array}{l}\text { Conidiophores irregularly branched; Conidia } 126-150 \times 12-16 \mu \mathrm{m} \text {, } \\
\text { fusiform, pointed at both ends, olive-green, } 12-15 \text {-distoseptate }\end{array}$ & Absent & [84] \\
\hline 2 & H. acaciae & $\begin{array}{l}\text { On dead branches of Acacia } \\
\text { farnesiana/Fabaceae }\end{array}$ & Sierra Leone & $\begin{array}{l}\text { Conidiophores } 140-280 \times 7-11 \mu \mathrm{m} \text {, dense, fasiculate, simple, } \\
\text { straight or flexuous, sometimes swollen at at the tip, septate, } \\
\text { smooth, thick-walled, brown, with well-difinded small pores at } \\
\text { the apex; Conidia } 31-(44-) 49 \times 10-(12-) 14 \mu \mathrm{m} \text { in widest part, } \\
\text { narrowing towards the apex to } 3-5 \mu \mathrm{m} \text {, obclavate, straight or } \\
\text { flexuous, smooth-walled subhyaline to pale brown, } \\
\text { 3-6-distoseptate, with a small dark blackish-brown to black scar } \\
\text { at the base }\end{array}$ & Absent & [85] \\
\hline 3 & H. acalyphae & $\begin{array}{l}\text { On leaves of Acalypha } \\
\text { angustifolia/Euphorbiaceae }\end{array}$ & Dominican Republic & $\begin{array}{l}\text { Conidiophores } 2.5-4 \mu \mathrm{m} \text { thick, erect, simple, superficial, } \\
\text { brown-blackish, septate; Conidia } 9-16 \times 4-6 \mu \mathrm{m} \text {, one for each } \\
\text { conidiophore, ovate-ellipsoid, olivaceous-brown or dull-brown, } \\
\text { 2-3-distoseptate }\end{array}$ & Absent & [86] \\
\hline 4 & H. accedens & $\begin{array}{l}\text { On living leaves of Dolichos } \\
\text { baumii/Fabaceae }\end{array}$ & Namibia & $\begin{array}{l}\text { Conidiophores } 250-300 \times 5-9 \mu \mathrm{m} \text {, erect, olive-brown; Conidia } \\
35-57 \times 6.5-9 \mu \mathrm{m} \text {, solitary, oblong-fusoid, olive, } \\
\text { 3-6-distoseptate }\end{array}$ & Absent & [87] \\
\hline 6 & H. aichrysonis & $\begin{array}{l}\text { On leaves of Aichryson } \\
\text { dichotomum/Crassulaceae }\end{array}$ & Spain & No information available & Absent & [88] \\
\hline 7 & H. alatum & $\begin{array}{l}\text { On dying leaves of Dioscorea } \\
\text { alata/Dioscoreaceae }\end{array}$ & Dominican Republic & No information available & Absent & [89] \\
\hline
\end{tabular}


Table 5. Cont.

\begin{tabular}{|c|c|c|c|c|c|c|}
\hline No. & Taxa & Host(Genus/Family) & Locality & Morphology & Sequence Data & References \\
\hline 8 & H. albiziae & $\begin{array}{l}\text { On leaves of Albizia } \\
\text { lebbeck/Fabaceae }\end{array}$ & Sri Lanka & $\begin{array}{l}\text { Conidiophores } 70 \times 7 \mu \mathrm{m} \text {; Conidia } 42-56 \times 12 \mu \mathrm{m} \text {, tapering to } 4 \\
\mu \mathrm{m} \text { diam. clavate, ends rounded, at the lower end, rough with } \\
\text { minute warts, fuliginous, terminal cell paler, strgight or curved } \\
\text { below, 3-4-distoseptate }\end{array}$ & Absent & [90] \\
\hline 9 & H. albiziicola & Albizzia lebbek/Fabaceae & India & $\begin{array}{l}\text { Conidiophores } 28-44 \times 4.5-6 \mu \mathrm{m} \text {, straight or slightly curved, } \\
\text { one-septate at the base; Conidia } 23.5-34 \times 8-9 \mu \mathrm{m} \text {, pyriform, } \\
\text { prolongate at the apex, rounded at the base, pale, } \\
\text { cinnamon-brown, 3-distoseptate }\end{array}$ & Absent & [91] \\
\hline 10 & H. allamandae & $\begin{array}{l}\text { On living leaves of Allamanda } \\
\text { cathartica/Apocynaceae }\end{array}$ & Dominican Republic & $\begin{array}{l}\text { Conidiophores } 100-180 \times 8-10 \mu \mathrm{m} \text {, solitary or aggregate, curved, } \\
\text { simple, dark-brown; Conidia } 66-110 \times 17-20 \mu \mathrm{m} \text {, clavate, } \\
\text { elongate-ellipsoid or subfusoid, erect or curved, gray-brown, } \\
7-10 \text {-distoseptate }\end{array}$ & Absent & [92] \\
\hline 11 & H. alphitoniae & $\begin{array}{l}\text { On living leaves of Alphitonia } \\
\text { sp./Rhamnaceae }\end{array}$ & $\begin{array}{l}\text { Malaysia/Mount } \\
\text { Kinabalu }\end{array}$ & $\begin{array}{l}\text { Conidiophores } 250-500 \times 5-8 \mu \mathrm{m} \text {, erect, dark-brown; Conidia } \\
25-66 \times 8-13 \mu \mathrm{m} \text {, obclavate, erect or curved, yellow-brown or } \\
\text { pale olive, } 1-6 \text {-distoseptate }\end{array}$ & Absent & [93] \\
\hline 12 & H. aneurolepidii & $\begin{array}{l}\text { On leaves of Aneurolepidium } \\
\text { ramosum/Poaceae }\end{array}$ & Russia/West Siberia & No information available & Absent & [94] \\
\hline 13 & H. anomalum & From soil & U.S.A./Iowa, Utah & No information available & Present & {$[17,63]$} \\
\hline 14 & H. anonymicum & In culture: former Soviet Union & Russia & No information available & Absent & [95] \\
\hline 15 & H. apiculatum & $\begin{array}{l}\text { On dry tree of Betula sp. } \\
\text { (Betulinum)/Betulaceae }\end{array}$ & Czech Republic & $\begin{array}{l}\text { Conidiophores fasiculate, flexuous, simple, hyaline; Conidia long, } \\
37 \mu \mathrm{m} \text {, elliptical-fusiform, with color, multi-septate }\end{array}$ & Absent & [96] \\
\hline 16 & H. appatternae & $\begin{array}{l}\text { From leaves of Cynodon } \\
\text { dactylon/Poaceae; from culture }\end{array}$ & India/Maharashtra & $\begin{array}{l}\text { Conidiophores unbranched, of two types; determinate } \\
\text { conidiophores uniform, } 182 \times 5.2 \mu \mathrm{m} \text {, single, olivaceous, } 1-3 \\
\text { septate; indeterminante conidiophores narrower, } 208-520 \times 7.8 \\
\mu \mathrm{m} \text {, paler and distantly septate at base, gradually broadened } \\
\text { into a darker, close septate; Conidia } 20.8-152.0 \times 7.8 \mu \mathrm{m} \text {, } \\
\text { 6-18-distoseptate }\end{array}$ & Absent & [18] \\
\hline 17 & H. appendiculatum & On branches of the trees & Czechia & $\begin{array}{l}\text { Conidiophores simple, fasciculate; Conidia } 65 \times 11 \mu \mathrm{m} \text {, clavate, } \\
\text { curved, blunted, whitish, multi-septate }\end{array}$ & Absent & [96] \\
\hline
\end{tabular}


Table 5. Cont.

\begin{tabular}{|c|c|c|c|c|c|c|}
\hline No. & Taxa & Host(Genus/Family) & Locality & Morphology & Sequence Data & References \\
\hline 18 & H. aquaticum & On submerged decaying wood & China/Yunnan & $\begin{array}{l}\text { Conidiophores } 410-580 \times 13-17 \mu \mathrm{m} \text {, solitary or in groups of } 2-4 \text {, } \\
\text { erect, flexuous, unbranched, smooth, dark brown paler towards } \\
\text { the apex, bulbous at base, } 14-23 \text { septate; Conidia } 70-80 \times 16-18 \\
\mu \mathrm{m} \text {, single, obclavate, straight or curved, pale brown to brown, } \\
\text { truncate and cicatrized at base, wider than apex, guttulate, } \\
8-10 \text {-distoseptate }\end{array}$ & Present & [20] \\
\hline 19 & H. arcautei & $\begin{array}{l}\text { On living leaves Scorpiurus } \\
\text { subvillosa/Fabaceae }\end{array}$ & Spain & $\begin{array}{l}\text { Conidiophores } 35-50 \times 7-8 \mu \mathrm{m} \text {, erect, simple, cylindrical, } \\
\text { brownish-purple, } 2-3 \text { septate; Conidia } 48-86 \times 10.5-11 \mu \mathrm{m} \text {, } \\
\text { cylindrical-fusoid, straight or slightly curved, light-brown } \\
\text { chestnut, 3-8-distoseptate }\end{array}$ & Absent & {$[95,97]$} \\
\hline 20 & H. asterinoides & $\begin{array}{l}\text { On living leaves of Eugenia } \\
\text { sp./Myrtaceae }\end{array}$ & Brazil & $\begin{array}{l}\text { Conidiophores 5-7 } \mu \mathrm{m} \text { thick, fasciculate, rhizoid; Conidia } 22-24 \times \\
5-6 \mu \mathrm{m} \text {, fusoid, curved, colorless at each bottom, 3-distoseptate }\end{array}$ & Absent & [98] \\
\hline 21 & H. asterinum & $\begin{array}{l}\text { On Liquidambar sp./ } \\
\text { Altingiaceae }\end{array}$ & U.S.A./Florida & $\begin{array}{l}\text { Conidiophores erect, simple, septate; Conidia 500-600 } \times 80 \mu \mathrm{m} \text {, } \\
\text { clavate, 3-4-distoseptate }\end{array}$ & Present & [99] \\
\hline 22 & H. astragali & $\begin{array}{l}\text { On leaves of Astragalus } \\
\text { siversianus/Fabaceae }\end{array}$ & Kyrgyzstan & No information available & Absent & {$[100]$} \\
\hline 23 & H. atypicum & $\begin{array}{l}\text { On leaves of Triticum } \\
\text { sp./Poaceae }\end{array}$ & India/Maharashtra & $\begin{array}{l}\text { Conidiophores } 3-7 \text { septate, unbranched, and of two types; shorter } \\
\text { conidiophore uniformly wide, } 62.4-72.8 \times 7.8 \mu \mathrm{m} \text {, brown; } \\
\text { longer ones narrow at the base and paler, gradually broadening } \\
\text { and darkening towards the apex, } 440-680 \times 5.2-10 \mu \mathrm{m} \text {; Conidia } \\
\text { yellow to brown, darkening at maturity, of two kinds; normal } \\
\text { ones } 23-93.6 \times 26 \mu \mathrm{m} \text {, elliptical with hemispherical edges, } \\
\text { widest at the middle, } 0-10 \text {-distoseptate; a typical conidia } \\
\text { abundant, forked or geniculate, septation forked, brown to dark } \\
\text { brown, } 5-8 \text {-distoseptate }\end{array}$ & Absent & [101] \\
\hline
\end{tabular}


Table 5. Cont.

\begin{tabular}{|c|c|c|c|c|c|c|}
\hline No. & Taxa & Host(Genus/Family) & Locality & Morphology & Sequence Data & References \\
\hline 24 & H. austriacum & $\begin{array}{l}\text { On dead corticated twigs of } \\
\text { Fagus sylvatica/Fagaceae }\end{array}$ & $\begin{array}{l}\text { Austria/Döbling, } \\
\text { Kahlenberg, Wien }\end{array}$ & $\begin{array}{l}\text { Conidiophores } 275-700(-920) \mu \mathrm{m} \text { long, } 11.5-19 \mu \mathrm{m} \text { wide at the } \\
\text { base, tapering to } 7-11 \mu \mathrm{m} \text { near the apex, solitarily or fasciculate, } \\
\text { erect, simple, sub-cylindrical, straight or flexuous, thick-walled, } \\
\text { smooth, brown to dark brown, paler near the apex, with } \\
\text { well-defined small pores at the apex, } 1-12 \text { septate; Conidia } \\
(30-) 35-48(-97) \times(10.0-) 13.7-16.5(-19.8) \mu \mathrm{m} \text {, tapering to } 4.5-6.0 \\
\mu \mathrm{m} \text { at the distal end, obpyriform to lageniform, straight or } \\
\text { curved, smooth, pale brown, }(4-) 5-7(-10) \text {-distoseptate, with a } \\
\text { blackish-brown } 3-6 \mu \mathrm{m} \text { wide scar at the base }\end{array}$ & Present & [21] \\
\hline 25 & H. avenae-pratensis & $\begin{array}{l}\text { On sheaths of Avena } \\
\text { pratensis/Poaceae }\end{array}$ & Germany & $\begin{array}{l}\text { Conidiophores } 300 \times 8-11 \mu \mathrm{m} \text {, solitary or fasciculate, } \\
\text { dark-chestnut, septate; Conidia } 70-107 \times 16-21 \mu \mathrm{m} \text {, cylindrical } \\
\text { or obclavate, light brown, on both sides paler, } 5 \text {-11-distoseptate }\end{array}$ & Absent & [102] \\
\hline 26 & H. bactridis & $\begin{array}{l}\text { On sheaths of Bactris } \\
\text { sp./Arecaceae }\end{array}$ & Brazil/Pará & $\begin{array}{l}\text { Conidiophores } 200 \times 3-4.5 \mu \mathrm{m} \text {, septate; Conidia } 20-30 \times 6-8 \mu \mathrm{m} \text {, } \\
\text { fusoid, } 6 \text {-7-distoseptate }\end{array}$ & Absent & [103] \\
\hline 27 & H. bakeri & $\begin{array}{l}\text { On dead stems of Premnavestita } \\
\text { sp./Lamiaceae }\end{array}$ & Philippines & $\begin{array}{l}\text { Conidiophores } 500-800 \times 12 \mu \mathrm{m} \text { wide at base to below, } 10 \mu \mathrm{m} \\
\text { wide, erect, unbranched, dark; Conidia } 80-150 \times 17-22 \mu \mathrm{m} \text {, } \\
\text { solitary, oblong, obclavate, 3-6-distoseptate }\end{array}$ & Absent & [104] \\
\hline 28 & H. bambusicola & $\begin{array}{l}\text { On dead culm of Bambusa } \\
\text { sp./Poaceae }\end{array}$ & China/Sichuan & $\begin{array}{l}\text { Conidiophores } 55-247 \times 4-6 \mu \mathrm{m} \text {, fasciculate or solitary, simple, } \\
\text { cylindrical, straight or flexuous, thick walled, smooth, brown, } \\
\text { paler towards the apex, with well-defined small pores, } 1-2 \\
\text { septate; Conidia } 36-66 \times 6-11 \mu \mathrm{m} \text { narrowing towards the apex } \\
\text { to } 2-4.5 \mu \mathrm{m} \text { wide, obclavate, straight or slightly flexuous, } \\
\text { thin-walled } 1-1.5 \mu \mathrm{m} \text { thick, smooth, pale brown, paler towards } \\
\text { the apex, 5-8-distoseptate, scar not distinct at the base }\end{array}$ & Absent & [105] \\
\hline 29 & H. bataticola & $\begin{array}{l}\text { On living leaves of Ipomoea } \\
\text { batatas/Convolvulaceae }\end{array}$ & Caucasus & No information available & Absent & [106] \\
\hline
\end{tabular}


Table 5. Cont.

\begin{tabular}{|c|c|c|c|c|c|c|}
\hline No. & Taxa & Host(Genus/Family) & Locality & Morphology & Sequence Data & References \\
\hline 30 & H. bauhiniae & $\begin{array}{l}\text { On dead twigs of Bauhinia } \\
\text { tomentosa/Fabaceae }\end{array}$ & Sierra Leone & $\begin{array}{l}\text { Conidiophores } 350-110 \times 10-15 \mu \mathrm{m} \text { thick at the apex, } 15-20 \mu \mathrm{m} \\
\text { thick at the base, dense, fasciculate, simple, straight or flexuous, } \\
\text { smooth-walled, dark brown, sometimes paler towards the apex, } \\
\text { with well definded, small pores septate; Conidia } 55-(86-) 145 \times \\
16-(17.2-) 18 \mu \mathrm{m} \text { thick in broadest part, tapering to } 3-4 \mu \mathrm{m} \text { the } \\
\text { apex, obclavate, straight or flexuous, rostrate, smooth-walled, } \\
\text { subhyaline to brown, } 7-18 \text {-distoseptate, with a dark blackish } \\
\text { brown to black scar ath the base }\end{array}$ & Absent & [85] \\
\hline 31 & H. belgaumense & $\begin{array}{l}\text { On litter, Calamus } \\
\text { thwaitesii/Arecaceae }\end{array}$ & India/Karnataka & $\begin{array}{l}\text { Conidiophores } 140-250 \times 6-9 \mu \mathrm{m} \text {, erect, straight to flexuous, } \\
\text { unbranched, smooth, brown; Conidia } 10-15 \times 6-11 \mu \mathrm{m} \text {, solitary, } \\
\text { dry, sub-spherical, dark brown, truncate at base, roundea at the } \\
\text { apex, 1-distoseptate }\end{array}$ & Absent & [107] \\
\hline 32 & H. bhawanii & $\begin{array}{l}\text { On leaves of Eragrostis } \\
\text { japonica/Poaceae }\end{array}$ & India/Bihar & No information available & Absent & [108] \\
\hline 33 & H. bigenum & $\begin{array}{l}\text { Palmae rotten } \\
\text { petiole/Arecaceae }\end{array}$ & Peru & No information available & Absent & [109] \\
\hline 35 & H. cacaliae & Cacalia sonchifolia/Asteraceae & Brazil & No information available & Absent & [111] \\
\hline 36 & H. cacaophilum & $\begin{array}{l}\text { From unfermented Cacao beans, } \\
\text { Theobroma cacao/Malvaceae }\end{array}$ & $\begin{array}{l}\text { Dominican } \\
\text { Republic/Santo } \\
\text { Domingo }\end{array}$ & No information available & Absent & [112] \\
\hline 37 & H. cactacearum & $\begin{array}{l}\text { In young plants of Cereus } \\
\text { species/Cactaceae }\end{array}$ & Italy & No information available & Absent & [113] \\
\hline 38 & H. caespitiferum & $\begin{array}{l}\text { Meliola spec. in leaf spots of } \\
\text { living leafs of Omphalea } \\
\text { pauciflora/ } \\
\text { Euphorbiaceae }\end{array}$ & $\begin{array}{l}\text { Dominican } \\
\text { Republic/Santo } \\
\text { Domingo }\end{array}$ & $\begin{array}{l}\text { Conidiophores } 150-300 \times 6.5-8 \mu \mathrm{m} \text {, simple, dark-brown, septate; } \\
\text { Conidia } 18-42 \times 8-11 \mu \mathrm{m} \text {, oblong to fusoid, dark-brown, } \\
\text { constrict at septum, }(3-) 6-7 \text {-distoseptate }\end{array}$ & Absent & [92] \\
\hline
\end{tabular}


Table 5. Cont.

\begin{tabular}{|c|c|c|c|c|c|c|}
\hline No. & Taxa & Host(Genus/Family) & Locality & Morphology & Sequence Data & References \\
\hline 39 & H. canephorae & Coffea canephora/Rubiaceae & $\begin{array}{l}\text { Democratic Republic of } \\
\text { the Congo/Zaire }\end{array}$ & No information available & Absent & [114] \\
\hline 40 & H. cantareirense & On dead stems & Brazil/São Paulo & $\begin{array}{l}\text { Conidiophores } 7-12 \mu \mathrm{m} \text { thick, erect, fasciculate; Conidia } 50-60 \times \\
8-12 \mu \mathrm{m} \text {, clavate, brown, constrict at septum, } 6 \text {-8-distoseptate }\end{array}$ & Absent & [115] \\
\hline 41 & H. cantonense & $\begin{array}{l}\text { On decaying culms of Bambusa } \\
\text { vulgaris/Poaceae }\end{array}$ & China & $\begin{array}{l}\text { Conidiophores 80-95 × } 6 \mu \mathrm{m} \text {; Conidia 50-62 } \times 8 \mu \mathrm{m} \text {, obclavate, } \\
\text { 7-9-distoseptate }\end{array}$ & Absent & [116] \\
\hline 42 & H. caperoniae & $\begin{array}{l}\text { On living leaves of Caperonia } \\
\text { palustris/Euphorbiaceae }\end{array}$ & Dominican Republic & $\begin{array}{l}\text { Conidiophores } 100-300 \times 3.5-5 \mu \mathrm{m}, 2-5 \text { fasciculate, simple, } \\
\text { olive-brown; Conidia } 22-55 \times 4-6 \mu \mathrm{m} \text {, oblong-fusoid or } \\
\text { subclavate, rarely cylindrical, yellow or gray-brown }\end{array}$ & Absent & [92] \\
\hline 43 & H. carpocrinum & $\begin{array}{l}\text { Parasite on perithecia of Meliola } \\
\text { funebris on leaves of Omphalea } \\
\text { sp./Euphorbiaceae }(O . \\
\text { pauciflora })\end{array}$ & $\begin{array}{l}\text { Dominican } \\
\text { Republic/Santo } \\
\text { Domingo }\end{array}$ & $\begin{array}{l}\text { Conidiophores } 1-4 \text { articulate, } 200-350 \mu \mathrm{m} \text { long, very densely } \\
\text { fasciculate, erect to sub-erect, straight or slightly irregularly } \\
\text { curved, almost straight ot curved, dark-brown to blackish, tip } \\
\text { light-colored; Conidia } 22-25 \times 8-10 \mu \mathrm{m}, 1-4 \text { to each conidiopore, } \\
\text { easily falling, ellipsoid to ovoid, with narrowed ends, or basal } \\
\text { end narrowed-truncate, apical end rounded to acute, not } \\
\text { caudate, central cells from dark-brown to brownish, and cells } \\
\text { light brown to yellowish, } 2-5 \text {-distoseptate }\end{array}$ & Absent & [117] \\
\hline 44 & H. carposaprum & $\begin{array}{l}\text { On Lycopersicon } \\
\text { esculentum/Solanaceae }\end{array}$ & $\begin{array}{l}\text { British Guiana, Haiti, } \\
\text { Mexico }\end{array}$ & No information available & Absent & [118] \\
\hline 45 & H. ceibae & $\begin{array}{l}\text { On leaves of Ceiba } \\
\text { pentandra/Malvaceae }\end{array}$ & Philippines & No information available & Absent & [119] \\
\hline 46 & H. chlorophorae & $\begin{array}{l}\text { On dead twigs of Chlorophora } \\
\text { regia/Moraceae }\end{array}$ & Sierra Leone & $\begin{array}{l}\text { Conidiophores } 120-270 \times 7-10 \mu \mathrm{m} \text { thick at the base, often swollen } \\
\text { towards the tip up to } 12 \mu \mathrm{m} \text {, single or fasciculate, simple, } \\
\text { straight or flexuous, smooth-walled, brown to dark brown, with } \\
1-3 \text { well-definded, small pores, septate; Conidia } 52-(73-) 102 \times \\
8-(9.5-) 11 \mu \mathrm{m} \text {, thick in the widest part narrowing gradually } \\
\text { towards the apex to } 3-5 \mu \mathrm{m} \text {, obclavate, straight or flexuous, } \\
\text { smooth-walled, subhyaline to pale brown, } 6-9 \text {-distoseptate, } \\
\text { with a tather large dark blackish-brown to black scar at the base }\end{array}$ & Present & {$[85,120]$} \\
\hline 47 & H. chrysobalani & $\begin{array}{l}\text { On dry leaves of Chrysobalanus } \\
\text { icaco/Chrysobalanaceae }\end{array}$ & $\begin{array}{l}\text { Dominican } \\
\text { Republic/Bonao }\end{array}$ & $\begin{array}{l}\text { Conidiophores up to } 6 \mu \mathrm{m} \text {, fasciculate, erect, } 2-3 \text { septate; Conidia } \\
25-50 \times 3-4 \mu \mathrm{m} \text {, fusoid, } 2-4 \text {-distoseptate }\end{array}$ & Absent & [121] \\
\hline
\end{tabular}


Table 5. Cont.

\begin{tabular}{|c|c|c|c|c|c|c|}
\hline No. & Taxa & Host(Genus/Family) & Locality & Morphology & Sequence Data & References \\
\hline 48 & H. chusqueae & $\begin{array}{l}\text { On living and dying leaves of } \\
\text { Chusquea serrulata/Poaceae }\end{array}$ & Ecuador/Tungurahua & $\begin{array}{l}\text { Conidiophores } 200-350 \times 4-6 \mu \mathrm{m} \text {, dense, erect, fasciculate, } \\
\text { simple, straight or slightly curved, dark-brown or olive, septate; } \\
\text { Conidia } 32-50 \times 9-11 \mu \mathrm{m} \text {, elongate-fusiform, blunt at both ends, } \\
\text { curved, rarly straight, gray or olive-brown, } 3-4 \text {-distoseptate }\end{array}$ & Absent & [122] \\
\hline 49 & H. cibotii & $\begin{array}{l}\text { On leaves of Cibotium } \\
\text { sp./Cibotiaceae }\end{array}$ & U.S.A./Hawaii Islands & No information available & Absent & [123] \\
\hline 50 & H. ciliare & - & - & No information available & Absent & [124] \\
\hline 52 & H. claviphorum & Rotten branch & Peru & No information available & Absent & [109] \\
\hline 53 & H. cleosmatis & $\begin{array}{l}\text { On living leaves of Clematis sp./ } \\
\text { Ranunculaceae (in foliisvivis } \\
\text { Cleosmati soctandri) }\end{array}$ & Dominican Republic & $\begin{array}{l}\text { Conidiophores } 140-250(-300) \mu \mathrm{m} \text { long, } 4-5 \mu \mathrm{m} \text { wide, solitary, } \\
\text { erect, simple, dark-brown, often becoming paler; Conidia } 28-52 \\
\times 6.5-9 \mu \mathrm{m} \text {, clavate or fusoid, yellow or pale olive-brownish, } \\
(3-) 4-5 \text {-distoseptate }\end{array}$ & Absent & [92] \\
\hline 55 & H. coffeae & $\begin{array}{l}\text { On leaves of Coffea } \\
\text { liberica/Rubiaceae }\end{array}$ & Ghana & $\begin{array}{l}\text { Conidiophores } 300-400 \times 7-8 \mu \mathrm{m} \text {, effuse, nigro-olivaceas, } \\
\text { aggregate, erect, cylindrical, rect or flexuous, olives-brown, } \\
\text { septate; Conidia } 45-55 \times 8-10 \mu \mathrm{m} \text {, obovate, 3-5-distoseptate }\end{array}$ & Absent & [127] \\
\hline 56 & H. conidiophorellum & On dead branches of tree & China/Guangxi & $\begin{array}{l}\text { Conidiophores } 60-280 \times 7.0-8.5 \mu \mathrm{m} \text {, fasciculate, simple, } \\
\text { subcylindrical, straight or flexuous, thick-walled, smooth, dark } \\
\text { brown, paler towards the apex, with } 1-3 \text { well-defined small } \\
\text { pores at the apex, } 1-2 \text { septate; Conidia } 100-147.5 \mu \mathrm{m} \text { long, } \\
9.5-11 \mu \mathrm{m} \text { diam in the widest part, narrowing towards the apex } \\
\text { to } 3-4 \mu \mathrm{m} \text { diam, straight or slightly flexuous, smooth-walled, } \\
\text { pale brown, sometimes verruculose at apex, } 11-17-\text { distoseptate, } \\
\text { with a large dark blackish-brown scar at the base, } 2-3 \mu \mathrm{m} \text { thick }\end{array}$ & Absent & [128] \\
\hline
\end{tabular}


Table 5. Cont.

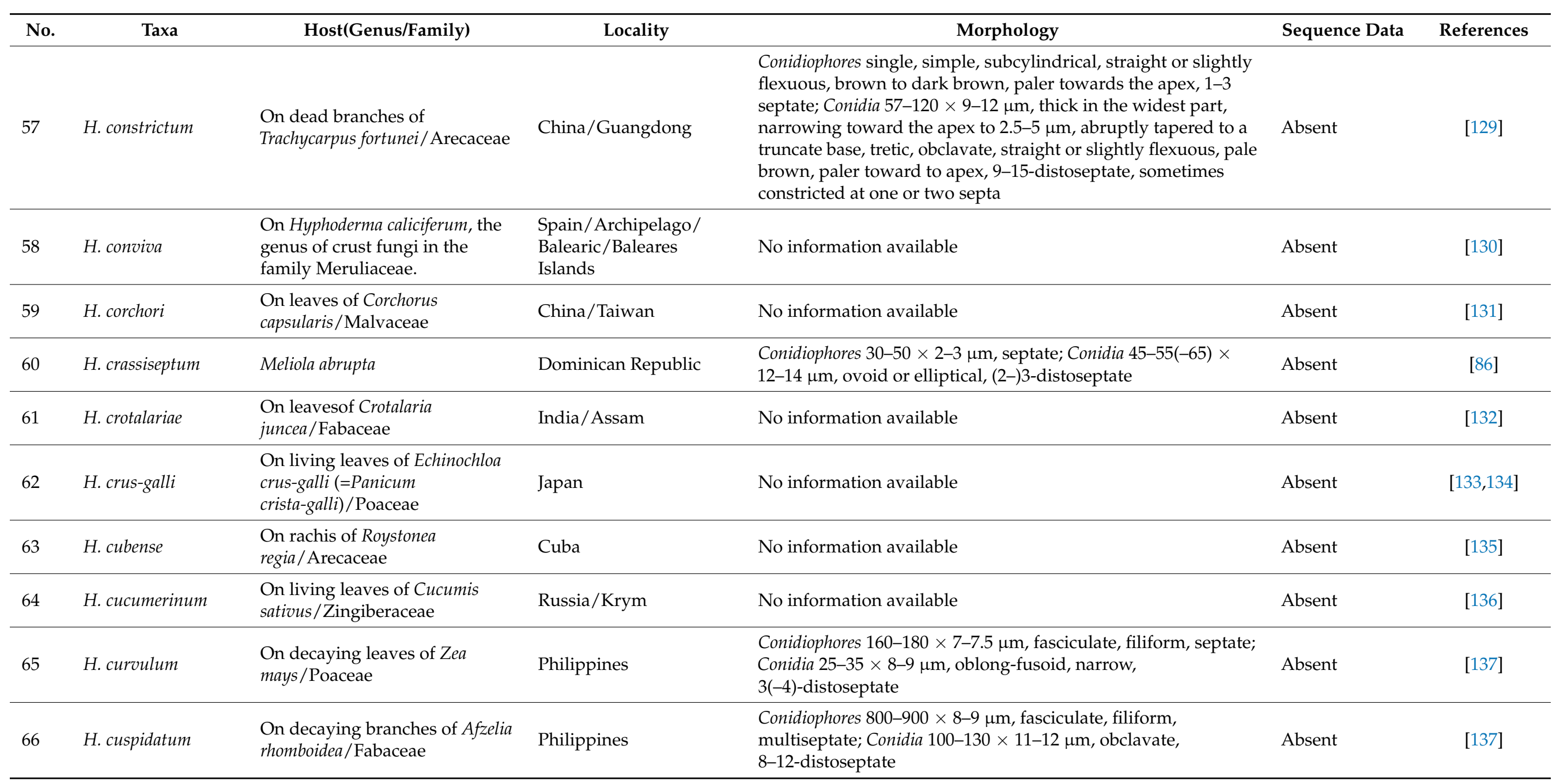


Table 5. Cont.

\begin{tabular}{|c|c|c|c|c|c|c|}
\hline No. & Taxa & Host(Genus/Family) & Locality & Morphology & Sequence Data & References \\
\hline 67 & H. cylindricum & On rotten wood & $\begin{array}{l}\text { Czech } \\
\text { Republic/Bohemia }\end{array}$ & $\begin{array}{l}\text { Conidiophores } 100-130 \times 4-5 \mu \mathrm{m} \text {, subfasciculate, filiform long, } \\
\text { simple, fuliginous up paler, septate; Conidia } 14-15 \times 2.5 \mu \mathrm{m} \text {, } \\
\text { cylindrical, apex rounded, base acuted, minute, pale fuliginous, } \\
\text { 3-distoseptate }\end{array}$ & Absent & [138] \\
\hline 68 & H. cymmartinii & $\begin{array}{l}\text { On leaves of Cymbopogon } \\
\text { martinii/Poaceae }\end{array}$ & India/Uttar Pradesh & No information available & Absent & [108] \\
\hline 69 & H. cyperi & $\begin{array}{l}\text { On Cyperus sp./ } \\
\text { Cyperaceae }\end{array}$ & Greece & $\begin{array}{l}\text { Conidiophores straight to subflexuous, greenish, paler at apex; } \\
\text { Conidia } 78 \times 9 \mu \mathrm{m} \text {, fusoid, fuscidull, 5-8-distoseptate }\end{array}$ & Absent & [139] \\
\hline 70 & H. dactylidis & $\begin{array}{l}\text { On leaves of Dactylis } \\
\text { glomerata/Poaceae }\end{array}$ & U.S.A./Pennsylvania & No information available & Absent & [140] \\
\hline 71 & H. dalbergiae & $\begin{array}{l}\text { On dead branches of Dalbergia } \\
\text { sissoo/Fabaceae }\end{array}$ & Pakistan & $\begin{array}{l}\text { Conidiophores } 300-1300 \times 10-12(-15) \mu \mathrm{m} \text {, dense, fasciculate, } \\
\text { simple, flexuous, smooth-walled, brown to dark brown, } \\
\text { sometimes paler towards the apex, with well-definded small } \\
\text { pores, septate; Conidia } 58-(93-) 125 \times 12-(13.2-) 14 \mu \mathrm{m} \text { thick in } \\
\text { broadest part, tapering to gradually towards the apex to } 3-5 \mu \mathrm{m} \text {, } \\
\text { obclavate, straight or flexuous, smooth-walled, straw-coloured } \\
\text { to pale brownwith, } 5-17 \text {-distoseptate, large dark } \\
\text { blackish-brown to black scar at the base }\end{array}$ & Present & [85] \\
\hline 72 & H. davillae & $\begin{array}{l}\text { On leaves of Davilla } \\
\text { rugosa/Dilleniaceae }\end{array}$ & U.S.A./San Francisco & $\begin{array}{l}\text { Conidiophores } 4-6 \mu \mathrm{m} \text {, thick filiform, flexuous, unbranched, } \\
\text { elongate, brown, septate; Conidia } 40-70 \times 4-6 \mu \mathrm{m} \text {, } \\
\text { elongate-obclavate, narrower and paler, (1-)2-4-distoseptate }\end{array}$ & Absent & [141] \\
\hline 73 & H. decacuminatum & $\begin{array}{l}\text { In the dry twigs on Vitis } \\
\text { vinifera/Vitaceae }\end{array}$ & Italy & $\begin{array}{l}\text { Conidiophores } 4 \mu \mathrm{m} \text { thick, extremely short-articulated, irregular, } \\
\text { dark reddish-brown; Conidia } 40-45 \times 10 \mu \mathrm{m} \text {, long clavate, } \\
\text { decacumina to tip, or cut down in pedicellum narrowed, pale } \\
\text { brown-gray, } 4-5 \text {-distoseptate }\end{array}$ & Present & {$[60,142]$} \\
\hline 74 & H. delicatulum & $\begin{array}{l}\text { On stems of Umbelliferae or } \\
\text { Apiaceae }\end{array}$ & UK/Great Britain & $\begin{array}{l}\text { Conidiophores slender, subulate, multi-articultate, brown, paler } \\
\text { at the tips; Conidia oblong, nearly colourless, with the apices } \\
\text { very obtuse, consisting of about five swollen articulations, one } \\
\text { or two of which have occasionally a vertical dissepiment }\end{array}$ & Absent & [143] \\
\hline 75 & H. delphinii & $\begin{array}{l}\text { On stems of Delphinium } \\
\text { brunonianum/Ranunculaceae }\end{array}$ & Russia & No information available & Absent & [144] \\
\hline
\end{tabular}


Table 5. Cont.

\begin{tabular}{|c|c|c|c|c|c|c|}
\hline No. & Taxa & Host(Genus/Family) & Locality & Morphology & Sequence Data & References \\
\hline 76 & H. dendroideum & On Acer sp./Sapindaceae & U.S.A./South Carolina & $\begin{array}{l}\text { Conidiophores } 1-2 \text { short branchlets termintated, oblong, } \\
\text { subfusiform, slightly curved, multiarticulate conidia; Conidia } \\
60 \mu \mathrm{m} \text { long, each joint containing a globose nucleus }\end{array}$ & Absent & [145] \\
\hline 77 & H. densum & - & - & No information available & Absent & [146] \\
\hline 78 & H. desmodii & $\begin{array}{l}\text { On Desmodium buergeri/ } \\
\text { Fabaceae }\end{array}$ & Japan & No information available & Absent & [147] \\
\hline 79 & H. diedickei & No information available & No information available & No information available & Absent & [148] \\
\hline 80 & H. dimorphosporum & $\begin{array}{l}\text { On decaying rotting stems of } \\
\text { unknown liana }\end{array}$ & Cuba & $\begin{array}{l}\text { Conidiophores } 150-400 \mu \mathrm{m} \text { long, at the apex } 9-12 \mu \mathrm{m} \text {, at the base } \\
10-14 \mu \mathrm{m} \text { wide, single or fasciculate } 2-10 \text {, simple, straight or } \\
\text { flexuous, smooth, dark brown, paler towards the apex, septate; } \\
\text { Conidia of two different types arising through pores a t the apex } \\
\text { (1-4 pores) and late rally beneath the upper septa: (a) } 19-24 \times \\
8-10.5 \mu \mathrm{m} \text {, broadly ellipsoidal, ovoid or broadly fusiform, } \\
\text { thick-walled, smooth, brown to dark brown, 1-distoseptate; (b) } \\
24-65 \mu \mathrm{m} \text { long, } 10-15 \mu \mathrm{m} \text { wide in the broadest part, tapering to } \\
3.2-4.8 \mu \mathrm{m} \text { at the apex, obclavate, rostrate, straight or flexuous, } \\
\text { pale brown, smooth, } 6-9 \text {-distoseptate, with a dark brown scar at } \\
\text { the base }\end{array}$ & Absent & [149] \\
\hline 81 & H. dolichi & $\begin{array}{l}\text { On living leaves of Dolichos } \\
\text { sp./Fabaceae }\end{array}$ & Namibia & $\begin{array}{l}\text { Conidiophores } 250-350 \times 4-6 \mu \mathrm{m} \text {, erect, olive-brown; Conidia } \\
27-38 \times 5.5-8 \mu \mathrm{m} \text {, solitary, oblong-subfusoid, olive, } \\
\text { 2-3-distoseptate }\end{array}$ & Absent & [87] \\
\hline 82 & H. dongxingense & Rhododendron sp. & China & No information available & Absent & [150] \\
\hline 83 & H. elasticae & - & - & No information available & Absent & [151] \\
\hline 84 & H. endiandrae & $\begin{array}{l}\text { On leaves of Endiandra } \\
\text { introrsa/Lauraceae }\end{array}$ & $\begin{array}{l}\text { Australia/New South } \\
\text { Wales, Nightcap } \\
\text { National Park }\end{array}$ & $\begin{array}{l}\text { Conidiophores } 200-300 \times 5-7 \mu \mathrm{m} \text {, solitary, erect, subcylindrical, } \\
\text { straight to flexuous, unbranched, thick-walled, base bulbous, } \\
\text { lacking rhizoids, brown, } 8-16 \text { septate; Conidia }(35-) 37-45(-57) \times \\
(7-) 8(-9) \mu \mathrm{m} \text {, solitary or in short chains }(2-3) \text {, obclavate, } \\
\text { thick-walled, finely roughened, brown, 3(-4)-distoseptate }\end{array}$ & Present & {$[21,59]$} \\
\hline
\end{tabular}


Table 5. Cont.

\begin{tabular}{|c|c|c|c|c|c|c|}
\hline No. & Taxa & Host(Genus/Family) & Locality & Morphology & Sequence Data & References \\
\hline 85 & H. eragrostiellae & $\begin{array}{l}\text { On inflorescence and leaves of } \\
\text { Eragrostis bifida/Poaceae }\end{array}$ & India/Uttar Pradesh & No information available & Absent & [108] \\
\hline 86 & H. erythrinae & $\begin{array}{l}\text { On leaves of Erythrina } \\
\text { suberosa/Leguminosae }\end{array}$ & India/Karnataka & $\begin{array}{l}\text { Conidiophores } 32-42 \times 4-5 \mu \mathrm{m} \text {, simple, brownish-yellow; Conidia } \\
39-62 \mu \mathrm{m} \text { at base, straight or vermiform, rounded at the apex } \\
\text { and flat at the base, pale cinnamon-brown, } 4-8 \text {-distoseptate }\end{array}$ & Absent & [91] \\
\hline 87 & H. erythrinicola & $\begin{array}{l}\text { On leaves of Erythrina } \\
\text { humeana/Fabaceae }\end{array}$ & $\begin{array}{l}\text { South Africa/Eastern } \\
\text { Cape }\end{array}$ & $\begin{array}{l}\text { Conidiophores } 500-1200 \times 6-10 \mathrm{~mm} \text {, fasciculate, subcylindrical, } \\
\text { unbranched, brown, becoming pale brown at apex, multiseptate; } \\
\text { Conidia }(70-) 80-90(-110) \times(9-) 10-11(-12) \mathrm{mm} \text {, obclavate, } \\
\text { straight to curved, apex subobtuse, smooth, medium brown, } \\
(6-) 7-8(-12) \text {-distoseptate }\end{array}$ & Present & [22] \\
\hline 88 & H. exasperatum & $\begin{array}{l}\text { On Dianthus barbatus / } \\
\text { Caryophyllaceae }\end{array}$ & UK/Great Britain & $\begin{array}{l}\text { Conidiophores flexuous, knotted above, each knot bearing oblong } \\
\text { conidia; Conidia } 30-45 \times 10-12 \mu \mathrm{m}\end{array}$ & Absent & [152] \\
\hline 89 & H. feijoae & $\begin{array}{l}\text { On leaves of } A c c a \\
\text { sellowiana/Myrtaceae (syn: } \\
\text { Feijoa sellowiana) }\end{array}$ & $\begin{array}{l}\text { North } \\
\text { America/Hispaniola } \\
\text { island }\end{array}$ & No information available & Absent & [153] \\
\hline 90 & H. ferrugineum & $\begin{array}{l}\text { On leaves of Hiraea sp. and } \\
\text { Heteropterys sp./Malpighiaceae }\end{array}$ & U.S.A./San Francisco & $\begin{array}{l}\text { Conidiophores } 8-9 \mu \mathrm{m} \text { thick, filiform, yellow, septate; Conidia } \\
50-62 \times 11-14 \mu \mathrm{m} \text {, obclavate, subhyaline, last } 2 \text { septate } \\
\text { hyaline-yellow to yellow }\end{array}$ & Absent & [141] \\
\hline 91 & H. fici & $\begin{array}{l}\text { On leaves of Ficus } \\
\text { retusa/Moraceae }\end{array}$ & Philippines, Thailand & $\begin{array}{l}\text { Conidiophores fusciculate, long, nodulosis, septate; Conidia 18-20 } \\
\times 5-6 \mu \mathrm{m} \text {, cylindrical, reddish-brown, 3-distoseptate }\end{array}$ & Absent & {$[137,154]$} \\
\hline 92 & H. ficinum & $\begin{array}{l}\text { On leaves of Ficus } \\
\text { ulmifolia/Moraceae }\end{array}$ & Philippines & $\begin{array}{l}\text { Conidiophores } 250 \times 6 \mu \mathrm{m} \text {, filiform, septate; Conidia 50-60 ×6-8 } \\
\mu \mathrm{m} \text {, obclavate, } 4-5 \text {-distoseptate }\end{array}$ & Absent & [137] \\
\hline 93 & H. filicicola & $\begin{array}{l}\text { On leaves of Lygodium } \\
\text { sp./Lygodiaceae and of } \\
\text { Selaginella sp./Selaginellaceae }\end{array}$ & Peru & $\begin{array}{l}\text { Conidiophores } 400 \times 3-5 \mu \mathrm{m} \text { thick, erect, simple, filiform, septate; } \\
\text { Conidia } 30-40 \times 6-10 \mu \mathrm{m} \text {, cylindrical-fusoid or clavate, both } \\
\text { side blunt, 3-5-distoseptate }\end{array}$ & Absent & [155] \\
\hline 94 & H. flagellatum & $\begin{array}{l}\text { On mycelium of Meliola, in } \\
\text { leaves of Ardisia } \\
\text { disticha/Myrsinaceae }\end{array}$ & Philippines & Conidiophores $2.5-4 \mu \mathrm{m}$ thick, erect, sub-hylaline & Absent & [156] \\
\hline 95 & H. flumeanum & $\begin{array}{l}\text { On leaves of Bambusa } \\
\text { sp./Bambuseae }\end{array}$ & Philippines & $\begin{array}{l}\text { Conidiophores 90-100 × 6-7 } \mu \mathrm{m} \text {, dense, fasticulate, filiform; } \\
\text { Conidia } 35-40 \times 9-12 \mu \mathrm{m} \text {, obclavate, 3-distoseptate }\end{array}$ & Absent & [157] \\
\hline
\end{tabular}


Table 5. Cont.

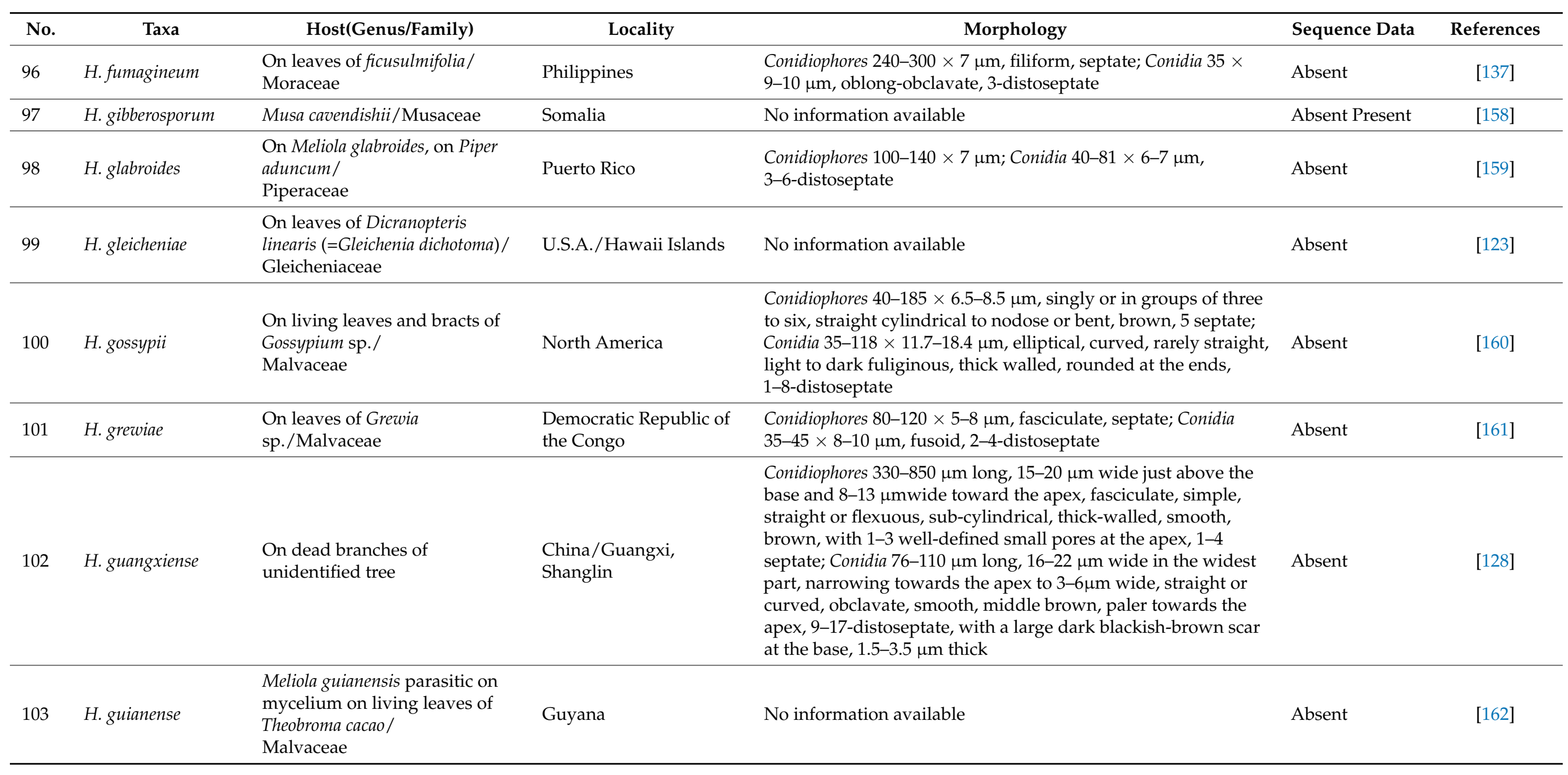


Table 5. Cont.

\begin{tabular}{|c|c|c|c|c|c|c|}
\hline No. & Taxa & Host(Genus/Family) & Locality & Morphology & Sequence Data & References \\
\hline 104 & H. heringerianum & $\begin{array}{l}\text { Tipuana speciosa/ } \\
\text { Fabaceae }\end{array}$ & Brazil & No information available & Absent & [163] \\
\hline 105 & H. hispanicum & $\begin{array}{l}\text { On dead corticated twigs of } \\
\text { Juglans regia/Juglandaceae }\end{array}$ & Asturias, Selviella, Spain & $\begin{array}{l}\text { Conidiophores } 130-540 \mu \mathrm{m} \text { long, } 13-22.5 \mu \mathrm{m} \text { wide at the base, } \\
\text { tapering to } 8-15 \mu \mathrm{m} \text { near the apex, solitarily or in small groups, } \\
\text { erect, simple, straight or flexuous, thick-walled, subcylindrical, } \\
\text { smooth, dark to blackish brown, paler near the apex, with } \\
\text { well-defined small pores at the apex, } 1-2 \text { septate; Conidia } \\
69-99(-130) \times(17-) 18-21(-24) \mu \mathrm{m} \text {, obclavate, straight or } \\
\text { flexuous, thin-walled, smooth, pale brown, } \\
(4-) 6-11(-14) \text {-distoseptate, with a blackish-brown } 4-6 \mu \mathrm{m} \text { wide } \\
\text { scar at the base }\end{array}$ & Present & {$[21]$} \\
\hline 106 & H. hispaniolae & $\begin{array}{l}\text { On living leaves of Manihot } \\
\text { utilissima/ } \\
\text { Euphorbiaceae }\end{array}$ & $\begin{array}{l}\text { Dominican } \\
\text { Republic/Haiti }\end{array}$ & $\begin{array}{l}\text { Conidiophores sub-hyaline to light-grey, when old, with an } \\
\text { almost hyaline tip; Conidia } 14.8-(53.5-) 81.4 \times 7.4-(11-) 14.8 \mu \mathrm{m} \text {, } \\
\text { sub-hyaline to smoky, irregular, cylindric-elongate to ellipsoidal, } \\
\text { straight or slightly curved, with the basal end applanate, } \\
\text { 1-8-distoseptate }\end{array}$ & Absent & [112] \\
\hline 107 & H. hunanense & $\begin{array}{l}\text { On dead branches of } \\
\text { unidentified tree }\end{array}$ & $\begin{array}{l}\text { China/Zhangjiajie, } \\
\text { Hunan }\end{array}$ & $\begin{array}{l}\text { Conidiophores } 70-226 \times 5-7 \text { above, } 8.5-14 \mu \mathrm{m} \text { base, solitary or } \\
\text { fasciculate, simple, cylindrical, straight or flexuous, } \\
\text { thick-walled, smooth, brown, well-defined small pores at the } \\
\text { apex, } 1-3 \text { septate; Conidia } 56-127 \times 10-14 \text { base, apex } 2-4 \mu \mathrm{m} \text {, } \\
\text { obclavate, straight or curved, smooth, middle brown, paler } \\
\text { towards the apex, } 4-12 \text {-distoseptate, blackish-brown scar at the } \\
\text { base, } 1.5 \mu \mathrm{m} \text { thick }\end{array}$ & Absent & {$[67]$} \\
\hline 108 & H. hygrophilae & $\begin{array}{l}\text { On leaves of Hygrophila } \\
\text { brasiliensis/Acanthaceae }\end{array}$ & Dominican Republic & No information available & Absent & [89] \\
\hline 109 & H. insigne & $\begin{array}{l}\text { On leaves of Mallotus } \\
\text { philippensis / } \\
\text { Euphorbiaceae }\end{array}$ & Philippines & $\begin{array}{l}\text { Conidiophores } 600-800 \times 50 \mu \mathrm{m} \text {, fasciculate, filiform, blackish, } \\
\text { septate; Conidia } 45-55 \times 7-8 \mu \mathrm{m} \text {, obclavate, often curved, } \\
\text { 4-5-distoseptate }\end{array}$ & Absent & [137] \\
\hline
\end{tabular}


Table 5. Cont.

\begin{tabular}{|c|c|c|c|c|c|c|}
\hline No. & Taxa & Host(Genus/Family) & Locality & Morphology & Sequence Data & References \\
\hline 110 & H. insuetum & $\begin{array}{l}\text { On living leaves of Philodendron } \\
\text { sodiroi (=Piplocarpha } \\
\text { sodiroi)/Araceae }\end{array}$ & Ecuador/Pichincha & $\begin{array}{l}\text { Conidiophores } 2.5-5 \mu \mathrm{m} \text { thick, olive brown or dark brown; } \\
\text { Conidia } 17-38 \times 7-12 \mu \mathrm{m} \text {, oblong, ellipsoid or oblong-ellipsoid } \\
\text { fusiform and often subclavate, rarely cylindrical, often straigtly, } \\
\text { rarely curved, olive brown or dark-brown, } \\
(3-) 5-7(-9) \text {-distoseptate, scared or a little more often in the } \\
\text { middle constricted }\end{array}$ & Absent & [122] \\
\hline 111 & H. iрomoeae & $\begin{array}{l}\text { On leaves of Ipomoea reptans/ } \\
\text { Convolvulaceae }\end{array}$ & China/Taiwan & No information available & Absent & [130] \\
\hline 112 & H. iranicum & $\begin{array}{l}\text { On living leaves of Indigofera } \\
\text { sp./Fabaceae }\end{array}$ & Iran/Bandar Abbas & $\begin{array}{l}\text { Conidiophores } 40-75 \times 6-9 \mu \mathrm{m} \text {, dense, curved, rarely straight, } \\
\text { dark-brown, septate; Conidia } 36(-42) \times 7-11 \mu \mathrm{m} \text {, oblong, } \\
\text { narrowly ellipsoid or curved, obtuse at both ends, straight or } \\
\text { curved, sometimes irregular, olive, } 1-3 \text {-distoseptate }\end{array}$ & Absent & [164] \\
\hline 113 & H. italicum & $\begin{array}{l}\text { On dead branch of Alnus } \\
\text { glutinosa/Betulaceae }\end{array}$ & Italy & $\begin{array}{l}\text { Conidiophores }(190-) 330-600 \times(12-) 16-18(-20) \mu \mathrm{m} \text {, aggregated, } \\
\text { erect, straight or slightly flexuous, unbranched, cylindrical, dark } \\
\text { brown, } 13-25 \text { septate; Conidia } 58-78 \times 15-19(-23) \mu \mathrm{m} \text {, } \\
\text { obclavate, straight or curved, pale brown to brown, slightly } \\
\text { truncate and black at base, rounded, narrowed, } \\
\text { 6-11-distoseptate }\end{array}$ & Absent & [61] \\
\hline 114 & H. juglandinum & $\begin{array}{l}\text { On dead corticated twigs of } \\
\text { Juglans regia/Juglandaceae }\end{array}$ & $\begin{array}{l}\text { Austria/ Niederösterre- } \\
\text { ich/Gießhübl, } \\
\text { Italy }\end{array}$ & $\begin{array}{l}\text { Conidiophores }(175-) 215-325(-455) \mu \mathrm{m} \text { long, } 11-23 \mu \mathrm{m} \text { wide at } \\
\text { the base, } 8.5-14 \mu \mathrm{m} \text { wide near the slightly inflated apex, } \\
\text { fasciculate, erect, simple, straight or flexuous, thick-walled, } \\
\text { sub-cylindrical, smooth, brown to dark brown, darker to black } \\
\text { at the apex, the latter with a well-defined apical pore; Conidia } \\
(69-) 89-145(-205) \times(15.0-) 16.5-20.0(-25.0) \mu \mathrm{m} \text {, rostrate, } \\
\text { straight or flexuous, thin-walled, smooth, pale brown, } \\
(5-) 9-17(-20) \text {-distoseptate, blackish-brown scar at the base }\end{array}$ & Present & [21] \\
\hline 115 & H. juglandis & Juglans sp./Juglandaceae & China, Yunnan & No information available & Absent & [165] \\
\hline
\end{tabular}


Table 5. Cont.

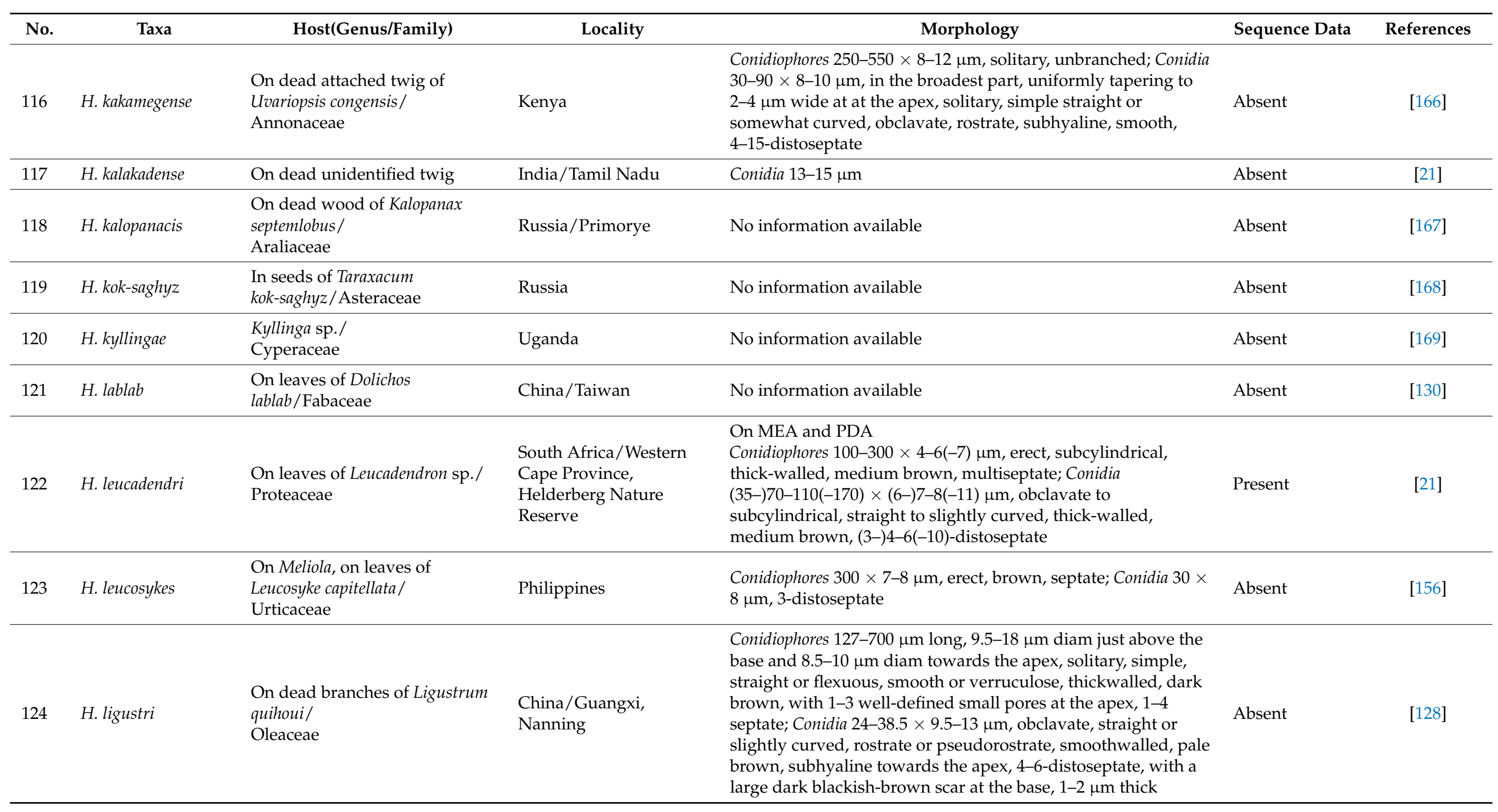


Table 5. Cont.

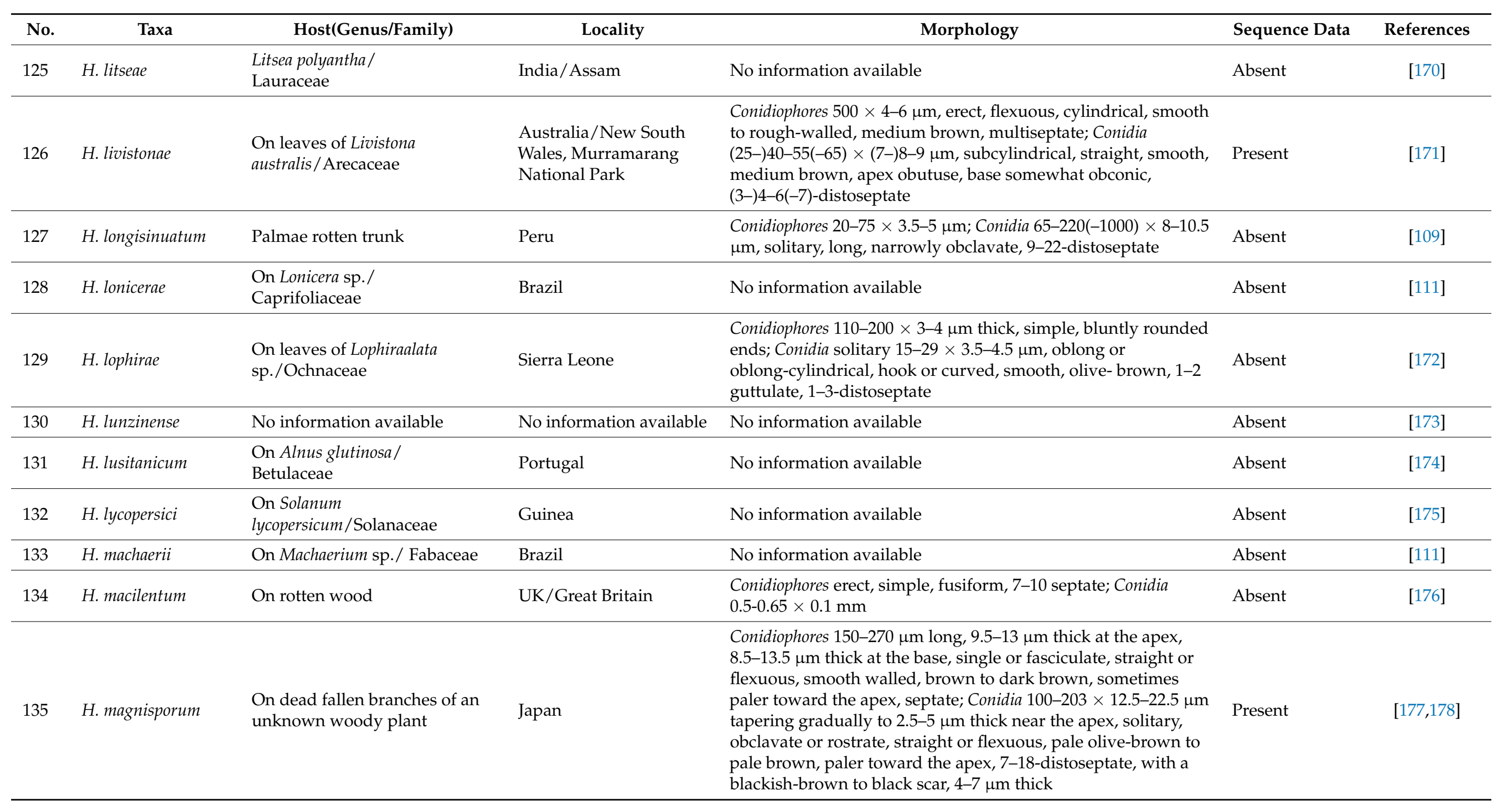


Table 5. Cont.

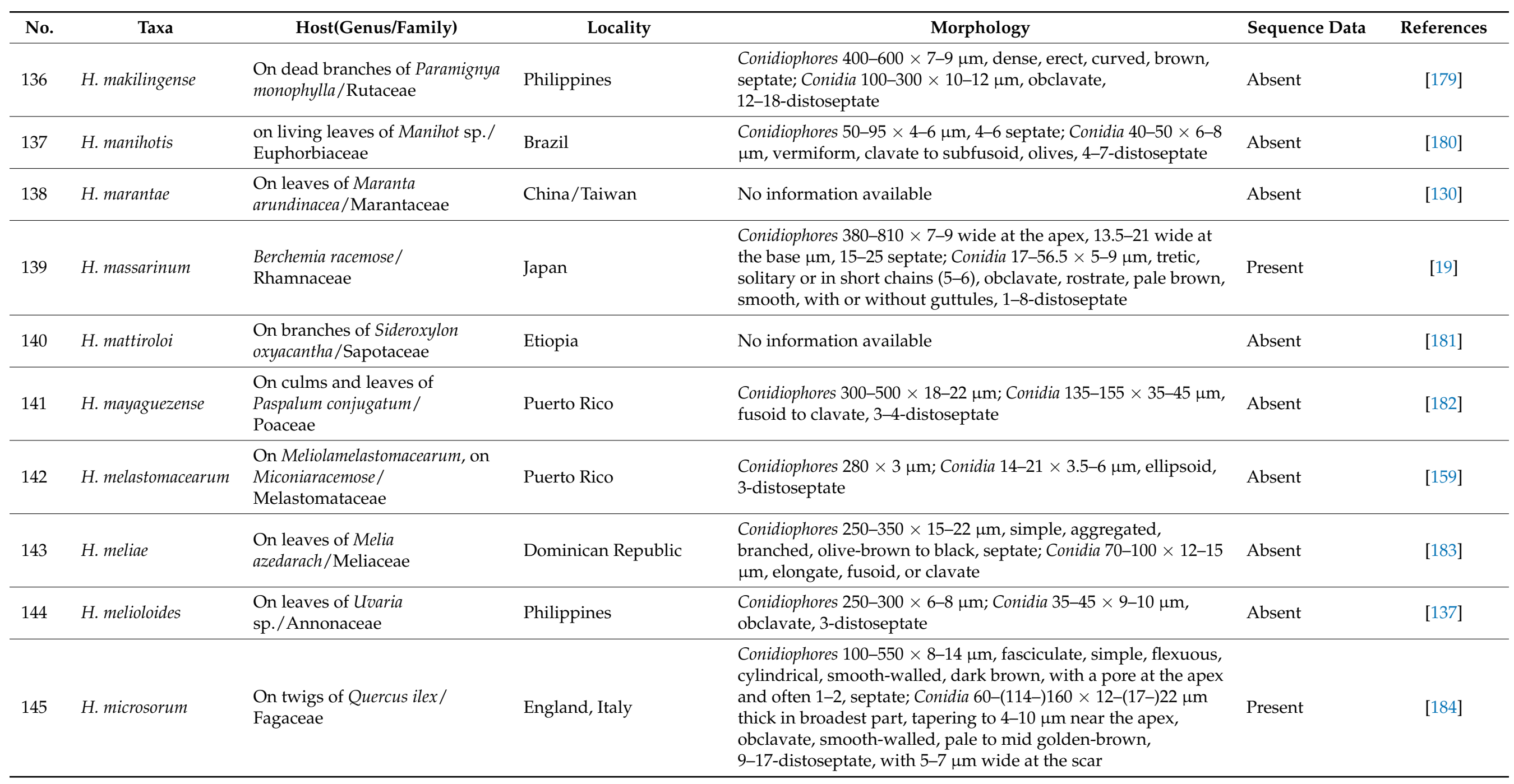


Table 5. Cont.

\begin{tabular}{|c|c|c|c|c|c|c|}
\hline No. & Taxa & Host(Genus/Family) & Locality & Morphology & Sequence Data & References \\
\hline 146 & H. microsporum & From soil & India/Maharashtra & $\begin{array}{l}\text { Conidiophores } 234-468 \times 10.8 \mu \mathrm{m} \text {, pale brown, } 10-16 \text { septate; } \\
\text { Conidia } 26-41 \times 22 \mu \mathrm{m} \text {, fusoid, widest at the middle, brown, } \\
\text { 2-7-distoseptate }\end{array}$ & Absent & [18] \\
\hline 147 & H. minimum & On dead decorticatd branches & $\begin{array}{l}\text { UK/Great } \\
\text { Britain/England }\end{array}$ & $\begin{array}{l}\text { Conidiophores erect, simple, septate; Conidia } 12-14 \times 3-4 \mu \mathrm{m} \text {, } \\
\text { fusiform, obtuse at the ends, triseptate, scarcely } \\
\text { constricted, hyaline }\end{array}$ & Absent & [185] \\
\hline 148 & H. multiseptatum & On dead branches & China/Guangdong & $\begin{array}{l}\text { Conidiophores } 390-650 \times 10-14 \mu \mathrm{m} \text { wide at the base, } 7-9 \mu \mathrm{m} \text { at } \\
\text { apex, simple, subcylindrical, straight or slightly flexuous, } \\
\text { smooth-walled, brown to dark brown, paler towards the apex, } \\
\text { with } 1-3 \text { well definded, small pores, } 1-3 \text { septate; Conidia } \\
78-190 \mu \mathrm{m} \text { long, } 11-16 \mu \mathrm{m} \text { thick in the widest part, narrowing } \\
\text { toward the apex to } 3-6 \mu \mathrm{m} \text {, tretic, straight or slightly flexuous, } \\
\text { obclavate or whip-like, smooth-walled, pale brown paler } \\
\text { toward the apex, } 13-25 \text {-distoseptate, with a dark } \\
\text { blackish-brown scar at the base }\end{array}$ & Absent & [129] \\
\hline 149 & H. nadsonii & $\begin{array}{l}\text { On fibers of } \\
\text { Gossypium sp./Malvaceae }\end{array}$ & Russia & No information available & Absent & [186] \\
\hline 151 & H. naviculare & $\begin{array}{l}\text { On leaves of Euphorbia sp./ } \\
\text { Euphorbiaceae }\end{array}$ & Brazil/Tubarão & $\begin{array}{l}\text { Conidiophores 6-8 } \mu \text { m thick, branched, often curved, yellow, } \\
\text { septate; Conidia } 50-84 \times 11-16 \mu \text { mnaviculiform, hyaline at } \\
\text { length, very pale with brown }\end{array}$ & Absent & [188] \\
\hline 152 & H. naviculatum & $\begin{array}{l}\text { On dead herbaceous stems of } \\
\text { Solidago sp./Asteraceae }\end{array}$ & U.S.A./New York & No information available & Absent & [189] \\
\hline 153 & H. newbouldiae & $\begin{array}{l}\text { On leaves of Newbouldialaevis / } \\
\text { Bignoniaceae }\end{array}$ & Guinea & No information available & Absent & [190] \\
\hline
\end{tabular}


Table 5. Cont.

\begin{tabular}{|c|c|c|c|c|c|c|}
\hline No. & Taxa & Host(Genus/Family) & Locality & Morphology & Sequence Data & References \\
\hline 154 & H. novae-zelandiae & $\begin{array}{l}\text { On dead wood and bark of Vitex } \\
\text { lucens/ } \\
\text { Lamiaceae }\end{array}$ & New Zealand & $\begin{array}{l}\text { Conidiophores } 165 \mu \mathrm{m} \text { long, } 4.8-7(-9) \mu \mathrm{m} \text {, erect, single or in } \\
\text { groups, simple, or once-branched at the base, straight or } \\
\text { flexuous, subcylindrical, brown to dark brown below, very pale } \\
\text { brown to subhyaline above, } 15 \text { septate; Conidia } 13.5-16.2 \times \\
7.2-9.0 \mu \mathrm{m} \text {, solitary, obovoid, sometimes slightly, smooth, the } 2 \\
\text { lower cells being brown and the distal cell paler with a dark } \\
\text { band of wall overlying each septum, 2-distoseptate }\end{array}$ & Absent & [191] \\
\hline 155 & H. obpyriforme & $\begin{array}{l}\text { On dead branches of } \\
\text { unidentified tree }\end{array}$ & China/Guangxi & $\begin{array}{l}\text { Conidiophores } 225-460 \mu \mathrm{m} \text { long, } 9.5-13 \mu \mathrm{m} \text { diam just above the } \\
\text { base and } 6-8.5 \mu \mathrm{m} \text { diam towards the apex, arising singly from } \\
\text { the upper cells of the stromata, simple, subcylindrical, straight } \\
\text { or flexuous, dark brown, paler towards the apex, with } \\
\text { well-defined small pores at the apex,1-3 septate; Conidia } \\
47-74 \mu \mathrm{m} \text { long, } 14-19 \mu \mathrm{m} \text { diam in the widest part, narrowing in } \\
\text { diameter towards the apex to } 2.5-5 \mu \mathrm{m} \text {, straight or slightly } \\
\text { curved, obpyriform, smooth-walled, middle brown, paler } \\
\text { towards the apex, } 5-9 \text {-distoseptate, with a large dark } \\
\text { blackish-brown scar at conidium base, } 1-2 \mu \mathrm{m} \text { thick }\end{array}$ & Absent & [128] \\
\hline 156 & H. ocoteae & $\begin{array}{l}\text { On Meliola ocoteae, on } \\
\text { Guareatrichilioides }\end{array}$ & Puerto Rico & $\begin{array}{l}\text { Conidiphores } 135-200 \times 4 \mu \mathrm{m} \text {, septate; Conidia 20-28 × 4-6 } \mu \mathrm{m} \text {, } \\
\text { 3-distoseptate }\end{array}$ & Absent & [159] \\
\hline 157 & H. oligosporum & $\begin{array}{l}\text { Holotype of Sporidesmium } \\
\text { olivaceum: on rotten branches of } \\
\text { Tilia sp. } \\
\text { Lectotype of } \\
\text { Coryneumoligosporum, here } \\
\text { designated: on rotten branches } \\
\text { of Corylus sp. } \\
\text { Epitype of } \\
\text { Sporidesmiumolivaceum and of } \\
\text { Coryneumoligosporum: on dead } \\
\text { corticated twigs of Tiliacordata } \\
\text { sp. }\end{array}$ & $\begin{array}{l}\text { Austria, Czech Republic, } \\
\text { Germany }\end{array}$ & $\begin{array}{l}\text { From Epitype specimen [21] } \\
\text { Conidiophores }(17-) 22-35(-46) \times(8.0-) 8.5-10.5(-11.5) \mu \mathrm{m}, \\
\text { densely crowded, erect, simple, straight, cylindrical to slightly } \\
\text { swollen at the apex, brown to dark brown, darker at the apex, } \\
\text { smooth, } 0-2 \text { septate; Conidia }(37-) 59-80(-124) \times \\
(14.8-) 15.8-18.0(-20.0) \mu \mathrm{m} \text {, tapering to } 4-10.5 \mu \mathrm{m} \text { at the distal } \\
\text { end, with } 4-8 \mu \mathrm{m} \text { wide, dark brown to black scar at the base, } \\
\text { obclavate, sometimes rostrate, straight or curved, smooth but } \\
\text { occasionally wrinkled with age, pale brown to brown, paler } \\
\text { toward the apex, } 6-12(-16) \text {-distoseptate }\end{array}$ & Present & {$[21,124]$} \\
\hline 158 & H. olisipponense & $\begin{array}{l}\text { Culture from the perithecia } \\
\text { stage of Pyrenophora polytricha }\end{array}$ & - & No information available & Absent & [192] \\
\hline
\end{tabular}


Table 5. Cont.

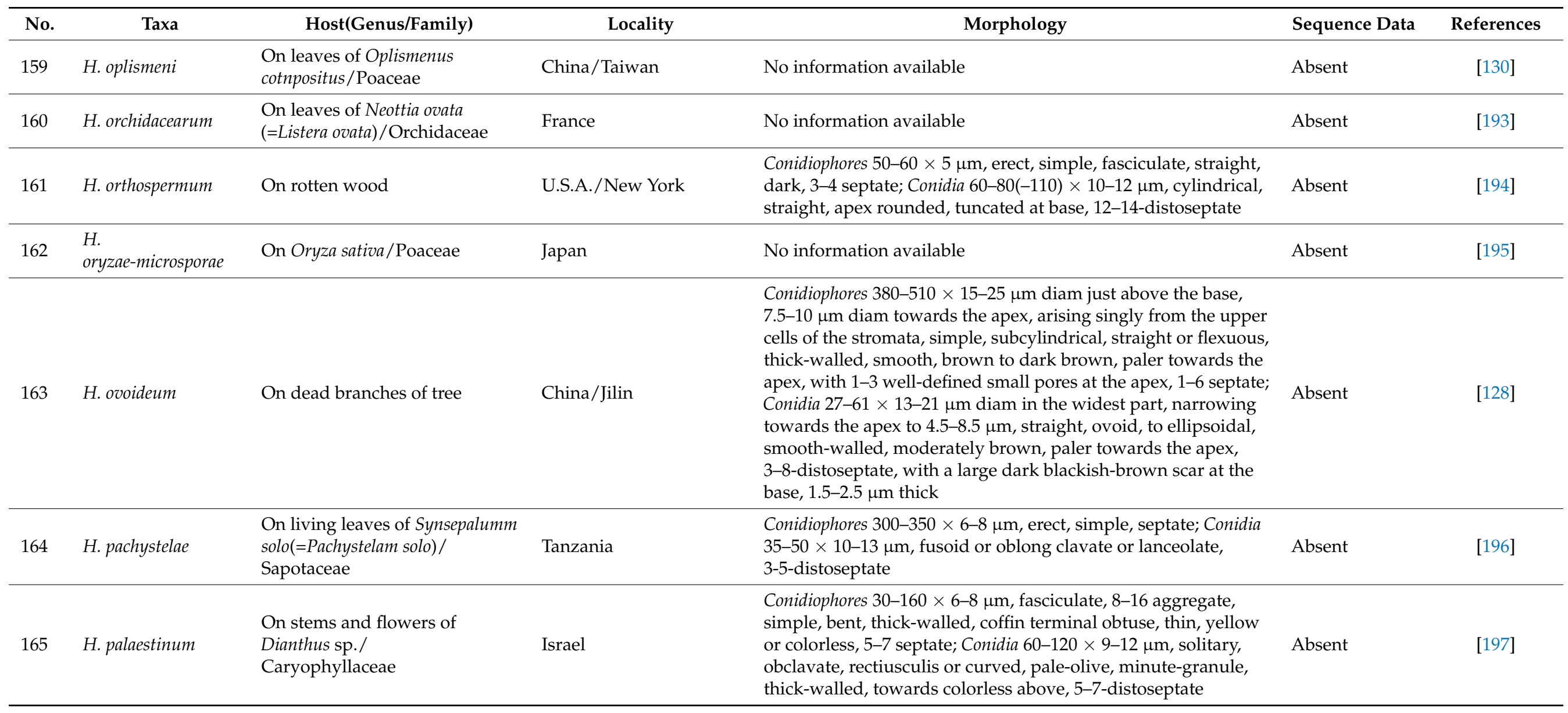


Table 5. Cont.

\begin{tabular}{|c|c|c|c|c|c|c|}
\hline No. & Taxa & Host(Genus/Family) & Locality & Morphology & Sequence Data & References \\
\hline 166 & H. palmigenum & $\begin{array}{l}\text { On rotten fruit of } \operatorname{Cocos} \\
\text { nucifera / Arecaceae; On petriole } \\
\text { and rachis from reference } \\
\text { specimen }\end{array}$ & $\begin{array}{l}\text { Brasil/Pará, Papua New } \\
\text { Guinea }\end{array}$ & $\begin{array}{l}\text { From reference specimen [190]; Conidiophores } 132.5-195 \times 5-6 \\
\mu \mathrm{m} \text {, solitary, erect, simple, cylindrical, straight or flexuous, } \\
\text { smooth, brown, light brown at the apex, } 7-10 \text { septate; Conidia } \\
38-53 \times 8-11 \text { base, } 3-4 \mu \mathrm{m} \text { apex, solitary, in small chains, } \\
\text { obclavate or cylindrical, straight or slightly curved, simple, } \\
\text { smooth, brown with light brown at apical cell, } 6-10 \text {-distoseptate }\end{array}$ & Absent & {$[198,199]$} \\
\hline 167 & H. panici & $\begin{array}{l}\text { On leaves of Panicum } \\
\text { maximum/Poaceae }\end{array}$ & Indonesia/Java & $\begin{array}{l}\text { Conidiophores } 115-180 \times 8-10 \mu \mathrm{m} \text {; Conidia }(35-) 50-75 \times \\
(7-) 10-13 \mu \mathrm{m} \text {, ellipsoidal-truncate, ellipsoidal-elongate, } \\
\text { dull-brown, }(1-) 3(-4) \text {-distoseptate }\end{array}$ & Absent & [159] \\
\hline 168 & H. papulosum & $\begin{array}{l}\text { On bark of Malus sylvestris or } \\
\text { Pyrus communis/Rosaceae }\end{array}$ & West Virginia & No information available & Absent & [200] \\
\hline 169 & H. parathesicola & $\begin{array}{l}\text { On Meliola parathesicola, on } \\
\text { Parathesis serrulate/Primulaceae }\end{array}$ & Puerto Rico & $\begin{array}{l}\text { Conidiophores } 120 \times 4 \mu \mathrm{m} \text {, solitary; Conidia } 17-20 \times 4-6 \mu \mathrm{m} \text {, base } \\
\text { truncate, apex beaked, beak often } 7 \mu \mathrm{m} \text { long, } 1-3 \text {-distoseptate }\end{array}$ & Absent & [159] \\
\hline 170 & H. paulense & On leaves of Myrtaceae & Brazil/São Paulo & $\begin{array}{l}\text { Conidiophores } 3-4.5 \mu \mathrm{m} \text { thick, brown, septate; Conidia } 15-24 \times 4 \\
\mu \mathrm{m} \text {, fusoid, brown, } 3 \text {-distoseptate }\end{array}$ & Absent & [115] \\
\hline 171 & H. penniseti & $\begin{array}{l}\text { On leaves of Pennisetum glaucum } \\
\text { (=Pennisetum typhoides)/Poaceae }\end{array}$ & India/Uttar Pradesh & No information available & Absent & [108] \\
\hline 172 & H. philippinum & $\begin{array}{l}\text { On decaying leaves of Arenga } \\
\text { mindorensis/ } \\
\text { Arecaceae }\end{array}$ & Philippines & $\begin{array}{l}\text { Conidiophores 300-400 × 6-7 } \mu \mathrm{m} \text {, fasciculate, filiform, curved, } \\
\text { septate; Conidia 33-35 × 8-9 } \mu \mathrm{m} \text {, obclavate, 4-distoseptate }\end{array}$ & Absent & [137] \\
\hline 173 & H. philodendri & $\begin{array}{l}\text { On Meliola philodendri, on } \\
\text { Philodendron krebsii/Araceae }\end{array}$ & Puerto Rico & $\begin{array}{l}\text { Conidiphores } 400 \times 3-4 \mu \mathrm{m} \text {; Conidia } 24-35 \times 5-9 \mu \mathrm{m} \text {, clavate, } \\
\text { 3-distoseptate }\end{array}$ & Absent & [159] \\
\hline 174 & H. phomatae & $\begin{array}{l}\text { On bark of Acer pennsylvanicum/ } \\
\text { Sapindaceae }\end{array}$ & U.S.A./New York & No information available & Absent & [189] \\
\hline 175 & H. phyllantheum & $\begin{array}{l}\text { On dead branches hanging } \\
\text { down of Phyllanthus } \\
\text { sp./Phyllanthaceae }\end{array}$ & Philippines & $\begin{array}{l}\text { Conidiophores } 180-200 \times 4.7-6 \mu \mathrm{m} \text {, fillifrom, blackedned, septate; } \\
\text { Conidia } 80-90 \times 9-10 \mu \mathrm{m} \text {, obclavate, long, 9-11-distoseptate }\end{array}$ & Absent & [137] \\
\hline
\end{tabular}


Table 5. Cont.

\begin{tabular}{|c|c|c|c|c|c|c|}
\hline No. & Taxa & Host(Genus/Family) & Locality & Morphology & Sequence Data & References \\
\hline 176 & H. piperis & $\begin{array}{l}\text { On leaves of Piper } \\
\text { betle/Piperaceae }\end{array}$ & China/Taiwan & No information available & Absent & [130] \\
\hline 177 & H. portoricense & $\begin{array}{l}\text { On dead branches hanging } \\
\text { down of Phyllanthus } \\
\text { sp./Phyllanthaceae }\end{array}$ & Philippines & $\begin{array}{l}\text { Conidiophores } 25-250 \times 2-5 \mu \mathrm{m} \text {; Conidia } 30-60 \times 6-10 \mu \mathrm{m} \text {, } \\
\text { elongate-fusoid, olive-brown or brown, }(2-) 4 \text {-distoseptate }\end{array}$ & Absent & {$[86,201]$} \\
\hline 178 & H. proliferatum & $\begin{array}{l}\text { On grain of Triticum } \\
\text { sp./Poaceae }\end{array}$ & India/Maharashtra & $\begin{array}{l}\text { Colony on PDA; Conidiophores } 292-510 \times 7-13.8 \mu \mathrm{m}, \\
\text { unbranched, pale, olivaceous, 5-20 septate; Conidia } 23-126 \times \\
11.5-13.8 \mu \mathrm{m} \text {; cylindrical, olivaceous, 3-13-distoseptate }\end{array}$ & Absent & [101] \\
\hline 179 & $\begin{array}{l}\text { H. } \\
\text { pseudomicrosorum }\end{array}$ & $\begin{array}{l}\text { On dead branches of } \\
\text { unidentified tree }\end{array}$ & $\begin{array}{l}\text { China/Changbaishan, } \\
\text { Jilin }\end{array}$ & $\begin{array}{l}\text { Conidiophores } 155-288 \times 11-15 \mu \mathrm{m} \text {, fasciculate, simple, } \\
\text { cylindrical, straight or flexuous, smooth, dark brown, paler } \\
\text { towards the apex, with } 1-3 \text { well-defined small, } 1-4 \text { septate; } \\
\text { Conidia } 82-142 \times 17-27 \mu \mathrm{m} \text { in the widest part, narrowing } \\
\text { towards the apex to } 3-6 \mu \mathrm{m} \text { diam, tretic, straight or slightly } \\
\text { flexuous, obclavate, smooth-walled, brown, paler towards the } \\
\text { apex, } 7-16 \text {-distoseptate, with a large dark blackish-brown scar } \\
\text { at the base, } 2-4 \mu \mathrm{m} \text { thick }\end{array}$ & Absent & [128] \\
\hline 181 & H. purpurascens & $\begin{array}{l}\text { On leaves of Panicum } \\
\text { purpurascens / Poaceae }\end{array}$ & U.S.A./Florida & No information available & Absent & [203] \\
\hline 182 & H. pyracanthae & Pyracantha sp./Rosaceae & Portugal & No information available & Absent & [204] \\
\hline 183 & H. quercicola & $\begin{array}{l}\text { On dead corticated branches of } \\
\text { Quercus cf. reticulata/Fagaceae }\end{array}$ & U.S.A. & $\begin{array}{l}\text { Conidiophores }(115-) 133-226(-300) \mu \mathrm{m} \text { long, } 14-20 \mu \mathrm{m} \text { wide at } \\
\text { the base, tapering to } 10-15 \mu \mathrm{m} \text { near the apex, solitarily or } \\
\text { fasciculate, simple, straight or flexuous, cylindrical, } \\
\text { thick-walled, smooth, brown to dark brown, with well-defined } \\
\text { small pores at the apex; Conidia } 60-100 \times 15-22 \mu \mathrm{m} \text {, straight or } \\
\text { flexuous, obclavate, smooth-walled, brown, } 8-10 \text {-distoseptate, } \\
\text { with blackish-brown to black scar at the base }\end{array}$ & Absent & [21] \\
\hline
\end{tabular}


Table 5. Cont

\begin{tabular}{|c|c|c|c|c|c|c|}
\hline No. & Taxa & Host(Genus/Family) & Locality & Morphology & Sequence Data & References \\
\hline 184 & H. quercinum & $\begin{array}{l}\text { On dead corticated twigs of } \\
\text { Quercus petraea/Fagaceae }\end{array}$ & $\begin{array}{l}\text { Austria/Niederösterreich, } \\
\text { Spitzerberg }\end{array}$ & $\begin{array}{l}\text { Conidiophores }(40-) 74-199(-332) \mu \mathrm{m} \text { long, } 11-18 \mu \mathrm{m} \text { wide at the } \\
\text { base, tapering to } 8.5-13.5 \mu \mathrm{m} \text { near the apex, solitarily or } \\
\text { fasciculate, simple, straight or flexuous, cylindrical, smooth, } \\
\text { brown to dark brown, with well-defined small pores at the apex, } \\
1-5 \text { septa; Conidia }(47-) 78-130(-201) \times(13.2-) 15.3-18.0(-20.5) \\
\mu \mathrm{m} \text {, straight or flexuous, rostrate, smooth-walled, brown, } \\
8-13(-20) \text {-distoseptate, with blackish-brown to black scar at } \\
\text { the base }\end{array}$ & Present & {$[21]$} \\
\hline 185 & H. repens & $\begin{array}{l}\text { On bark of dead Acer } \\
\text { grandidentatum/ } \\
\text { Sapindaceae }\end{array}$ & $\begin{array}{l}\text { U.S.A./Utah, Red Butte } \\
\text { Canyon }\end{array}$ & Conidia 40-45(-60) × 8-9 $\mu \mathrm{m}$, sub-oblong, 5-12-distosepate & Absent & [205] \\
\hline 186 & H. reyesii & $\begin{array}{l}\text { On dead branch of Guioa sp./ } \\
\text { Sapindaceae }\end{array}$ & Philippines & $\begin{array}{l}\text { Conidiophores } 130 \times 8-10 \mu \mathrm{m}, \text { erect, brown, septate; Conidia } \\
34-112 \times 8-13 \mu \mathrm{m} \text {, tereti-fusoid, brown, ends hyaline, } \\
\text { 5-14-distosepate }\end{array}$ & Absent & [137] \\
\hline 187 & H. rhodomyrti & $\begin{array}{l}\text { On leaves of Rhodomyrtus } \\
\text { tomentosa/Myrtaceae }\end{array}$ & China/Guangdong & Conidia $42-60 \times 17-20 \mu \mathrm{m}$, fusoid, brown, 5-7-distosepate & Absent & [206] \\
\hline 189 & H. schelkownikowii & On branches & $\begin{array}{l}\text { Armenia, Azerbaijan, } \\
\text { Georgia, Russia }\end{array}$ & No information available & Absent & [209] \\
\hline 190 & H. scolecoides & On dry woood & Germany/Reichenberg & $\begin{array}{l}\text { Conidiophores simple, branched; Conidia } 80 \times 7.5 \mu \mathrm{m} \text {, torulus, } \\
\text { fusciculate, septate, yellow }\end{array}$ & Absent & [96] \\
\hline 191 & H. sechiicola & $\begin{array}{l}\text { On Sechium edule/ } \\
\text { Cucurbitaceae }\end{array}$ & Puerto Rico & No information available & Absent Present & [210] \\
\hline 192 & H. sichuanense & On dead branches of tree & China/Sichuan & No information available & Absent Present & [211] \\
\hline
\end{tabular}


Table 5. Cont.

\begin{tabular}{|c|c|c|c|c|c|c|}
\hline No. & Taxa & Host(Genus/Family) & Locality & Morphology & Sequence Data & References \\
\hline 193 & H. solani & $\begin{array}{l}\text { On stem of Solanum } \\
\text { nigrum/Solanaceae (type); } \\
\text { Citrus linella; Leucaena glauac; } \\
\text { Solanum dulcamara; S. nigrum; } \\
\text { Solanum tuberosum }\end{array}$ & $\begin{array}{l}\text { England, Guernsey, New } \\
\text { Zealand, New Guinea, } \\
\text { Sierra Leone, Wales }\end{array}$ & $\begin{array}{l}\text { Conidiophores } 120-600 \times 9-15 \mu \mathrm{m} \text { thick near base, } 6-9 \mu \mathrm{m} \text { thick } \\
\text { near the apex, erect, simple, straight or flexuous, smooth or } \\
\text { occasionally, brown to very dark brown, paler near apex, } \\
\text { septate, with small pores at apex, } 1-8 \text { septate; Conidia }(24-) 39-85 \\
\times(7-) 9-11 \mu \mathrm{m} \text {, straight or curved, obclavated, smooth-walled, } \\
\text { subhyaline to brown, } 2-8 \text {-distosepate, with a welll-defind dark } \\
\text { brown to black scar at base }\end{array}$ & Present & [212] \\
\hline 194 & H. solitarium & On leaves of Iris sp./Iridaceae & U.S.A./Minnesota & $\begin{array}{l}\text { Conidiophores } 60-150 \times 6 \mu \mathrm{m} \text {, solitary, slightly fasciculate, erect, } \\
\text { swollen at the base, lighter colored at the apex, dark brown, } \\
\text { septate; Conidia } 24-30 \times 8-9 \mu \mathrm{m} \text {, oblong-elliptical, sometimes } \\
\text { slightly curved, dark brown, at first } 2-4 \text { guttulate, } \\
\text { 3-5-distosepate }\end{array}$ & Absent & [213] \\
\hline 195 & H. spirotrichum & $\begin{array}{l}\text { On withered leaves of } \\
\text { Cyrtophyllum } \\
\text { fragrans/Gentianaceae }\end{array}$ & Singapore & $\begin{array}{l}\text { Conidiophores } 190-220 \times 6 \mu \mathrm{m} \text {, fasciculate, filiform, brown, } \\
\text { septate; Conidia } 23-25 \times 9 \mu \mathrm{m} \text {, oblong-obclavate, gently curving, } \\
\text { brown, 3-distosepate }\end{array}$ & Absent & [214] \\
\hline 196 & H. spurirostrum & On dead branches of tree & China/Sichuan & No information available & Absent & [211] \\
\hline 197 & H. subapiculatum & $\begin{array}{l}\text { On dead wood of Sambucus } \\
\text { callicarpa/Adoxaceae }\end{array}$ & U.S.A./Washington & $\begin{array}{l}\text { Conidiophores } 8-10 \mu \mathrm{m} \text { thick; Conidia } 35-80 \times 12-16 \mu \mathrm{m} \text {, oblong } \\
\text { or subfusiform, } 6 \text {-7-distosepate }\end{array}$ & Absent & [215] \\
\hline 198 & H. subhyalinum & $\begin{array}{l}\text { On living leaves of Phoenix } \\
\text { hanceana/Arecaceae }\end{array}$ & China/Guangdong & $\begin{array}{l}\text { Conidiophores } 120-200 \times 10-12 \text { (basal), above } 6-8.5 \mu \mathrm{m} \text { thick, } \\
\text { simple or fasciculate, erect, subcylindrical, brown, pores } 1-3 \mu \mathrm{m} \text {, } \\
\text { septate; Conidia } 72-125 \times 9-11.5 \mu \mathrm{m} \text {, obclavate, straight or } \\
\text { flexuous, subhyaline, apex } 2.5-5 \mu \mathrm{m} \text {, black at tip, } \\
6 \text {-9-distosepate, dark blackish-brown scar }\end{array}$ & Absent & [129] \\
\hline 199 & H. submersum & On submerged decaying wood & China/Yunnan & $\begin{array}{l}\text { Conidiophores } 239-423 \times 8.5-15.5 \mu \mathrm{m} \text {, solitary or in group of } 2-4 \text {, } \\
\text { unbranched, straight or curved, smooth, dark brown, paler } \\
\text { towards to the apex, bulbous at base } 9-14 \text { septate; Conidia } 41-55 \\
\times 14.5-18.5 \mu \mathrm{m} \text {, straight or curved, wider below than apex, } \\
\text { truncate and dark at base, apically rostrate and pale, smooth, } \\
\text { pale brown to mid-brown, guttulate, } 6-10 \text {-distosepate }\end{array}$ & Present & [24] \\
\hline
\end{tabular}


Table 5. Cont.

\begin{tabular}{|c|c|c|c|c|c|c|}
\hline No. & Taxa & Host(Genus/Family) & Locality & Morphology & Sequence Data & References \\
\hline 200 & H. subsimile & $\begin{array}{l}\text { On withered and dead leaves of } \\
\text { Bruguiera sexangula (=Bruguiera } \\
\text { eriopetala)/Rhizophoraceae }\end{array}$ & Singapore & $\begin{array}{l}\text { Conidiophores } 200-250 \times 8-9 \mu \mathrm{m} \text {, filiform-fasciculate, brown, } \\
\text { septate; Conidia }(38-) 45-50 \times 11-12(-14) \mu \mathrm{m} \text {, brown, } \\
\text { 3-distoseptate }\end{array}$ & Absent & [216] \\
\hline 201 & H. syzygii & $\begin{array}{l}\text { On bark canker of Syzygium } \\
\text { sp./Myrtaceae }\end{array}$ & $\begin{array}{l}\text { South Africa/Eastern } \\
\text { Cape Province }\end{array}$ & $\begin{array}{l}\text { Conidiophores } 150-400 \times 10-15 \mathrm{~mm} \text {, fasciculate, unbranched, } \\
\text { clavate at apex, dark brown, multiseptate; Conidia } \\
(70-) 80-100(-150) \times(19-) 22-23(-25) \mathrm{mm} \text {, obclavate, curved, } \\
\text { apex subobtuse, warty, inner surface striate, medium brown, } \\
\text { (7-)9-12-distoseptate }\end{array}$ & Present & [22] \\
\hline 202 & H. theobromae & $\begin{array}{l}\text { On leaves of Theobroma } \\
\text { cacao/Malvaceae }\end{array}$ & Italy & $\begin{array}{l}\text { Conidiophores } 500-1000 \mu \mathrm{m} \text {, erect, } 6-10 \text { septate; Conidia } 60-160 \times \\
12-20 \mu \mathrm{m} \text {, obclavate to tereti-obclavate }\end{array}$ & Absent & [217] \\
\hline 203 & H. theobromicola & $\begin{array}{l}\text { On rotten leaves of Theobroma } \\
\text { cacao/Malvaceae }\end{array}$ & $\begin{array}{l}\text { Dominican } \\
\text { Republic/Moca }\end{array}$ & $\begin{array}{l}\text { Conidiophores } 20-33 \times 3.5-5 \mu \mathrm{m} \text { olives-brown, septate; Conidia } \\
46-58 \times 10-13.5 \mu \mathrm{m} \text {, elliptic-oblong or subfusoid, irregular, } \\
\text { 3-5-distoseptate }\end{array}$ & Absent & [218] \\
\hline 204 & H. tritici & $\begin{array}{l}\text { On seedhead of Triticum } \\
\text { vulgare/Poaceae }\end{array}$ & Tanzania & $\begin{array}{l}\text { Conidiophores } 3.5-5 \mu \mathrm{m} \text {, thick fasciculate, erect, sepate; Conidia } \\
12-25 \times 4-7 \mu \mathrm{m} \text {, subcylindrical-oblong, clavate or fusoid, } \\
2-4 \text {-distoseptate, constrict at septum }\end{array}$ & Absent & [219] \\
\hline 206 & H. turbinatum & On unidentified wood & Great Britain & $\begin{array}{l}\text { Conidiophores simple, slender; Conidia elongated, turbinatis, } \\
\text { tuncatus, apiculate, brown, } 4 \text {-7-distoseptate }\end{array}$ & Absent & [220] \\
\hline 207 & H. ubangiense & $\begin{array}{l}\text { On leaves of Coffea } \\
\text { sp./Rubiaceae }\end{array}$ & $\begin{array}{l}\text { Democratic Republic of } \\
\text { the Congo/Ubangi River }\end{array}$ & $\begin{array}{l}\text { Conidiophores (2-)3-6 } \mu \mathrm{m} \text {, fasciculate, erect, branched, septate; } \\
\text { Conidia 30-60 } \times 5-8 \mu \mathrm{m} \text {, fusoid, 3-4-distoseptate }\end{array}$ & Absent & [221] \\
\hline 208 & H. ustilaginoideum & $\begin{array}{l}\text { On flowers of Panicum } \\
\text { spicatum/Poaceae }\end{array}$ & $\begin{array}{l}\text { Democratic Republic of } \\
\text { the Congo }\end{array}$ & $\begin{array}{l}\text { Conidiophores 3-3.5 } \mu \mathrm{m} \text { thick, fasciculate; Conidia } 10-50 \times 3.5-4.5 \\
\mu \mathrm{m} \text {, cylindrical or subfusoid, blunted, } 1-5 \text {-distoseptate }\end{array}$ & Absent & [121] \\
\hline 209 & H. varium & $\begin{array}{l}\text { On decaying leaves of } \\
\text { unidentified plants }\end{array}$ & Brazil/Pernambuco & $\begin{array}{l}\text { Conidiophores } 150-200 \times 10-14 \mu \mathrm{m} \text {, erect, unbranched, straight } \\
\text { or flexuous, cylindrical, slightly inflated at the apex, smooth, } \\
\text { brown, } 5-7 \text { septate; Conidia } 29-58 \times 4-7 \mu \mathrm{m} \text {, } \\
\text { cylindrical-obclavate, subcylindrical, oblong or navicular, dry, } \\
\text { trick-walled, with wall verrucose or verruculose, gray-brown, } \\
\text { lumina pale yellow, }(0-) 1-4 \text {-distoseptate }\end{array}$ & Absent & [222] \\
\hline
\end{tabular}


Table 5. Cont.

\begin{tabular}{|c|c|c|c|c|c|c|}
\hline No. & Taxa & Host(Genus/Family) & Locality & Morphology & Sequence Data & References \\
\hline 210 & H. varroniae & $\begin{array}{l}\text { On leaves of Varronia } \\
\text { sp./Boraginaceae }\end{array}$ & Puerto Rico & 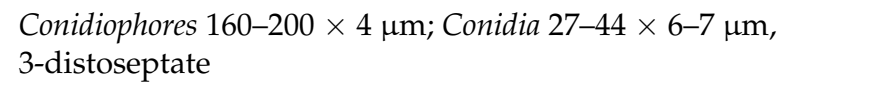 & Absent & [223] \\
\hline 211 & H. velutinum & $\begin{array}{l}\text { Fagus sylvatica dead corticated } \\
\text { twigs/saprobic on decaying } \\
\text { wood submerged in stream }\end{array}$ & $\begin{array}{l}\text { Austria, Wien, Döbling, } \\
\text { Kahlenberg/China }\end{array}$ & $\begin{array}{l}\text { From reference specimen [20]; Conidiophores } 530-655 \times 16-18 \\
\mu \mathrm{m} \text {, erect or flexuousk, unbranched, dark brown, } 17-23 \text { septate; } \\
\text { Conidia } 67-79 \times 15-19 \mu \mathrm{m} \text {, single, obclavate, straight or curved, } \\
\text { smooth, pale brown to brown, } 7-9 \text {-distoseptate, rounded at } \\
\text { apex, guttulate when young, non-guttulate at maturity }\end{array}$ & Present & {$[16,20]$} \\
\hline 212 & H. viticis & On leaves of Vitis sp./Vitaceae & Brazil/Pará & $\begin{array}{l}\text { Conidiophores } 80 \times 2-3 \mu \mathrm{m} \text {, fasciculate, septate; Conidia } 12-20 \times \\
2.5-3.5 \mu \mathrm{m} \text { cylindrical, } 1-3 \text {-distoseptate }\end{array}$ & Absent & [223] \\
\hline 213 & H. wagateae & $\begin{array}{l}\text { On leaves of Moullava spicata } \\
\text { (=Wagatea spicata)/Fabaceae }\end{array}$ & India/Karnataka & $\begin{array}{l}\text { Conidiophores } 81-125 \times 1.5-2.5 \mu \mathrm{m} \text {, yellowish-brown, } \\
\text { multiseptate; Conidia } 15.5-28 \times 3-4 \mu \mathrm{m} \text {, clavate-cylindric, } \\
\text { cinnamon-yellow, rounded at both ends, } 2-4 \text {-distoseptate }\end{array}$ & Absent & [91] \\
\hline 214 & H. warpuriae & $\begin{array}{l}\text { On stem of Warpuria } \\
\text { clandestina/Acanthaceae }\end{array}$ & Great Britain/England & $\begin{array}{l}\text { Conidiophores } 300-500 \times 6-8 \mu \mathrm{m} \text {; Conidia } 115-190 \times 12-14 \mu \mathrm{m} \text {, } \\
\text { obclavate, } 8-11 \text {-distoseptate }\end{array}$ & Absent & [224] \\
\hline 215 & H. xanthosomatis & $\begin{array}{l}\text { On leaves of Xanthosoma } \\
\text { violaceum/Araceae }\end{array}$ & $\begin{array}{l}\text { Dominican } \\
\text { Republic/Moca }\end{array}$ & $\begin{array}{l}\text { Conidiophores } 35-90 \mu \mathrm{m} \text { long, septate; Conidia } 185 \times 24 \mu \mathrm{m} \text {, } \\
\text { fusoid, subfusoid to subclavate, } 3-7(-10) \text {-distoseptate }\end{array}$ & Absent & [225] \\
\hline
\end{tabular}


Author Contributions: Conceptualization, S.K., K.D.H., S.C.K., C.S. and S.T.; Data curation, S.K.; Methodology, S.K., A.M. and S.T.; Resources, K.D.H., S.C.K., J.X. and S.L.; Supervision, K.D.H. and S.T.; Writing-original draft, S.K., K.D.H., S.C.K., A.M., C.S., L.A.P.D., C.M.N., J.X. and S.T.; Writing-review \& editing, S.K., K.D.H., S.C.K., S.T. and S.L. All authors have read and agreed to the published version of the manuscript.

Funding: Saowaluck Tibpromma would like to thank the International Postdoctoral Exchange Fellowship Program (number Y9180822S1), CAS President's International Fellowship Initiative (PIFI) (number 2020PC0009), China Postdoctoral Science Foundation and the Yunnan Human Resources, and Social Security Department Foundation for funding her postdoctoral research. Kevin D. Hyde thanks the Thailand Research Funds for the grant "Impact of climate change on fungal diversity and biogeography in the Greater Mekong Subregion (RDG6130001)". Samantha Karunarathna thanks CAS President's International Fellowship Initiative (PIFI) for funding his postdoctoral research (number 2018PC0006) and the National Science Foundation of China (NSFC) for funding this research work under project code 31750110478 . This work was partly supported by Chiang Mai University.

Institutional Review Board Statement: Not applicable.

Informed Consent Statement: Not applicable.

Data Availability Statement: Not applicable.

Acknowledgments: Sirinapa Konta is grateful to Paul Kirk, Shaun Pennycook, Jayarama Bhat, and Sirilak Radbouchoom, for their valuable suggestions and comments.

Conflicts of Interest: The authors declare no conflict of interest.

\section{References}

1. Hyde, K.D.; Norphanphoun, C.; Chen, J.; Dissanayake, A.J.; Doilom, M.; Hongsanan, S.; Jayawardena, R.S.; Jeewon, R.; Perera, R.H.; Thongbai, B.; et al. Thailand's amazing diversity: Up to $96 \%$ of fungi in northern Thailand may be novel. Fungal Divers. 2018, 93, 215-239. [CrossRef]

2. Hyde, K.D.; de Silva, N.I.; Jeewon, R.; Bhat, D.J.; Phookamsak, R.; Doilom, M.; Boonmee, S.; Jayawardena, R.S.; Maharachchikumbura, S.S.N.; Senanayake, I.C.; et al. AJOM new records and collections of fungi: 1-100. AJOM 2020, 3, 22-294. [CrossRef]

3. Dai, D.Q.; Phookamsak, R.; Wijayawardene, N.N.; Li, W.J.; Bhat, D.J.; Xu, J.C.; Taylor, J.E.; Hyde, K.D.; Chukeatirote, E. Bambusicolous fungi. Fungal Divers. 2017, 82, 1-105. [CrossRef]

4. Tibpromma, S.; Hyde, K.D.; McKenzie, E.H.; Bhat, D.J.; Phillips, A.J.; Wanasinghe, D.N.; Samarakoon, M.C.; Jayawardena, R.S.; Dissanayake, A.J.; Tennakoon, D.S.; et al. Fungal diversity notes 840-928: Micro-fungi associated with Pandanaceae. Fungal Divers. 2018, 93, 1-160. [CrossRef]

5. Pinruan, U.; Hyde, K.D.; Lumyong, S.; McKenzie, E.H.C.; Jones, E.G. Occurrence of fungi on tissues of the peat swamp palm Licuala longicalycata. Fungal Divers. 2007, 25, 157-173.

6. Pinnoi, A.; Phongpaichit, S.; Hyde, K.D.; Jones, E.G. Biodiversity of fungi on Calamus (Palmae) in Thailand. Cryptogamie 2009, 30, 181-190.

7. Konta, S.; Hongsanan, S.; Tibpromma, S.; Thongbai, B.; Maharachchikumbura, S.S.N.; Bahkali, A.H.; Hyde, K.D.; Boonmee, S. An advance in the endophyte story: Oxydothidaceae fam. nov. with six new species of Oxydothis. Mycosphere 2016, 7, 1425-1446. [CrossRef]

8. Konta, S.; Hongsanan, S.; Eungwanichayapant, P.D.; Liu, J.K.; Jeewon, R.; Hyde, K.D.; Maharachchikumbura, S.S.N.; Boonmee, S. Leptosporella (Leptosporellaceae fam. nov.) and Linocarpon and Neolinocarpon (Linocarpaceae fam. nov.) are accommodated in Chaetosphaeriales. Mycosphere 2017, 8, 1943-1974. [CrossRef]

9. Konta, S.; Hyde, K.D.; Eungwanichayapant, P.D.; Doilom, M.; Tennakoon, D.S.; Senwanna, C.; Boonmee, S. Fissuroma (Aigialaceae: Pleosporales) appears to be hyperdiverse on Arecaceae: Evidence from two new species from southern Thailand. Acta Bot. Bras. 2020, 34, 384-393. [CrossRef]

10. Konta, S.; Maharachchikumbura, S.S.N.; Senanayake, I.C.; McKenzie, E.H.C.; Stadler, M.; Boonmee, S.; Phookamsak, R.; Jayawardena, R.S.; Senwanna, C.; Hyde, K.D.; et al. A new genus Allodiatrype, five new species and a new host record of diatrypaceous fungi from palms (Arecaceae). Mycosphere 2020, 11, 239-268. [CrossRef]

11. Zhang, S.N.; Hyde, K.D.; Jones, E.B.G.; Cheewangkoon, R.; Liu, J.K. Additions to Fissuroma and Neoastrosphaeriella (Aigialaceae, Pleosporales) from palms. Mycosphere 2020, 11, 269-284. [CrossRef]

12. Hongsanan, S.; Hyde, K.D.; Phookamsak, R.; Wanasinghe, D.N.; McKenzie, E.H.C.; Sarma, V.V.; Lücking, R.; Boonmee, S.; Bhat, J.D.; Liu, N.G.; et al. Refined families of Dothideomycetes: Orders and families incertae sedis in Dothideomycetes. Fungal Divers. 2020, 105, 17-318. [CrossRef]

13. Wijayawardene, N.N.; Hyde, K.D.; Al-Ani, L.K.T.; Tedersoo, L.; Haelewaters, D.; Rajeshkumar, K.C.; Zhao, R.L.; Aptroot, A.; Leontyev, D.V.; Saxena, R.K.; et al. Outline of Fungi and fungus-like taxa. Mycosphere 2020, 11, 1060-1456. [CrossRef]

14. Munk, A. On Metasphaeria coccodes (Karst.) Sacc. (Massarinaceae n. fam.). Friesia 1956, 5, 303-308. 
15. Saccardo, P.A. Sylloge Fungorum; Johnson Reprint Corporation: New York, NY, USA, 1883; Volume 2.

16. Link, H.F. Observationes in ordines plantarum naturales. Dissertatio I. Mag. der Ges. Nat. Freunde Berl. 1809, 3, 3-42.

17. Gilman, J.C.; Abbott, E.V. A summary of the soil fungi. Iowa State Coll. J. Sci. 1927, 1, 225-343.

18. Deshpande, K.S.; Deshpande, K.B. Contribution to the taxonomy of the genus Helminthosporium II. Sydowia 1969, $23,69-76$.

19. Tanaka, K.; Hirayama, K.; Yonezawa, H.; Sato, G.; Toriyabe, A.; Kudo, H.; Hashimoto, A.; Matsumura, M.; Harada, Y.; Kurihara, Y.; et al. Revision of the Massarineae (Pleosporales, Dothideomycetes). Stud. Mycol. 2015, 82, 75-136. [CrossRef]

20. Zhu, D.; Luo, Z.L.; Baht, D.J.; Mckenzie, E.H.; Bahkali, A.H.; Zhou, D.Q.; Su, H.Y.; Hyde, K.D. Helminthosporium velutinum and H. aquaticum sp. nov. from aquatic habitats in Yunnan Province, China. Phytotaxa 2016, 253, 179-190. [CrossRef]

21. Voglmayr, H.; Jaklitsch, W.M. Corynespora, Exosporium and Helminthosporium revisited new species and generic reclassification. Stud. Mycol. 2017, 87, 43-76. [CrossRef]

22. Crous, P.W.; Carnegie, A.J.; Wingfield, M.J.; Sharma, R.; Mughini, G.; Noordeloos, M.E.; Santini, A.; Shouche, Y.S.; Bezerra, J.D.P.; Dima, B.; et al. Fungal Planet description sheets: 868-950. Pers. Mol. Phylogeny Evol. Fungi 2019, 42, 291-473. [CrossRef] [PubMed]

23. Rashmi, M.; Kushveer, J.S.; Sarma, V.V. A worldwide list of endophytic fungi with notes on ecology and diversity. Mycosphere 2019, 10, 798-1079. [CrossRef]

24. Zhao, N.; Luo, Z.L.; Hyde, K.D.; Su, H.Y.; Bhat, D.J.; Liu, J.K.; Bao, D.F.; Hao, Y.E. Helminthosporium submersum sp. nov. (Massarinaceae) from submerged wood in north-western Yunnan Province, China. Phytotaxa 2018, 348, 269-278. [CrossRef]

25. Drechsler, C. Some graminicolous species of Helminthosporium. J. Agric. Res. 1923, 24, 641-739.

26. Drechsler, C. Phytopathological and taxonomical aspects of Ophilobolus, Pyrenophora, Helminthosporium and a new genus Cochliobolus. Phytopathology 1934, 24, 953-985.

27. Shoemaker, R.A. Nomenclature of Drechslera and Bipolaris, grass parasites segregated from 'Helminthosporium'. Can. J. Bot. 1959, 37, 879-887. [CrossRef]

28. Misra, A.P.; Prakash, O. Helminthosporium species occurring on graminaceous hosts in India. Indian J. Mycol. Plant Pathol. 1972, 2, 95-97.

29. Misra, A.P. Helminthosporium Species Occurring in Cereals and Other Gramineae; U.S.P.L. 480 Project No.A7-CR 133, Grant No. FG-IN-223Tirhut college of Agriculture, Dholi, Muzaffarpur, Bihar, India; Catholic Press: Ranchi, India, 1973; p. 289.

30. Shenoy, B.D.; Jeewon, R.; Wu, W.P.; Bhat, D.J.; Hyde, K.D. Ribosomal and RPB2 DNA sequence analyses suggest that Sporidesmium and morphologically similar genera are polyphyletic. Mycol. Res. 2006, 110, 916-928. [CrossRef]

31. Bärlocher, F. Molecular approaches promise a deeper and broader understanding of the evolutionary ecology of aquatic hyphomycetes. J. N. Am. Benthol. Soc. 2010, 29, 1027-1041. [CrossRef]

32. Manamgoda, D.S.; Cai, L.; McKenzie, E.H.; Crous, P.W.; Madrid, H.; Chukeatirote, E.; Shivas, R.G.; Tan, Y.P.; Hyde, K.D. A phylogenetic and taxonomic re-evaluation of the Bipolaris-Cochliobolus-Curvularia complex. Fungal Divers. 2012, 56, 131-144. [CrossRef]

33. Manamgoda, D.S.; Rossman, A.Y.; Castlebury, L.A.; Crous, P.W.; Madrid, H.; Chukeatirote, E.; Hyde, K.D. The genus Bipolaris. Stud. Mycol. 2014, 79, 221-288. [CrossRef] [PubMed]

34. Zhang, Y.; Crous, P.W.; Schoch, C.L.; Hyde, K.D. Pleosporales. Fungal Divers. 2012, 53, 1-221. [CrossRef] [PubMed]

35. Baschien, C.; Tsui, C.K.M.; Gulis, V.; Szewzyk, U.; Marvanová, L. The molecular phylogeny of aquatic hyphomycetes with affinity to the Leotiomycetes. Fungal Biol. 2013, 117, 660-672. [CrossRef] [PubMed]

36. Woudenberg, J.H.; Groenewald, J.Z.; Binder, M.; Crous, P.W. Alternaria redefined. Stud. Mycol. 2013, 75, 171-212. [CrossRef]

37. Ariyawansa, H.A.; Thambugala, K.M.; Manamgoda, D.S.; Jayawardena, R.; Camporesi, E.; Boonmee, S.; Wanasinghe, D.N.; Phookamsak, R.; Hongsanan, S.; Singtripop, C.; et al. Towards a natural classification and backbone tree for Pleosporaceae. Fungal Divers. 2015, 71, 85-139. [CrossRef]

38. Senanayake, I.C.; Rathnayaka, A.R.; Marasinghe, D.S.; Calabon, M.S.; Gentekaki, E.; Lee, H.B.; Hurdeal, V.G.; Pem, D.; Dissanayake, L.S.; Wijesinghe, S.N.; et al. Morphological approaches in studying fungi: Collection, examination, isolation, sporulation and preservation. Mycosphere 2020, 11, 2678-2754. [CrossRef]

39. Jayasiri, S.C.; Hyde, K.D.; Ariyawansa, H.A.; Bhat, J.; Buyck, B.; Cai, L.; Dai, Y.C.; Abd-Elsalam, K.A.; Ertz, D.; Hidayat, I.; et al. The Faces of Fungi database: Fungal names linked with morphology, phylogeny and human impacts. Fungal Divers. 2015, 74, 3-18. [CrossRef]

40. Index Fungorum. 2021. Available online: http://www.indexfungorum.org/names/Names.asp (accessed on 30 April 2020).

41. Dissanayake, A.J.; Bhunjun, C.S.; Maharachchikumbura, S.S.N.; Liu, J.K. Applied aspects of methods to infer phylogenetic relationships amongst fungi. Mycosphere 2020, 11, 2652-2676. [CrossRef]

42. Vilgalys, R.; Hester, M. Rapid genetic identification and mapping of enzymatically amplified ribosomal DNA from several Cryptococcus species. J. Bacteriol. 1990, 172, 4238-4246. [CrossRef]

43. White, T.J.; Bruns, T.; Lee, S.J.W.T.; Taylor, J.W. Amplification and Direct Sequencing of Fungal Ribosomal RNA Genes for Phylogenetics; Innis, M.A., Gelfand, D.H., Sninsky, J.J., White, T.J., Eds.; PCR Protocols: A Guide to Methods and Applications; Academic Press: New York, NY, USA, 1990; pp. 315-322. [CrossRef]

44. Rehner, S. Primers for Elongation Factor 1- $\alpha$ (EF1- $\alpha)$. 2001. Available online: http:/ / ocid.NACSE.ORG/research/deephyphae/ EF1primer.pdf (accessed on 1 November 2019).

45. Rehner, S.A.; Buckley, E. A Beauveria phylogeny inferred from nuclear ITS and EF1- $\alpha$ sequences: Evidence for cryptic diversification and links to Cordyceps teleomorphs. Mycologia 2005, 97, 84-98. [CrossRef] 
46. Katoh, K.; Standley, D.M. MAFFT multiple sequence alignment software version 7: Improvements in performance and usability. Mol. Biol. Evol. 2013, 30, 772-780. [CrossRef] [PubMed]

47. Kumar, S.; Stecher, G.; Tamura, K. MEGA7: Molecular evolutionary genetics analysis version 7.0 for bigger datasets. Mol. Biol. Evol. 2016, 33, 1870-1874. [CrossRef] [PubMed]

48. Glez-Peña, D.; Gómez-Blanco, D.; Reboiro-Jato, M.; Fdez-Riverola, F.; Posada, D. ALTER: Program-oriented conversion of DNA and protein alignments. Nucleic Acids Res. 2010, 38, 14-18. [CrossRef] [PubMed]

49. Miller, M.A.; Pfeiffer, W.; Schwartz, T. The CIPRES science gateway: A community resource for phylogenetic analyses. In Proceedings of the 2011 TeraGrid Conference: Extreme Digital Discovery, Association for Computing Machinery, New York, NY, USA, 18-21 July 2011; pp. 1-8. [CrossRef]

50. Huelsenbeck, J.P.; Ronquist, F. MRBAYES: Bayesian inference of phylogenetic trees. Bioinformatics 2001, 17, 754-755. [CrossRef]

51. Ronquist, F.; Huelsenbeck, J.P. MrBayes 3: Bayesian phylogenetic inference under mixed models. Bioinformatics 2003, 19, 1572-1574. [CrossRef]

52. Nylander, J.A.A. MrModeltest 2.0.; Program distributed by the author; Evolutionary Biology Centre, Uppsala University: Uppsala, Sweden, 2004.

53. Rambaut, A. FigTree version 1.4.0. 2012. Available online: http://tree.bio.ed.ac.uk/software/figtree/ (accessed on 1 November 2019).

54. Schoch, C.L.; Crous, P.W.; Groenewald, J.Z.; Boehm, E.W.A.; Burgess, T.I.; De Gruyter, J.; De Hoog, G.S.; Dixon, L.J.; Grube, M.; Gueidan, C.; et al. A class-wide phylogenetic assessment of Dothideomycetes. Stud. Mycol. 2009, 64, 1-15. [CrossRef]

55. Déon, M.; Fumanal, B.; Gimenez, S.; Bieysse, D.; Oliveira, R.R.; Shuib, S.S.; Breton, F.; Elumalai, S.; Vida, J.B.; Seguin, M.; et al. Diversity of the cassiicolin gene in Corynespora cassiicola and relation with the pathogenicity in Hevea brasiliensis. Fungal Biol. 2014, 118, 32-47. [CrossRef]

56. Jaklitsch, W.M.; Voglmayr, H. Hidden diversity in Thyridaria and a new circumscription of the Thyridariaceae. Stud. Mycol. 2016, 85, 35-64. [CrossRef]

57. Lumbsch, H.T.; Lindemuth, R. Major lineages of Dothideomycetes (Ascomycota) inferred from SSU and LSU rDNA sequences. Mycol. Res. 2001, 105, 901-908. [CrossRef]

58. Schoch, C.L.; Shoemaker, R.A.; Seifert, K.A.; Hambleton, S.; Spatafora, J.W.; Crous, P.W. A multigene phylogeny of the Dothideomycetes using four nuclear loci. Mycologia 2006, 98, 1041-1052. [CrossRef]

59. Crous, P.W.; Wingfield, M.J.; Schumacher, R.K.; Summerell, B.A.; Giraldo, A.; Gené, J.; Guarro, J.; Wanasinghe, D.N.; Hyde, K.D.; Camporesi, E.; et al. Fungal Planet description sheets: 281-319. Pers. Mol. Phylogeny Evol. Fungi. 2014, 33, 212-319. [CrossRef] [PubMed]

60. Vu, D.; Groenewald, M.; De Vries, M.; Gehrmann, T.; Stielow, B.; Eberhardt, U.; Al-Hatmi, A.; Groenewald, J.Z.; Cardinali, G.; Houbraken, J.; et al. Large-scale generation and analysis of filamentous fungal DNA barcodes boosts coverage for kingdom fungi and reveals thresholds for fungal species and higher taxon delimitation. Stud. Mycol. 2019, 92, 135-154. [CrossRef]

61. Tian, Q.; Li, W.J.; Hyde, K.D.; Camporesi, E.; Bhat, D.J.; Chomnunti, P.; Xu, J.C. Molecular taxonomy of five species of microfungi on Alnus spp. from Italy. Mycol. Prog. 2018, 17, 255-274. [CrossRef]

62. Quaedvlieg, W.; Verkley, G.J.M.; Shin, H.D.; Barreto, R.W.; Alfenas, A.C.; Swart, W.J.; Groenewald, J.Z.; Crous, P.W. Sizing up septoria. Stud. Mycol. 2013, 75, 307-390. [CrossRef] [PubMed]

63. Crous, P.W.; Wingfield, M.J.; Richardson, D.M.; Le Roux, J.J.; Strasberg, D.; Edwards, J.; Roets, F.; Hubka, V.; Taylor, P.W.J.; Heykoop, M.; et al. Fungal Planet description sheets: 400-468. Pers. Mol. Phylogeny Evol. Fungi. 2016, 36, 316-458. [CrossRef]

64. Rosado, A.W.C.; de Jesus Boari, A.; Custódio, F.A.; Quadros, A.F.F.; Batista, I.C.A.; Pereira, O.L. Helminthosporiella stilbacea associated with African oil palm (Elaeis guineensis) in Brazil. For. Pathol. 2019, 49, e12529. [CrossRef]

65. Hernández-Restrepo, M.; Schumacher, R.K.; Wingfield, M.J.; Ahmad, I.; Cai, L.; Duong, T.A.; Edwards, J.; Gené, J.; Groenewald, J.Z.; Jabeen, S.; et al. Fungal systematics and evolution: FUSE 2. Sydowia 2016, 68, 193-230. [CrossRef]

66. Hashimoto, A.; Matsumura, M.; Hirayama, K.; Tanaka, K. Revision of Lophiotremataceae (Pleosporales, Dothideomycetes): Aquasubmersaceae, Cryptocoryneaceae, and Hermatomycetaceae fam. nov. Pers. Mol. Phylogeny Evol. Fungi 2017, 39, 51-73. [CrossRef]

67. Zhang, Y.; Wang, H.K.; Fournier, J.; Crous, P.W.; Jeewon, R.; Pointing, S.B.; Hyde, K.D. Towards a phylogenetic clarification of Lophiostoma/Massarina and morphologically similar genera in the Pleosporales. Fungal Divers. 2009, 38, $225-251$.

68. Liew, E.C.; Aptroot, A.; Hyde, K.D. An evaluation of the monophyly of Massarina based on ribosomal DNA sequences. Mycologia 2002, 94, 803-813. [CrossRef]

69. Kodsueb, R.; Lumyong, S.; Ho, W.H.; Hyde, K.D.; Mckenzie, E.H.; Jeewon, R. Morphological and molecular characterization of Aquaticheirospora and phylogenetics of Massarinaceae (Pleosporales). Bot. J. Linn. Soc. 2007, 155, 283-296. [CrossRef]

70. De Gruyter, J.; Aveskamp, M.M.; Woudenberg, J.H.; Verkley, G.J.; Groenewald, J.Z.; Crous, P.W. Molecular phylogeny of Phoma and allied anamorph genera: Towards a reclassification of the Phoma complex. Mycol. Res. 2009, 113, 508-519. [CrossRef]

71. Hu, F.J.; Jeewon, R.; Hyde, K.D. Relationships among Astrosphaeriella, Caryospora and Trematosphaeria. Ph.D. Thesis, The University of Hong Kong, Hong Kong, China, 2009.

72. Thambugala, K.M.; Hyde, K.D.; Tanaka, K.; Tian, Q.; Wanasinghe, D.N.; Ariyawansa, H.A.; Jayasiri, S.C.; Boonmee, S.; Camporesi, E.; Hashimoto, A.; et al. Towards a natural classification and backbone tree for Lophiostomataceae, Floricolaceae, and Amorosiaceae fam. nov. Fungal Divers. 2015, 74, 199-266. [CrossRef] 
73. Chethana, T.; Liu, M.; Ariyawansa, H.A.; Konta, S.; Wanasinghe, D.N.; Zhou, Y.; Yan, J.; Camporesi, E.; Bulgakov, T.M.; Chukeatirote, E.; et al. Splanchnonema-like species in Pleosporales: Introducing Pseudosplanchnonema gen. nov. in Massarinaceae. Phytotaxa 2015, 231, 133-144. [CrossRef]

74. Thambugala, K.M.; Wanasinghe, D.N.; Phillips, A.J.L.; Camporesi, E.; Bulgakov, T.S.; Phukhamsakda, C.; Dissanayake, A.; Tennakoon, D.S.; Tibpromma, S.; Chen, Y.Y.; et al. Mycosphere notes 1-50: Grass (Poaceae) inhabiting Dothideomycetes. Mycosphere 2017, 8, 697-796. [CrossRef]

75. Crous, P.W.; Shivas, R.G.; Quaedvlieg, W.V.; van der Bank, M.; Zhang, Y.; Summerell, B.A.; Guarro, J.; Wingfield, M.J.; Wood, A.R.; Alfenas, A.C. Fungal Planet description sheets: 214-280. Pers. Mol. Phylogeny Evol. Fungi 2014, 32, 184-306. [CrossRef]

76. Wijayawardene, N.N.; Hyde, K.D.; Bhat, D.J.; Goonasekara, I.D.; Nadeeshan, D.; Camporesi, E.; Schumacher, R.K.; Wang, Y. Additions to brown spored coelomycetous taxa in Massarinae, Pleosporales: Introducing Phragmocamarosporium gen. nov. and Suttonomyces gen. nov. Cryptogam. Mycol. 2015, 36, 213-224. [CrossRef]

77. Wanasinghe, D.N.; Phukhamsakda, C.; Hyde, K.D.; Jeewon, R.; Lee, H.B.; Jones, E.G.; Tibpromma, S.; Tennakoon, D.S.; Dissanayake, A.J.; Jayasiri, S.C.; et al. Fungal diversity notes 709-839: Taxonomic and phylogenetic contributions to fungal taxa with an emphasis on fungi on Rosaceae. Fungal Divers. 2018, 89, 1-236. [CrossRef]

78. Knapp, D.G.; Kovács, G.M.; Zajta, E.; Groenewald, J.Z.; Crous, P.W. Dark septate endophytic pleosporalean genera from semiarid areas. Pers. Mol. Phylogeny Evol. Fungi 2015, 35, 87-100. [CrossRef]

79. Raja, H.A.; Miller, A.N.; Pearce, C.J.; Oberlies, N.H. Fungal identification using molecular tools: A primer for the natural products research community. J. Nat. Prod. 2017, 80, 756-770. [CrossRef]

80. Species Fungorum. 2021. Available online: http:/ / www.speciesfungorum.org/Names/Names.asp (accessed on 30 April 2021).

81. Goh, T.K.; Hyde, K.D.; Lee, D.K. Generic distinction in the Helminthosporium-complex based on restriction analysis of the nuclear ribosomal RNA gene. Fungal Divers. 1998, 1, 85-107.

82. Mukerji, K.G. Current Concepts in Botany; IK International Publishing House Pvt Ltd.: New Delhi, India, $2006 ;$ pp. 49-78.

83. Hernández-Restrepo, M.; Madrid, H.; Tan, Y.P.; da Cunha, K.C.; Gene, J.; Guarro, J.; Crous, P.W. Multi-locus phylogeny and taxonomy of Exserohilum. Pers. Mol. Phylogeny Evol. Fungi 2018, 41, 71-108. [CrossRef] [PubMed]

84. Cooke, W.B.; Shaw, C.G. Western fungi. III. Mycologia 1952, 44, 795-812. [CrossRef]

85. Ellis, M.B. Dematiaceous hyphomycetes. III. Mycol. Pap. 1961, 82, 1-55.

86. Ciferri, R. Observations on meliolicolous Hyphales from Santo Domingo. Sydowia 1955, 9, $296-335$.

87. Sydow, H.; Sydow, P. Novae fungorum species. Ann. Mycol. 1904, 2, 162-174.

88. Jørstad, I. Parasitic fungi from the Canaries chiefly collected by J. Lid, with a note on Schizophyllum commune. Blyttia 1966, 24, 222-231.

89. Ciferri, R. Mycoflora Domingensis Integrata. Quaderno del Laboratorio Crittogamico del Istituto Botanicodell' Università di Pavia 1961, 19, 1-539.

90. Petch, T. New Ceylon fungi. Ann. R. Bot. Gard. Perad. 1909, 4, 299-307.

91. Thirumalachar, M.J. Some new or interesting fungi II. Sydowia 1950, 4, 66-73.

92. Petrak, F.; Ciferri, R. Fungi Dominicani. II. Ann. Mycol. 1932, 30, 149-353.

93. Petrak, F. Beiträgezur Pilzflora von Britisch Nord-Borneo. Sydowia 1954, 8, 12-26.

94. Lavrov, N.P. Trud. tomsk. gos. Univ. Kuibysheva 1951, 110, 254.

95. Jaczewski, A.L.A. Type species-Jaczewskiella altajensis. Mater. Mikol. Fitopat. Ross. 1915, 1, 41.

96. Corda, A.C.J. Gliostroma. Icon. Fung. 1837, 1, 13.

97. Unamuno, L.M. NotasMicológicas. II. Adiciones a los Hifales de la flora española. Boletín de la Real Soc. Española de Hist. Nat. 1932, 32, 161-169.

98. Saccardo, P.A. Sylloge Fungorum. Mem. Reale Ist. Veneto Sci. 1902, 13, (reprint).

99. Cooke, M.C. Ravenel's American fungi. Grevillea 1878, 6, 129-146.

100. Zaprometov, N.G. Fungal flora of the Kyrgyz SSR. Frunze Acad. Sci. Kyrg. SSR 1957, 1, 98.

101. Deshpande, K.S.; Deshpande, K.B. Contribution to the taxonomy of genus Helminthosporium. I. Sydowia 1966, 20, $39-45$.

102. Diedicke, H. Aufzählungen der in der Umgebung Erfurts Beobachteten Micromyceten; Academische Loge Sincera Concordia: Erfurt, Germany, 1910; Volume 36, p. 221.

103. Hennings, P. Fungi paraënses III. Hedwigia 1908, 48, 101-117.

104. Sydow, H.; Sydow, P. Weitere Diagnosen neuer philippinischer Pilze. Ann. Mycol. 1916, 14, 353-375.

105. Zhang, M.; Wu, H.Y.; Wang, Z.Y. Taxonomic studies of Helminthosporium from China 5. Two new species from Hunan and Sichuan Province. Mycotaxon 2010, 113, 95-99. [CrossRef]

106. Dounine, M.S.; Yakimovitch, E.D. Sweet Potato Diseases and Their Control; Pan-Soviet Science Research Institute Cultural Soybean and Spice Crops: Moscow, Russia, 1934; p. 247.

107. Subramanian, C.V.; Bhat, D.J. Hyphomycetes from South India I. Some new taxa. Kavaka 1987, 15, 41-74.

108. Misra, A.P. Helminthosporium Species Occurring on Cereals and Other Gramineae; Tirhut College of Agriculture: Dholi, India, 1976; pp. $1-289$.

109. Matsushima, T. Matsushima Mycological Memoirs 7; Matsushima Fungus Collection: Kobe, Japan, 1993; Volume 7, pp. 1-141.

110. Pidoplichko, N.M. New fungus species on coarse fodders. Mikrobiol. Zh. 1950, 12, 38.

111. Viégas, A.P. Algunsfungos do Brasil: XIII-Hifomicetos. Bragantia 1946, 6, 353-442. [CrossRef] 
112. Ciferri, R. Mycoflora domingensis exsiccata (Cent. I, no. 1-100). Ann. Mycol. 1931, 29, 283-299.

113. Bongini, V. Sur una malattia delle Cactacee. Difesa delle Piante. 1932, 9, 38.

114. Steyaert, R.L. Contribution à l'étude des parasites des végétaux du Congo. Bull. Soc. R. Bot. Belg. 1948, 80, 11-58.

115. Hennings, P.; Fungi, S. Paulensis IV a cl. Puttemanscollecti. Hedwigia 1909, 48, 1-20.

116. Saccardo, P.A. Notae mycologicae. Ser. XXVII. Fungi sinenses aliquot a cl. Prof. Otto A. Reinking collecti et communicati. Philipp J. Sci. 1921, 18, 595-605.

117. Ciferri, R. Mycoflora domingensis exsiccata. Ann. Mycol. 1938, 36, 198-245.

118. McColloch; Pollack. Phytopathology 1946, 36, 991.

119. Orillo, F.T. An undescribed species of Helminthosporium on kapok in the Philippines. Philipp. Agric. 1955, 38, 548-550.

120. Olivier, C.; Berbee, M.L.; Shoemaker, R.A.; Loria, R. Molecular phylogenetic support from ribosomal DNA sequences for origin of Helminthosporium from Leptosphaeria-like loculoascomycete ancestors. Mycologia 2000, 92, 736-746. [CrossRef]

121. Hennings, P. Fungi. Ann. Musée Congo Belge Bot. 1907, 2, 85-106.

122. Petrak, F. Beiträgezur Pilzflora von Ekuador. Sydowia 1950, 4, 450-587.

123. Stevens, F.L. Hawaiian fungi. Bull. Bernice Bishop Mus. 1925, 19, 1-189.

124. Hughes, S.J. Revision es hyphomycetum aliquot cum appendice de nominibusrejiciendis. Can. J. Bot. 1958, 36, 727-836. [CrossRef]

125. Sawada, K. Descriptive Catalogue of the Formosan Fungi V.; Report of the Department of Agriculture Government Research Institute of Formosa; Department of Agriculture Government Research Institute of Formosa: Formosa, Japan, 1931; Volume 51, pp. 1-131.

126. Ciferri, R.; Fragoso, G. Bulletin of the Royal Spanish Society of Natural History; National Museum of Natural Sciences: Madrid, Spain, 1926; Volume 26, p. 340.

127. Massee, G.E. Fungi exotici, III. Bull. Misc. Inf. R. Bot. Gard. Kew. 1901, 150-169.

128. Zhang, M.; Zhang, T.Y. Taxonomic studies of Helminthosporium from China 4. Six new species and a key to Helminthosporium from China. Mycotaxon 2009, 109, 399-413. [CrossRef]

129. Zhang, M.; Zhang, T.; Wu, W. Taxonomic studies of Helminthosporium from China III. Three new species in Guangdong Province. Mycotaxon 2007, 99, 137-142.

130. Malençon, G.; Bertault, R. Champignons de la Péninsule Ibérique, IV. Les Iles Baleares. Acta Phytotax. Barcinon. 1972, 11, 1-64.

131. Sawada, K. Descriptive catalogue of Taiwan (Formosan) fungi. Part XI. Spec. Publ. Coll. Agric. Natl. Taiwan Univ. 1959, 8, 1-268.

132. Chowdhury, S. Notes on fungi from Assam. II. Lloydia 1957, 20, 133-138.

133. Petrak, F. Petrak's Lists 5; Commonwealth Agricultural Bureaux: Wallingford, UK, 1930; p. 214.

134. Nisikado, Y. Ber. Ohara Inst. Landw. Forsch. Kurashiki. 1925, 2, 597-612.

135. Matsushima, T. Matsushima Mycological Memoirs 5; Matsushima Fungus Collection: Kobe, Japan, 1987; Volume 5, pp. 1-100.

136. Garbowski, L. Bull. Acad. Polon. Sci. Lett. Cracoviae Cl. Math. Nat. Ser. B. 1923 1924, 15.

137. Saccardo, P.A. Notae mycologicae series XXIII. Fungi Philippinenses. Attidella Accad. Sci. Veneto-Trentino-Istriana 1917, 10, 57-94.

138. Sturm, J.W. Deutschl. Fl. 3 Abt. (Pilze Deutschl.) 1831, 3, 21.

139. Baccarini, P. Funghidell'Eritrea. Ann. Bot. 1906, 4, 269-277.

140. Nishihara, N. Ann. Phytopath. Soc. Japan 1969, 35, 89.

141. Sydow, H.; Sydow, P. Fungi novibrasilienses a cl. Ulelecti. Bull. del 'Herb. Boissier 1901, 1, 77-85.

142. Von Thümen, F. Die Pilze des Weinstockes; W. Braumüller: Wien, Austria, 1878; pp. 1-225.

143. Berkeley, M.J. Notices of British fungi [208-256]. Ann. Mag. Nat. Hist. 1841, 6, 430-439. [CrossRef]

144. Golovin, P.N. Novye vidy gribov Srednej Azii. Trudy Sredneaz. Univ. 1950, 14, 1-47.

145. Berkeley, M.J.; Broome, C.E. Notices of British fungi (901-951). Ann. Mag. Nat. Hist. 1861, 7, 373-382.

146. Roumeguère, C.; Saccardo, P.A. Fungi Algerienses Trabutiani-Sertulum II. Rev. Mycol. Toulouse 1881, 3, $26-32$.

147. Katsuki, S. Notes on parasitic fungi of Yaku island. J. Jap. Bot. 1953, 28, 279-288.

148. Magnus, P. Ein neues Helminthosporium. Hedwigia 1903, 42, 222-225.

149. Holubová-Jechová, V. Studies on hyphomycetes from Cuba VI. New and rare species with tretic and phialidic conidiogenous cells. Ceská Mykol. 1987, 41, 107-114.

150. Zhang, M.; Zhang, T.Y. Flora Fungorum Sinicorum; Science Press: Beijing, China, 2009; Volume 30, pp. 1-272.

151. Koorders, S.H. Botanische Untersuchungen. Verh. K. Ned. Akad. van Wet. Afd. Nat. 1907, 13, 1-264.

152. Berkeley, M.J.; Broome, C.E. Notices of British fungi (1335-1401). Ann. Mag. Nat. Hist. 1873, 11, 339-349. [CrossRef]

153. Ciferri, R. Notae mycologicae et phytopathologicae Serie II, Nr. 1-14. Riv. Patol. Veg. 1927, 17, 35-40.

154. Rostrup, E. Flora of Koh Chang. Contributions to the knowledge of the vegetation of the gulf of Siam. Fungi. Bot. Tidsskr. 1902, 24, 355-363.

155. Hennings, P. Fungi Amazonici IV. a cl. Ernesto Ulecollecti. Hedwigia 1905, 44, 57-71.

156. Yates, H.S. Some recently collected Philippine fungi, II. Philipp. J. Sci. C. Botany 1918, 13, 361-384.

157. Trotter, A. Supplementum Universale, Pars X. Myxomycetae, Myxobacteriaceae, Deuteromycetae, Mycelia sterilia. Sylloge Fungorum. 1931, 25, 1-1093.

158. Curzi, M. Helminthosporium gibberosporum. C. R. Accad. Lincei. 1931, 6, 146.

159. Stevens, F.L. Some meliolicolous parasites from Porto Rico. Bot. Gaz. Crawfordsville 1918, 65, 227-249. [CrossRef]

160. Tucker, C.M. J. Agric. Res. 1926, 32, 391. 
161. Wildeman, E.de. Etude de Systématique et de Géographie Botanique sur la Flore du Bas- et du Moyen-Congo. Ann. Musée Congo Belge Bot.Sér. 5 1907, 2, 85-106.

162. Stevens, F.L.; Dowell, R.I. A Meliola disease of cacao. Phytopathology 1923, 13, 247-250.

163. Viégas, A.P. Algunsmicetos Brasileiros. Bragantia 1947, 7, 25-48. [CrossRef]

164. Errampalli, D.; Saunders, J.M.; Holley, J.D. Emergence of silver scurf (Helminthosporium solani) as an economically important disease of potato. Plant Pathol. 2001, 50, 141-153. [CrossRef]

165. Zhao, G.C.; Zhao, R.L. The Higher Microfungi from Forests of Yunnan Province; Yunnan Science and Technology Press: Kunming, China, 2012; p. 564.

166. Siboe, G.M.; Kirk, P.M.; Cannon, P.F. New dematiaceous hyphomycetes from Kenyan rare plants. Mycotaxon 1999, 73, $283-302$.

167. Gornostai, V.I. Mikol. Fitopatol. 1972, 6, 154.

168. Cheremisinov. Chaetomium subaffine Sergeeva. Notulae Syst. Sect. Crypt. Inst. Bot. Acad. Sci. U.S.S.R. 1951, 7, 158.

169. Hansford, C.G. Contribution towards the fungus flora of Uganda. V. Fungi Imperfecti. Proc. Linn. Soc. Lond. 1943, $155,34-67$. [CrossRef]

170. Chowdhury, S. Notes on fungi of Assam. Lloydia 1955, 18, 82-87.

171. Crous, P.W.; Wingfield, M.J.; Burgess, T.I.; Hardy, G.S.J.; Gené, J.; Guarro, J.; Baseia, I.G.; García, D.; Gusmão, L.F.P.; Souza-Motta, C.M.; et al. Fungal Planet description sheets: 716-784. Pers. Mol. Phylogeny Evol. Fungi 2018, 40, 240-393. [CrossRef]

172. Sydow, H. Novae fungorum species. XXV. Ann. Mycol. 1937, 35, $244-286$.

173. Von Szilvinyi, A. Mikrobiologische Boden untersuchungenim Lunzer Gebiet. Zent. Bakteriol. und Parasitenkd. Abt. 2 1941, 103, 133-189.

174. Sousa da Câmara, M. Mycetes aliquot Lusitaniae IX. Agron. Lusit. 1949, 11, 39-73.

175. Roldan, E.F. Philipp. J. Sci. 1936, 60, 121.

176. Cooke, M.C. New British fungi [cont.]. Grevillea 1877, 6, 71-76.

177. Shirouzu, T.; Harada, Y. Lignicolous dematiaceous hyphomycetes in Japan: Five new records for Japanese mycoflora, and proposals of a new name, Helminthosporium magnisporum, and a new combination, Solicorynespora foveolata. Mycoscience 2008, 49, 126-131. [CrossRef]

178. Shirouzu, T.; Harada, Y. Notes on species of Helminthosporium and its allied genera in Japan. Mycoscience 2004, 45, 17-23. [CrossRef]

179. Sydow, P.; Sydow, H. Weitere neue Micromyceten der Philippinen-Inseln. Ann. Mycol. 1920, 18, 98-104.

180. Rangel, E.S. Arch. Jard. Bot. Rio de Janeiro. 1902, 2, 71.

181. Castellani, E.; Ciferri, R. Scissioni di generi di licheni sulla base delle caratteristiche del fungo. Atti. Ist. Bot. Univ. Pavia Suppl. Agli. Ser. 5. 1950, 37.

182. Miles, L.E. Trans. Ill. St. Acad. Sci. 1917, 10, 253.

183. Ciferri, R.; González Fragoso, R. Hongosparásitos y saprofitos de la República Dominicana (4a serie). Boletín de la Real Soc. Española de Hist. Nat. 1926, 26, 192-202.

184. Saccardo, D. Contribuzione alla micologia veneta e modenense. Malpighia 1898, 12, 201-228.

185. Cooke, M.C. New British fungi. Grevillea 1888, 16, 77-81.

186. Jaczewski, A.L.A. Alternative: Transactions of the Illinois Academy of Science. Microbiol. J. 1929, 9, 166.

187. Wang, X.; Wu, H.; Zhang, M. A new species of Helminthosporium from Jiangsu, China. Mycotaxon 2014, 127, 1-4. [CrossRef]

188. Sydow, H.; Sydow, P. Beitragzur Pilzflora Süd-Amerikas. Hedwigia 1903, 42, 105-106.

189. Dearness, J.; House, H.D. New or noteworthy species of fungi. IV. Bull. N. Y. State Mus. 1925, 266, 57-98.

190. Viennot-Bourgin, G. Champignons nouveaux de la Guinée. Bull. Soc. Mycol. Fr. 1959, 75, 33-37.

191. Hughes, S.J. New Zealand Fungi 27. New species of Guedea, Hadrosporium, and Helminthosporium. N. Z. J. Bot. 1980, 18, 65-72. [CrossRef]

192. Da Câmara, S.M. Contribution esadmyco floram Lusitaniae. Centuria XI. Bol. Agric. Lisboa 1936, 2, 1-80.

193. Chevassut, G. Sur cinq espècesnouvelles et quelquesespècesrares de Micromycètes parasites du groupe des Adelomycetes (régions du Languedoc et de Franche-Comté) (Five new species and some rare species of parasitic Micromycetes from the Adelomycetes group (Languedoc and Franche-Comté) (en)). Bull. Trimest. Société Mycol. France 1992, 108, $101-106$.

194. Saccardo, P.A. Micromycetes Americani novi. J. Mycol. 1906, 12, 47-52.

195. Hiroë, I.M. Trans. Tottori Soc. Agric. Sci. 1935, 5, 175.

196. Hennings, P. Fungi Africae orientalis III. Bot. Jahrbücher für Syst. Pflanzengesch. und Pflanzengeogr. 1904, $34,39-57$.

197. Savulescu, T.; Rayss, T. Contribution à l'étude de la mycoflore de Palestine. Ann. Crypt. Exot. 1935, 8, 49-87.

198. Matsushima, T. Microfungi of the Solomon Islands and Papua-New Guinea; Matsushima Fungus Collection: Kobe, Japan, 1971; pp. 1-78.

199. Castro, C.C.D.; Gutiérrez, A.H.; Sotão, H.M.P. Fungosconidiaisem Euterpe oleracea Mart.(açaizeiro) nallha do Combu, Pará-Brasil. Acta. Bot. Bras. 2012, 26, 761-771. [CrossRef]

200. Berg, A. Pamietn. Towarz. Nauk Sci. Paryzu. 1934, 260, 14.

201. Liu, L.J. A New Species of Helminthosporium causing leaf spot disease of sugarcane in Puerto Rico. J. Agr. U. Puerto. Rico. 1971, 55, 12-22. [CrossRef]

202. Cooke, W.B. Western fungi. II. Mycologia 1952, 44, 245-261. [CrossRef] 
203. Bourne, B.A. Mém. Mus. Hist. Nat. 1956, 1087.

204. Lucas, M.T.; Sousa da Câmara, M. Fungi Lusitaniae. V. Agron. Lusit. 1953, 15, 153-182.

205. Dearness, J. New or noteworthy North American fungi. Mycologia 1917, 9, 345-364. [CrossRef]

206. Sydow, H.; Sydow, P. Aufzählungeiniger in den Provinzen Kwangtung und Kwangsi (Süd-China) gesammelter Pilze. Ann. Mycol. 1919, 17, 140-143.

207. Fresenius, G. Beitr. Mykol. 1863, 3, 50. Available online: ia800500.us.archive.org/33/items/beitrgezurmyko00fres/ beitrgezurmyko00fres.pdf (accessed on 12 May 2021).

208. Berlese, A.N. Sur le développement de quelques champignons nouveaux ou critiques. Bull. Soc. Mycol. Fr. 1892, 8, 94-110.

209. Woronichin, N.N. Contribution à la floremycologique du Caucase. Trav. du Musée Bot. de l'Académie des Sci. de Russ. 1927, 21, 87-243.

210. Stevenson, J.A. Rep. P. Ricoinsul. Agric. Exp. Station. 1919, 1917-18, 137.

211. Zhang, M.; Zhang, T.; Wu, W. Taxonomic studies of Helminthosporium from China II. Two new species in Sichuan Province. Mycosystema 2004, 23, 179-182. [CrossRef]

212. Durieu de Maisonneuve, M.C. Expl. Sci. Alg. Fl. Algér. 1 (Livr. 9) 1848, 1, 321-360.

213. Patterson, F.W. New species of fungi. Bull. Torrey Bot. Club. 1900, 27, 282-286. [CrossRef]

214. Saccardo, P.A. Notae mycologicae. Series XXIV. I. Fungi Singaporenses Barkesiani. Bolletino dell'Orto Bot. Regia dell'Universita de Napoli. 1921, 6, 39-73.

215. Peck, C.H. Report of the state botanist. Bull. N. Y. State Mus. 1911, 150, 5-100.

216. Saccardo, P.A. Bulletino dell'orto Botanico della R.; Universitá di Napoli: Napoli, Italy, 1918; Volume 6, p. 23.

217. Turconi, M. Sopra una nuovamalattia del cacao (Theobroma cacao L.). Atti dell'Istituto Bot. Univ. e Lab. Crittogam. di Pavia. 1920, 17, 1-8.

218. Ciferri, R.; González Fragoso, R. Hongosparásitos y saprofitos de la RepúblicaDominicana (10a serie). Boletín de la Real Soc. Española de Hist. Nat. 1927, 27, 165-177.

219. Hennings, P. Schädliche Pilze auf Kulturpflanzenaus Deutsch-Ostafrika. Notizbl. des Bot. Gart. und Mus. Berl. $1903,3,239-243$.

220. Berkeley, M.J.; Broome, C.E. Notices of British fungi (502-537). Ann. Mag. Nat. Hist. 1851, 7, 95-102.

221. Hennings, P.C. Mission. E. Lauren. 1906, 3, 318.

222. Alves-Barbosa, M.; Costa, P.M.; Malosso, E.; Castañeda-Ruiz, R.F. Two new species of Dictyosporium and Helminthosporium (Ascomycota) from the Brazilian Atlantic forest. Nova Hedwig 2017, 105, 65-73. [CrossRef]

223. Sydow, H.; Sydow, P. Fungi Paraenses. Hedwigia 1910, 49, 78-84.

224. Wakefield, E.M. New and rare British fungi. Bull. Misc. Inf. R. Bot. Gard. Kew. 1918, 1918, 229-233. [CrossRef]

225. Ciferri, R.; González Fragoso, R. Parasitic and saprophytic fungi of the Dominican Republic, (11th Series.). Bol. de la Real Soc. Esp. de Hist. Nat. Madr. 1927, 27, 267-280.

226. Batista, A.C.; Maia, H.S.; Lima, J.A.; Matta, E.A.F. Moniliales-descrição e revisão de algumasespécies. Atas do Inst. de Micol. Univ. de Pernamb. Recife 1960, 1, 247-274. 